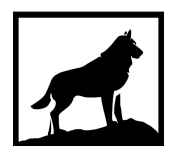

Michigan Technological

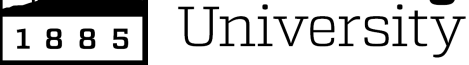

Michigan Technological University Digital Commons @ Michigan Tech

\title{
AGE, GROWTH, AND OTOLITH MICROCHEMISTRY OF GOLDEN TILEFISH (LOPHOLATILUS CHAMAELEONTICEPS) IN THE NW ATLANTIC
}

Katy Dawson

Michigan Technological University, kdawson@mtu.edu

Copyright 2021 Katy Dawson

Recommended Citation

Dawson, Katy, "AGE, GROWTH, AND OTOLITH MICROCHEMISTRY OF GOLDEN TILEFISH (LOPHOLATILUS CHAMAELEONTICEPS) IN THE NW ATLANTIC", Open Access Master's Thesis, Michigan Technological University, 2021.

https://doi.org/10.37099/mtu.dc.etdr/1263 
AGE, GROWTH, AND OTOLITH MICROCHEMISTRY OF GOLDEN TILEFISH (LOPHOLATILUS CHAMAELEONTICEPS) IN THE NW ATLANTIC

By

Kaitlyn M. Dawson

\begin{abstract}
A THESIS
Submitted in partial fulfillment of the requirements for the degree of MASTER OF SCIENCE

In Biological Sciences
\end{abstract}

MICHIGAN TECHNOLOGICAL UNIVERSITY

2021

(C) 2021 Kaitlyn M Dawson 
This thesis has been approved in partial fulfillment of the requirements for the Degree of MASTER OF SCIENCE in Biological Sciences.

Department of Biological Sciences

\author{
Thesis Advisor: $\quad$ Jill A. Olin \\ Committee Member: Casey Huckins \\ Committee Member: Gordon Paterson \\ Department Chair: Chandrashekhar P. Joshi
}




\section{Table of Contents}

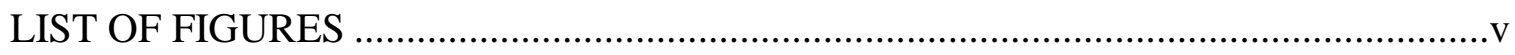

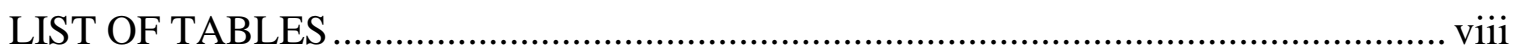

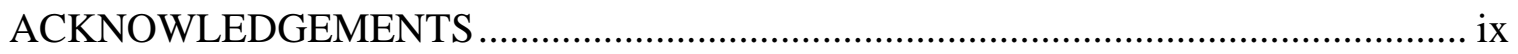

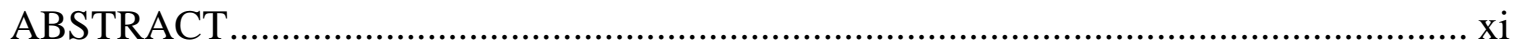

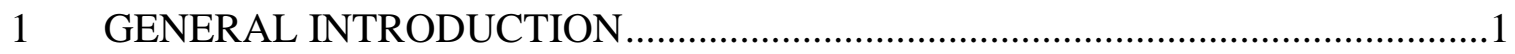

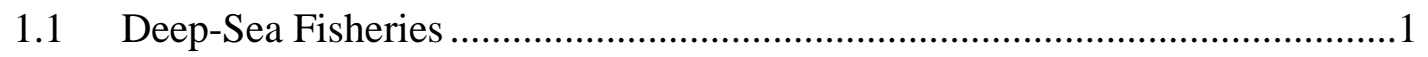

1.2 Metapopulation Dynamics and Stock Structure …………………………........

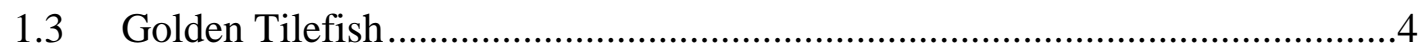

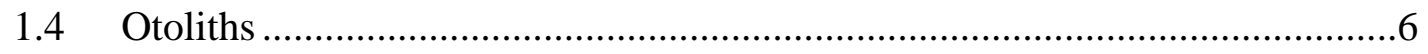

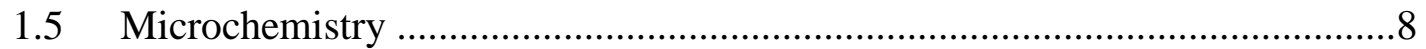

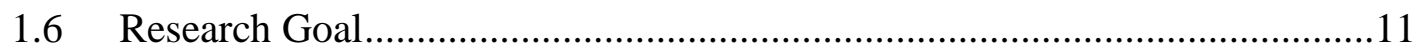

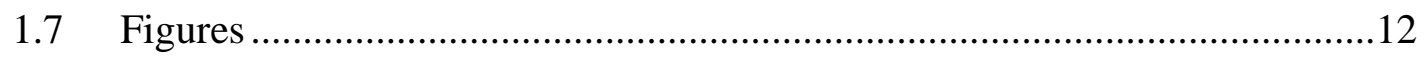

2 AGE AND GROWTH ESTIMATION OF GOLDEN TILEFISH (LOPHOLATILUS CHAMAELEONTICEPS) FROM THE NW ATLANTIC ……………….........................14

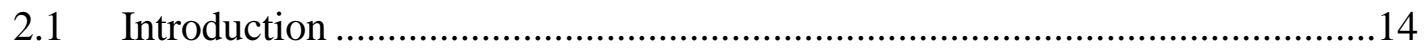

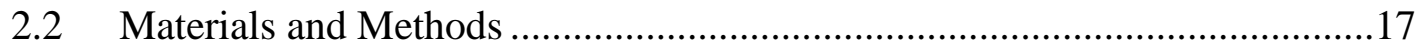

2.2.1 Sample Collection .........................................................................17

2.2.2 Otolith Processing …………...........................................................17

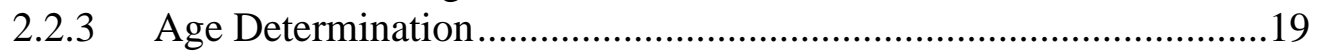

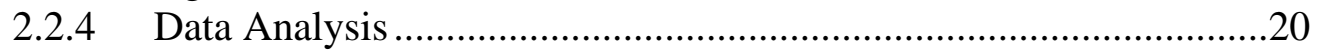

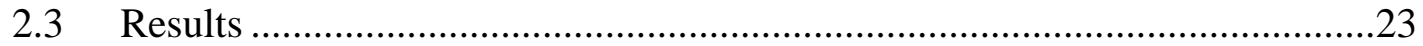

2.3.1 Population Demographics ..............................................................23

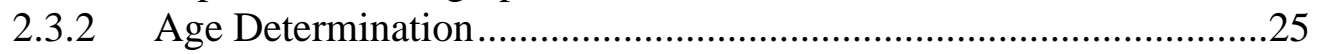

2.3.3 Von-Bertalanffy Growth Curves.......................................................25

2.3.4 Individual Growth Patterns ..........................................................26

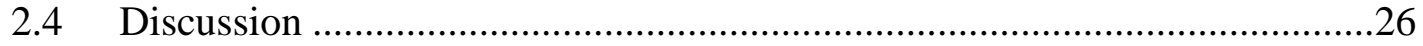

2.4.1 Population Demographics ..............................................................27

2.4.2 Von-Bertalanffy Growth Curves......................................................30

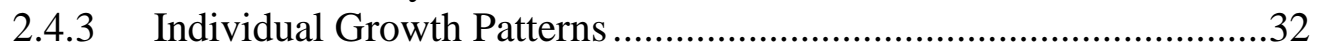

2.4.4 Conclusions .................................................................................

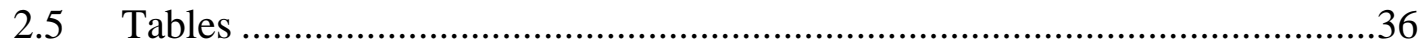

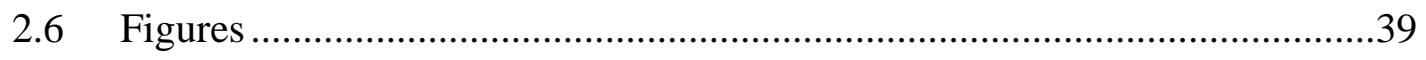


3 SPATIAL AND TEMPORAL PATTERNS IN OTOLITH CHEMICAL

SIGNATURES OF JUVENILE GOLDEN TILEFISH (LOPHOLATILUS

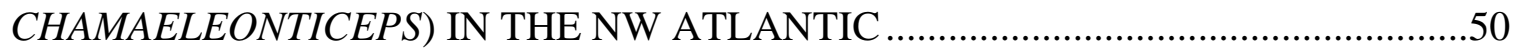

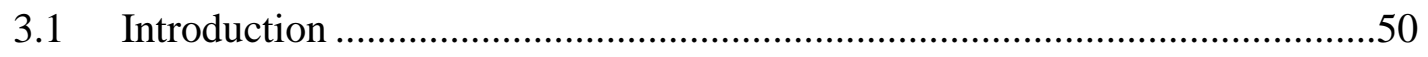

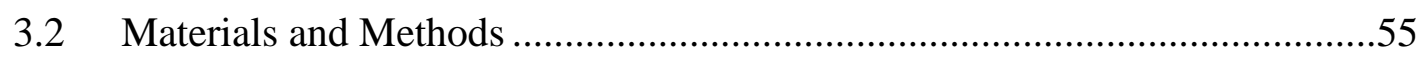

3.2.1 Sample Collection and Otolith Preparation ....................................55

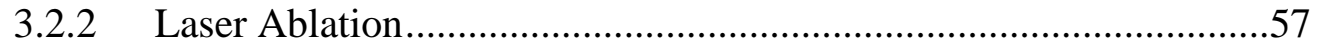

3.2.3 Microchemistry Data Analysis ................................................58

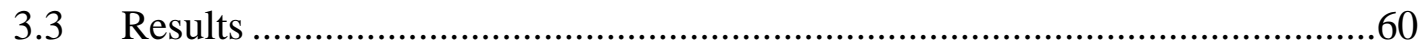

3.3.1 Regional Differences in Otolith Signatures ................................60

3.3.2 Temporal Differences in Otolith Signatures .................................66

3.3.3 Classification to Region of Capture ............................................62

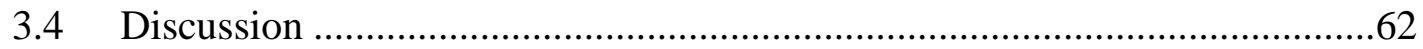

3.4.1 Regional Differences ........................................................63

3.4.2 Temporal Differences ...........................................................66

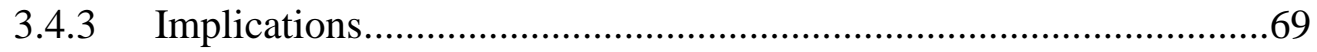

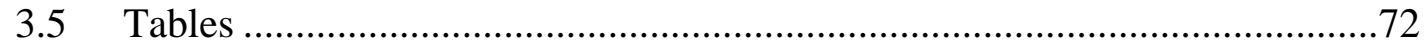

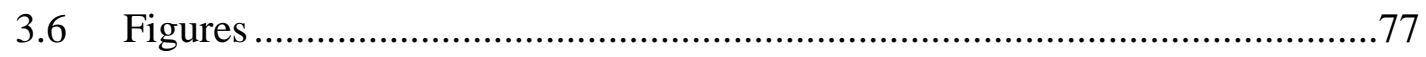

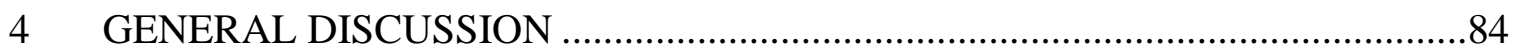

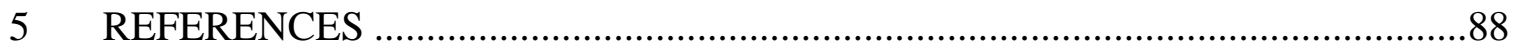




\section{LIST OF FIGURES}

Figure 1.1. Sagittal otolith of a Golden Tilefish annotated with morphological information

Figure 1.2. Sectioned otolith under reflected light, displaying the alternating opaque and translucent zones. Black dashed lines represent opaque zones, while grey lines represent translucent zones.

Figure 2.1. 2017 map of the sampling area. Red dots represent longline station locations. These were divided into 9 North-South regions (01-09) based on the NESFC bottom trawl survey latitudinal strata boundaries, and 4 depth strata $(75-303.6 \mathrm{~m})$, represented in the figure as a gradient from light blue-dark blue. .39

Figure 2.2. Annotated example of a thin sectioned Golden Tilefish sagittal otolith (male, fork length $=53 \mathrm{~cm}$, est. age-5) viewed using a stereomicroscope with transmitted light $(20 \times)$ with a $1 \mathrm{~mm}$ scale bar. Age estimates were determined by interpreting opaque zones along the ventral growth axis (represented as white dots). 40

Figure 2.3. Frequency distribution of fork length $(\mathrm{cm})$ of female (left panel), male (middle panel) and Golden Tilefish of unknown sex (right panel) collected from the NW Atlantic in 2017. Frequency is displayed as proportion relative to the total population.

Figure 2.4. Boxplots comparing fork length $(\mathrm{cm})$ of female (left), male (middle) and Golden Tilefish of unknown sex (right) collected from the NW Atlantic in 2017. The notch represents the median, the top and bottom indicate the interquartile range (the $25^{\text {th }}$ and $75^{\text {th }}$ percentiles), and the whiskers represent the maximum and minimum ranges. Black points represent outliers.

Figure 2.5. Frequency distribution of weight $(\mathrm{kg})$ of female (left panel), male (middle panel) and Golden Tilefish of unknown sex (right panel) collected from the NW Atlantic in 2017. Frequency is displayed as proportion relative to the total population.

Figure 2.6. Boxplots comparing body weight $(\mathrm{kg})$ of female (left), male (middle) and Golden Tilefish of unknown sex (right) collected from the NW Atlantic in 2017. The notch represents the median, the top and bottom indicate the interquartile range (the $25^{\text {th }}$ and $75^{\text {th }}$ percentiles), and the whiskers represent the maximum and minimum ranges. Black points represent outliers.

Figure 2.7. Frequency distribution of age (years) of female (left panel), male (rmiddle panel), and individuals of unknown sex (right panel) collected from the NW Atlantic in 2017. Frequency is displayed as proportion relative to the total population. 
Figure 2.8. Von Bertalanffy growth curves estimated for female (dark grey points, solid line), male (black points, short-dashed line) and all (unknown sex are light gray points, long-dashed line) Tilefish sampled from the NW Atlantic in 2017. For specific growth model estimates see Table 2.3.

Figure 2.9. Fork length-weight relationships for female (dark grey points, solid line), male (black points, short-dashed line) and all (unknown sex are light gray points, long-dashed line) Golden Tilefish sampled from the NW Atlantic in 2017. The power function trendline equations are shown on the top left of the graph

Figure 2.10. Individual growth rates $(\mathrm{cm} / \mathrm{yr})$ for all Golden Tilefish sampled from the NW Atlantic in 2017. This includes female (dark grey points), male (black points) and unknown sex (light gray points). Frequency is displayed as proportion relative to the total population. 48

Figure 2.11. Boxplot comparing growth $(\mathrm{cm} / \mathrm{yr})$ of female (left panel), male (middle panel) and Golden Tilefish of unknown sex (right panel) collected from the NW Atlantic in 2017. The notch represents the median, the top and bottom indicate the interquartile range (the $25^{\text {th }}$ and $75^{\text {th }}$ percentiles), and the whiskers represent the maximum and minimum ranges. Black points represent outliers.

Figure 3.1. Distribution of the Golden Tilefish chosen for microchemical analysis sampled from the NW Atlantic Ocean. Red points indicate capture stations within the two regions of the study; Southern New England near Hudson Canyon and Southern New England Middle Grounds near Veatch and Atlantis Canyons. ......77

Figure 3.2. Polished otolith of an aged-3 Golden Tilefish imaged under reflected light (magnification 25x). The core is visible, having an appearance similar to an eye, and is designated by an arrow

Figure 3.3. Sectioned otolith post-ablation. The transect path of the laser can be seen left to right from the dorsal to ventral side, covering the entire span of the otolith.....79

Figure 3.4. Annual classification of an aged-3 fish. The image has been edited to display the transect path linearly. The $\mathrm{Mg} / \mathrm{Ca}$ ratio transect was overlaid on an image of the otolith to aid in the annuli designation, following Limburg et al. (2018). The transect section corresponding to the first growth band or annuli represents 2015 (yellow); the transect section corresponding to the second annuli represents 2016 (green); the transect section corresponding to the third annuli represents 2017 (red

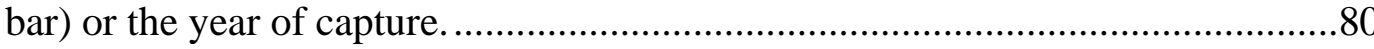

Figure 3.5. Box plots depicting raw otolith Element/Ca ratios by region and year. The notch represents the median, the top and bottom indicate the interquartile range (the $25^{\text {th }}$ and $75^{\text {th }}$ percentiles), and the whiskers represent the maximum and minimum ranges. Black points represent outliers. 
Figure 3.6. Multidimensional Scaling (MDS) plot of regional Golden Tilefish otolith elemental signatures fitted with $95 \%$ confidence ellipses. Each point represents Box-Cox transformed Element/Ca ratios, including eight element/calcium ratios of the respective otolith. Black points represent individuals from Southern New England (SNE) and light grey points represent individuals from the SNE-Middle Grounds (SNE-MG). Squares represent the Northern Hudson Canyon (NHC), circles represent the Southern Hudson Canyon (SHC), triangles represent the Atlantis Canyon (AC), and diamonds represent the Veatch Canyon (VC)

Figure 3.7. Multidimensional Scaling (MDS) plot of temporal Golden Tilefish otolith elemental signatures fitted with $95 \%$ confidence ellipses. Each point represents Box-Cox transformed Element/Ca ratios, including eight element/calcium ratios of the respective otolith. Black points represent individuals from Southern New England (SNE) and light grey points represent individuals from the SNE-Middle Grounds (SNE-MG). Circles represent individuals that were 1 year old during the year in question, triangles represent individuals that were 2 years old during the year in question, and squares were individuals that were 3 years old during the year in question 


\section{LIST OF TABLES}

Table 2.1. Fork length $(\mathrm{cm})$ and weight $(\mathrm{kg})$ by sex of Golden Tilefish sampled from NW Atlantic. Data are mean $\pm 1 \mathrm{SD}$ and range and represent all sampled individuals, except individual excluded from analysis for inaccurate weight and length .........36

Table 2.2. Summary of otolith morphometrics, including number collected, age (yr), length (post-rostrum to rostrum; $\mathrm{mm}$ ) and weight (mg) measured by sex from NW Atlantic Golden Tilefish that were used in age analyses. Data are mean $\pm 1 \mathrm{SD}$ and range, and only represent otoliths from aged individuals (i.e., excluding backcalculate individuals).

Table 2.3. Von Bertalanffy growth curve model results $\left[\mathrm{L}_{\infty}\right.$ represents the asymptotic length at which growth equals zero $(\mathrm{cm}), \mathrm{K}$ represents the growth coefficient $\left(\mathrm{yr}^{-}\right.$ $\left.{ }^{1}\right)$, and $t_{0}$ represents age at size zero] summarized by female, male and the total population (including all aged individuals, even of unknown sex) of Golden Tilefish sampled from the NW Atlantic. Values are based on growth zone counts.

Table 3.1. Demographics of Golden Tilefish used for otolith microchemistry analysis. .72

Table 3.2. Results of MANOVA examining regional and temporal differences in the otolith chemistry of Golden Tilefish. Significant results at $\alpha=0.05$ are bolded...73

Table 3.3. Univariate results of MANOVA examining regional and temporal differences in otolith chemistry of Golden Tilefish. Significant results at $\alpha=0.05$ are bolded.

Table 3.4. QDFA classification success using leave-one out cross-validation of Box-Cox transformed ratios. The predicted region columns represent the number of individuals assigned to a region based on elemental signature, while the rows represent the actual capture region. Bold numbers represent the number of individuals correctly assigned to their capture region, and \% correct represents this number divided by the actual number of individuals captured from the region. The first matrix represents the total classification success using Box-Cox transformed elemental ratios averaged over both years, while the following matrixes represent the year specific classification. SNE = Southern New England, SNE-MG = SNE-Middle Grounds. 


\section{ACKNOWLEDGEMENTS}

Firstly, I would like to thank the Mid-Atlantic Fisheries Management Council (Award \#: 77632), Michigan Tech's REF program (Award \#: 180513) and the Great Lakes Research Center's Student Research Grant Program for funding this project, and everyone that conducted the fisheries-independent field survey, including Michael Frisk, Jill Olin, Robert Cerrato, Paul Nitschke, and Laurie Nolan.

There are countless individuals in the Michigan Tech community who made this thesis possible. I am incredibly grateful for my advisor, Dr. Jill Olin, for always being there for me and answering any questions I had, and for being so understanding and patient with me. Neither of us could have predicted the ways things had to be adjusted due to the pandemic, and other setbacks, but you were there guiding me every step of the way. I would also like to thank my committee, Dr. Gordon Paterson and Dr. Casey Huckins for their guidance, patience, and support throughout this process, including chatting about statistics, and allowing me access to lab equipment. A big thank you also to Dr. Jim Junker for his help with stats and Rstudio questions. I also grateful to the Biological Sciences department coordinator chair, Tori Connors, for her administrative help, and the department chair, Dr. Chandrashekhar Joshi for his support.

This research would not have been possible without the help of my collaborators, Dr. Karin Limburg and Debra Driscoll and their work in the laser ablation lab. Thank you both for making this research possible, being flexible, and always being willing to 
virtually meet with me when I have questions. I hope I can meet you both in person some day! I am also very grateful to the researchers of NOAA, including Linda LombardiCarlson, Naeem Willett, and Kaitlin Rogers for teaching me more about the intricacies of Tilefish aging, and taking time from their days to perform some age readings for my samples. I would also like to thank Dr. Matthew Siskey for his advice on otolith preparation and cutting.

Finally, I would like to thank my friends and family for always being there for me and supporting me every step of the way, whether it be to give me advice, letting me vent, or just allowing me a reprieve from the stresses or graduate school life. I could not have done this without you! 


\section{ABSTRACT}

Knowledge of life-history characteristics and patterns of connectivity are important parameters to fisheries management, especially for species inhabiting hard to reach environments, such as the deep-sea. Golden Tilefish (Lopholatilus chamaeleonticeps) are slow growing, long-lived, demersal species that exhibit a patchy distribution along the continental shelf-edge of the NW Atlantic Ocean. Golden Tilefish create burrows in the clay sediment and maintain high site fidelity. These characteristics suggest the possibility of localized subpopulations across the species' distribution; an important consideration for the resilience of this species to fishing pressure. My objectives are (1) to estimate age, and model growth of fish captured from a fishery-independent survey and compare these estimates to assessments derived from fishery-dependent data, and (2) to investigate temporal and spatial patterns of habitat connectivity using otolith elemental signatures as natural tags that discriminate subpopulations. Age and growth estimates were consistent consistency with previous assessments and provided an unbiased analysis of the population that can be used for further monitoring. Analysis of elemental profiles indicated subtle spatial differences, suggesting the application for delineating subpopulations. Elemental profiles also varied between years and may represent differing environmental characteristics experienced by the individuals during their pelagic larval stage and subsequent settlement. My thesis contributes age, growth and population connectivity data that will aid in monitoring the stock and development of management decisions. 


\section{GENERAL INTRODUCTION}

\subsection{Deep-Sea Fisheries}

Steep declines in commercially important fish populations during the past 50 years are well documented (Hutchings 2000, Myers and Worm 2003, McBride et al. 2013), as are the effects of fishing on ecosystems and population production (Pikitch et al. 2004, Worm et al. 2009). Long-term exploitation of marine fishes has the potential to change the overall structure of food webs as well as individual populations (Jennings et al. 1999). Beyond declines in overall abundance, fishing can increase population variability over time in comparison to unexploited species, particularly for size-selective fisheries (Hsieh et al. 2006, Garcia et al. 2012). This can result from both market demand and management actions. Long-term exploitation and selection of larger individuals in a cohort have been associated with reductions of size, age, size-at-maturity, and reproductive capacity (Hutchings 2000, Hixon et al. 2014). Additionally, with gear that specifically targets certain size (and age) categories, fisheries can lead to demographic changes in fish populations. Such changes in life history traits (e.g., growth rate, mean maximum size, age-at-maturity, or size-at-maturity) have been observed in a number of species (Jennings and Kaiser 1998, Edeline et al. 2007, Jorgensen et al. 2007, Swain et al. 2007, Allendorf et al. 2008), such as pike (Esox lucius) in Windermere, U.K., which showed decreased somatic growth during times of greater fishing pressure (Edeline et al. 2007). These changes in life history, in turn, have resulted in loss of yield, and ecosystem services (Trippel 1995, Jennings et al. 1999, Law 2000, Jorgensen et al. 2007). 
Increasing global demand for fish has pushed fisheries to move to deeper depths of the oceans and expand the number of species captured and sold, increasing the fishing pressure placed on these species (Haedrich et al. 2001, Devine et al. 2006). Deep-sea fish species, however, tend to be long-lived, with slow growth rates, increasing their susceptibility to overfishing (Norse et al. 2012). These life history characteristics, in part, have led to overexploitation of species and subsequent population collapse. Atlantic Cod (Gadus morhua), for example, was harvested for centuries with minimal issues, creating a valuable, sustainable fishery around Newfoundland (Haedrich and Hamilton 2000). Pressures to increase catch rates and improved fishing technology, however, and a misunderstanding of their life history lead to overexploitation by multiple countries, and eventual population collapse (Kurlansky 2011). It is difficult to predict the recovery of Atlantic Cod to previous abundances, largely due to overexploitation but also due to subpopulation structure, and changes in the food web (Smedbol and Wroblewski 2002, McQuinn 2009, McCain et al. 2016). This species exemplifies how critical it is to understand a species' life history characteristics as a means to inform management and maintain population sustainability.

Many aspects of a deep-sea fish's ecology and life-history, such as longevity, growth, habitat use, foraging and population structure remain unknown, and are difficult to estimate using traditional assessment techniques, due to their depth distribution. This lack of knowledge, especially of complex, non-homogenous habitat use, creates substantial gaps in our capacity to sustainably manage such stocks (Dransfeld et al. 2013). Indeed, the majority of information towards deep-sea fish demographics is derived from the 
fishing industry, specifically from reported commercial and recreational catches. Both commercial and recreational fisheries are structured to target individuals of greatest market value (Pennino et al. 2016). Due to this targeting, fishery data is inherently biased in its demographic scope. Fishery-independent surveys, in comparison, are scientifically designed and standardized, removing some of the previous biases, though they are more limited in their time frame (Pennino et al. 2016). Fishery-independent surveys are, therefore, important for developing a more comprehensive understanding of a species' life history demographics. Sampling a more representative population provides an opportunity to estimate age, growth patterns, and species' habitat use more broadly; all metrics important for calculating maximum sustainable yield, and informing management decisions, such as catch and size limits.

\subsection{Metapopulation Dynamics and Stock Structure}

Inconsistencies between complex stock structure and management can cause unsustainable fishery management practices, overexploitation of unique populations, and reduced biodiversity (Kerr et al. 2017). Stocks are principally structured by rates of birth and death rather than immigration and emigration, thus managing several distinct stocks as a single unit can lead to unintended overexploitation, localized depletion, lower recruitment and overly restrictive regulations on the fishery (Tuckey et al. 2007, Ying et al. 2011, Spies et al. 2015).

Metapopulation ecology is an ecological approach to management that incorporates a species' spatial structure. A metapopulation is a large scale grouping of a species in 
which a fragmented landscape, or breeding scheme, creates a series of localized subpopulations (Hanski 1998). Understanding the connections between these subpopulations is critical to management. In metapopulations, structure develops through breeding, exchange of individuals and extirpation events (Hanski 1998). The role that larval and adult movement plays in the persistence and productivity of interconnected subpopulations is critical to fisheries management (Frisk et al. 2014). This is particularly relevant for species with patchy distributions. For example, if individuals exhibit spatially explicit use of habitat patches, and corridors of connectivity among patches are not available within the larger seascape, then the likelihood for patch persistence is compromised (Hanski 1998). As a result, understanding metapopulation dynamics not only requires estimation of larval connectivity, but also variation in juvenile and adult habitat choice and the environmental and resource drivers of individual movement (Smedbol and Wroblewski 2002, Frisk et al. 2014). Therefore, it is also necessary to discriminate among individuals of varying locations to develop a comprehensive view of the metapopulation and manage the species effectively.

\subsection{Golden Tilefish}

Golden Tilefish (Lopholatilus chamaeleonticeps) is keystone taxa in northwest (NW) Atlantic continental shelf-edge environment due to its biotic (trophic-mediated) and abiotic (ecosystem engineering) functional roles combined with high-value fisheries (Olin et al. 2020). The Golden Tilefish is a demersal fish that ranges from Nova Scotia, Canada, along the western Atlantic Ocean continental shelf and through the northern Gulf of Mexico, occupying depths between 100-300 meters (Turner et al. 1983). Golden 
Tilefish have patchy distributions, with a propensity for high site fidelity that may be linked to sediment and thermal preference (Able et al. 1982, Grimes et al. 1986, Able et al. 1987, McBride et al. 2013, Nitschke and Miller 2016). Specifically, after a pelagic larval period, Golden Tilefish settle and create vertical, funnel shaped burrows in fine grained clay substrate (Able et al. 1982, Able et al. 1993) that they inhabit throughout life; a life of up to 35 years (Turner et al. 1983). These burrows are most commonly found in environments ranging between $9-14^{\circ} \mathrm{C}$. These specific habitat requirements limit the species to a narrow band of preferred habitat, and therefore a patchy population distribution (Grimes et al. 1988, Fisher et al. 2014, Frisk et al. 2018). Mark-recapture studies have shown adult Golden Tilefish fish movement restricted to one nautical mile even after more than a year (Grimes et al. 1986). Their burrows have a profound effect on the landscape, creating habitat for other species, such as crustaceans. When not maintained by the fish, the burrows will fill in, resulting in a loss of habitat for other species seeking refuge in the structures (Able et al. 1993).

Golden Tilefish are also a commercially and recreationally valued species, with two separate stocks in the Northern and Southern Atlantic (Nitschke and Miller 2016). The modern fishery for Golden Tilefish developed in the early 1970's along the Mid-Atlantic Bight, near southern New England, while the southern fishery surrounds Florida and the Gulf of Mexico and is genetically distinct from the North Atlantic population (Katz et al. 1983). Landings of the Mid-Atlantic and Southern New England fishery remained high until the late 1970 's, when overharvesting lead to the stock being reduced over one half of its previous population density (Turner et al. 1983, Grimes et al. 1988). This 
overexploitation decreased the population's mean size and fish age at maturity, the effects of which are still experienced in the population even decades later (Grimes et al. 1988). While Golden Tilefish are not currently considered to be overfished, the sizes and mean age remain lower than previous records (McBride et al. 2013).

Many aspects of the Golden Tilefish's life history remain undescribed, including their habitat use across age, despite their ecological and commercial importance. Due to their patchy distribution, it is possible that the stock is functioning as a spatially structured metapopulation, with a series of interconnected subpopulations. Further knowledge of the habitat use across age is necessary to access subpopulation structure, contribution to the total population, and patch connectivity, all of which have important implications for subpopulations persistence. For example, while it is known that the larvae are pelagic, the timing and age of settlement into the benthic habitat is unknown. Due to the high site fidelity of adults, however, the recruitment of individuals to local populations depends in part on the timing of larval settlement. A gap in knowledge about habitat use across life history, such as settlement age and timing, impedes our ability to determine population recruitment and connectivity to sustainably manage these populations.

\subsection{Otoliths}

Age estimation is especially important for estimating population structure and examining life history demographics (Campana 2001, Jackson 2007). While there are multiple structures that can be used to estimate an individual's age such as, teeth and fin rays, the most commonly used structures in fishes is the otolith, or "ear stone" (Secor et al. 1995, 
Campana 1999). Otoliths (Figure 1.1) are calcium carbonate structures found beneath the brain case of most teleost fishes that aid in hearing and balance in the water column (Hüssy et al. 2020). Most teleost fishes have three pairs of otoliths: sagitta (the largest pair), lapillus, and asteriscus. Otoliths are not attached to the skull or any other bone, but rather are contained within separate chambers of endolymphatic epithelium surrounded by endolymph (Hüssy et al. 2020). Only cartilaginous fishes (sharks, rays and chimaeras) and jawless fishes (lampreys and hagfish) lack otoliths (Carlström 1963), although there has been recent evidence suggesting otolith presence in these individuals (Schnetz et al. 2019).

Otoliths continuously accrete calcium carbonate from the local environment and diet, throughout a fish's life (Hüssy et al. 2020). They accrete in concentric daily and annual rings based on the growth rate and metabolism of the fish, which create recurring alternating opaque and translucent zones representing different seasons (Figure 1.2; (Panella 1971, Fablet et al. 2011, Hüssy et al. 2020). As growth is seasonally variable in fishes, annuli ring structures are formed in the otolith. For temperate fish, opaque zones typically accumulate during periods of high fish growth normally experienced over summer, and are high in organic material, while the translucent zones represent the winter where fish growth is slower, and are more mineral rich (Heimbrand et al. 2020, Hüssy et al. 2020). Age can be determined through the counting of these growth zones (Panella 1971). Many variables, however, can affect otolith biomineralization, including feeding conditions, temperature, and hypoxia exposure, which can disrupt the seasonal pattern and affect the interpretation, create aging error (Fablet et al. 2011, Hüssy et al. 
2020). For example, seasonal ring formation in Atlantic Cod in Eastern Baltic has been found to be difficult to discern due to spawning, hydrology, and migration (Hüssy et al. 2016, Heimbrand et al. 2020). It can be difficult to age many deep-sea fish species due to seasonal environmental stability, and their long lives lead to indistinct growth zone patterns in the otolith (Cailliet et al. 2001). This can lead to inaccurate age estimations and growth analysis, which is critical for population assessment (Campana 2001).

One limitation of using otoliths to age individuals is the destructive nature of the technique. This is especially relevant when considering age estimation of vulnerable or protected species (Heupel and Simpfendorfer 2010, Hammerschlag and Sulikowski 2011). Though the use of non-lethal structures to age fish is growing, there remain drawbacks, for example, scales have been used for estimating the age of young individuals, however their use can lead to underestimation of age among older fish due to outer annuli being less distinct (Muir et al. 2008, Khan et al. 2015, Kumbar and Lad 2016). It also has been found to be more difficult to identify the first annuli when using fin rays, as shown in Brook Trout (Salvelinus fontinalis) studies (Stolarski and Hartman 2008). Thus, otoliths are preferable for age analysis due to their distinct annuli at older ages, growth across the entire life span and are robust to reabsorption (Campana 1999, Thresher 1999).

\subsection{Microchemistry}

Otoliths are widely used in fisheries science to determine the age of fish, information that is critical in evaluating life history parameters for fisheries assessment and management (e.g., growth rate, mortality rates, and production; Campana 2001). Otoliths can also 
provide information on migration and stock composition through proxy indicators such as chemical and isotopic tracers, which are incorporated during the growth of calcified structures (Elsdon et al. 2008, Secor 2010). As the otolith forms, trace elements and stable isotopes are incorporated into its calcium carbonate structure, given the fish's environment and physiology, creating a chemical signature or fingerprint (Thomas et al. 2017). The chemical signature of the otolith is influenced by several factors, such as water chemistry, temperature, geology, diet, and salinity (Campana 1999), creating timeand location-specific fingerprints that are permanently incorporated into the otolith (Campana 1999). As otoliths grow continuously with the fish, this creates a natural tag for movement and other life history events to be chronologically tracked over the course of a fish's life (Limburg 1995, Thorrold et al. 1998).

Laser Ablation Inductively Coupled Plasma Mass Spectrometry (LA-ICPMS) is a technique used to detail the chemical composition across the span of the otolith, providing insights into the entire life of the individual fish when used in combination with age analysis (Thorrold and Shuttleworth 2000). LA-ICPMS works by using a laser to ablate otolith material across its entire length, which is then transported by carrier gas into a plasma, and then sorted by mass into an ICPMS machine that will perform assays to determine elemental concentrations relative to reference material (Campana et al. 1997, Campana 1999, Limburg and Elfman 2017). This technique has been used to examine multiple aspects of life history in fish populations, including natal origins, population connectivity, stock discrimination, and estuary use (Vasconcelos et al. 2008, Clarke et al. 2009, Cook 2011, Ley and Rolls 2018). For example, Limburg (1995) used 
Strontium (Sr) content in the otolith of young-of-the-year American Shad (Alosa sapidissima) to identify the timing of outmigration of individuals from freshwater to marine habitats, as seawater has a higher Sr concentration relative to freshwater sources.

A number of elements have been used in the analysis of otolith microchemistry, providing different information about the environment the individual was inhabiting. Barium $(\mathrm{Ba})$ and $\mathrm{Sr}$, for example, reflect ambient water concentrations, with $\mathrm{Ba}$ increasing in concentration in freshwater environments and $\mathrm{Sr}$ being positively correlated with salinity, with some minor temperature effects (Limburg 1995, Bath et al. 2000, Brown and Severin 2009, Hüssy et al. 2020). Magnesium (Mg) positively correlates with metabolism and has been correlated with age in some species (Limburg et al. 2018, Heimbrand et al. 2020). Manganese (Mn) has been found to be a useful marker of environmental hypoxia, with Limburg and Casini (2018) demonstrating an increase in $\mathrm{Mn} / \mathrm{Mg}$ ratios during periods of Baltic Sea hypoxia over multiple decades in the otoliths of Eastern Baltic Cod. In addition, heavy metals such as Nickel (Ni), Zinc (Zn), Lead $(\mathrm{Pb})$ and Copper $(\mathrm{Cu})$ have been used to determine whether lesion formation observed in Gulf of Mexico Golden Tilefish and Red Grouper (Epinephelus morio) following the Deepwater Horizon oil spill correlated with heavy metal exposure (Granneman et al. 2017). Therefore, the application of this technique has the capacity to provide information regarding a species life-history, such as movement and natal origins (Brown and Severin 2009, Clarke et al. 2010), and is especially important to identity characteristics in deep-sea species that cannot be studied easily. 


\subsection{Research Goal}

The goal of my thesis research is to use otoliths to further the understanding of Golden Tilefish populations in the NW Atlantic Ocean by (1) generating age and growth parameters of the Southern New England/ Mid-Atlantic Golden Tilefish stock from the first fishery-independent survey and compare my estimates to previous commercial studies (Chapter 2) and (2) assessing differences in microchemistry over time and location to investigate the ability of otoliths to act as natural tags in the distinction of different groups within the species (Chapter 3). The elemental signatures acquired by otolith microanalysis provides the ability to track and quantify habitat-specific production while also providing a record of individual fish growth and movement patterns. This information has the potential to identify subpopulations at risk of overexploitation and will provide additional life-history data that may aid in establishing fishery quotas and harvest limits to maintain sustainable populations. 


\subsection{Figures}

Figure 1.1. Sagittal otolith of a Golden Tilefish annotated with morphological information.

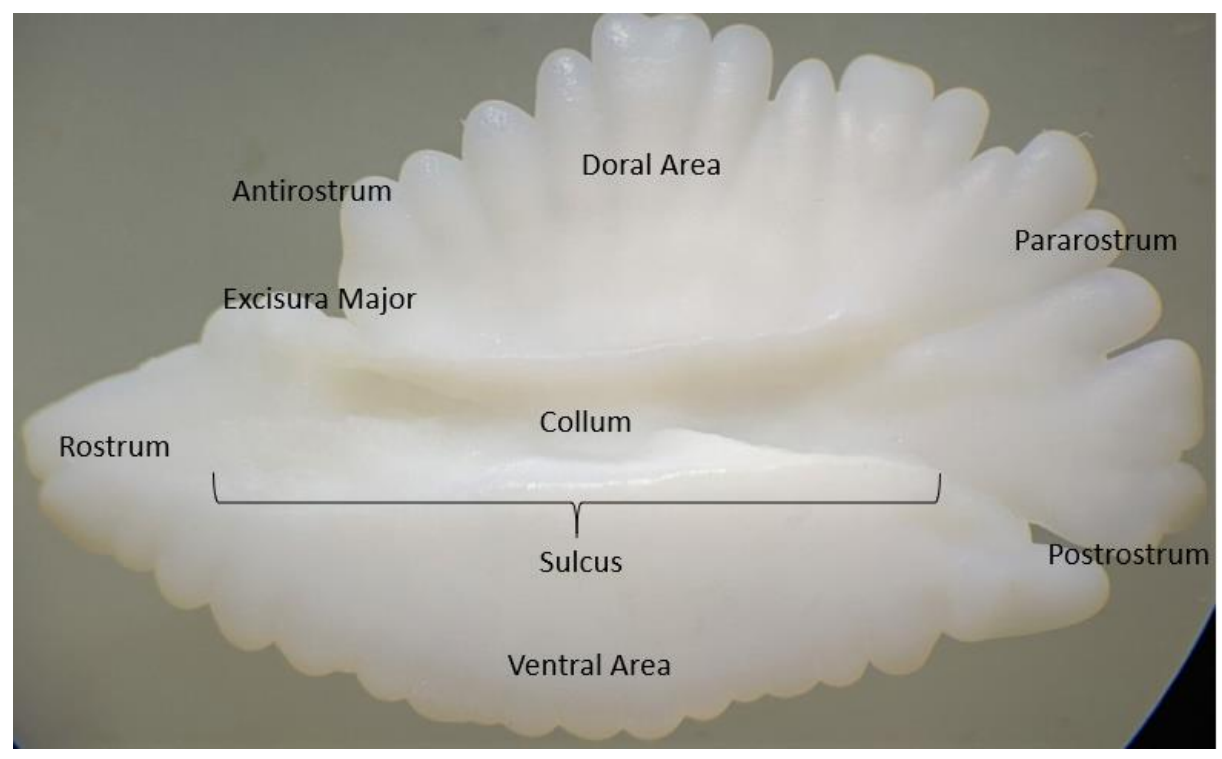


Figure 1.2. Sectioned otolith under reflected light, displaying the alternating opaque and translucent zones. Black dashed lines represent opaque zones, while grey lines represent translucent zones.

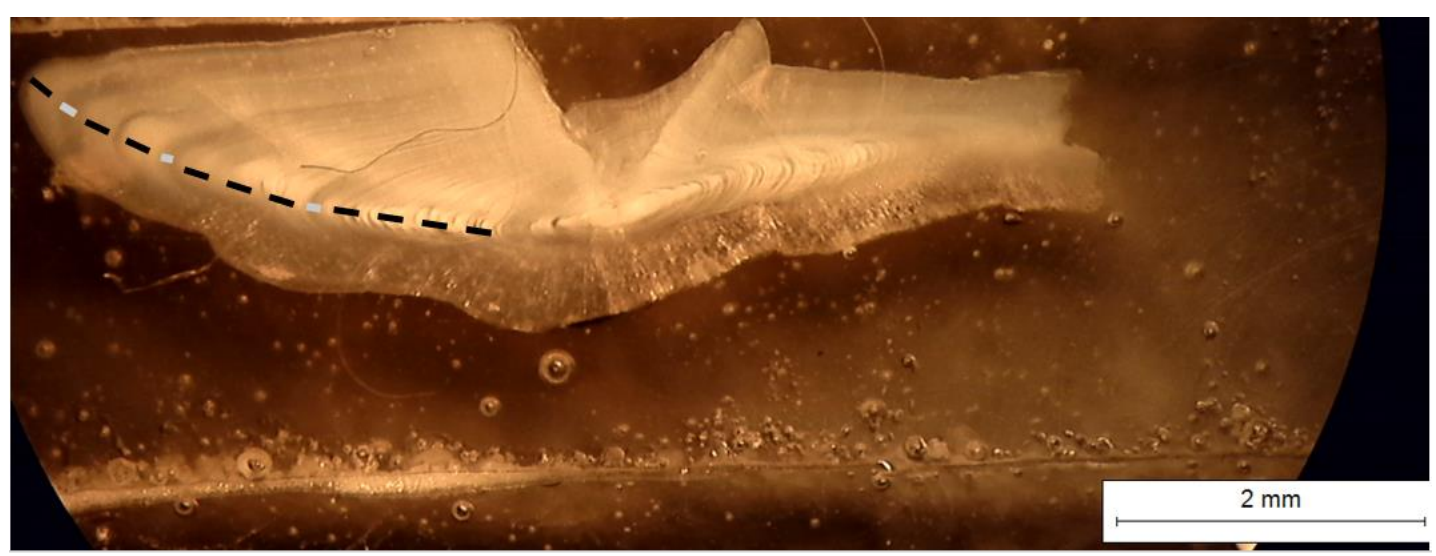




\section{AGE AND GROWTH ESTIMATION OF GOLDEN TILEFISH (LOPHOLATILUS CHAMAELEONTICEPS) FROM THE NW ATLANTIC}

\subsection{Introduction}

Golden Tilefish, Lopholatilus chamaeleonticeps (Goode and Bean 1879) is a deep-sea demersal fish found in the Atlantic Ocean from Nova Scotia, Canada to Florida, USA and through the Gulf of Mexico (Dooley 1978). Golden Tilefish are managed by three fishery management councils (Northeast Atlantic, South Atlantic, and Gulf of Mexico). Golden Tilefish are both commercially and recreationally fished in the North Atlantic and Gulf of Mexico (NOAA 2018, Ortega-Ortiz et al. 2020). From 2010 to 2016 total commercial landings for Golden Tilefish were 1,360 metric tons, worth \$7.7 million (NOAA 2018). Demographic analysis of Golden Tilefish populations from the waters of southern New England, South and North Carolina and Georgia and the Gulf of Mexico concluded that Golden Tilefish are a long-lived fish, have a slow growth rate, display sexual dimorphic growth and mature by age-5 (Turner et al. 1983, Harris and Grossman 1985, Grimes et al. 1986, Palmer et al. 2004, Lombardi-Carlson and Andrews 2015).

Golden Tilefish have been estimated to reach 40 years of age. Golden Tilefish also exhibit sexual dimorphic growth, whereby males grow faster than females and reach maturity at an earlier age (Turner et al. 1983). Specifically, Lombardi et al. (2010) showed that of individuals captured from the Gulf of Mexico, males had a growth 
coefficient of $0.15 \mathrm{yr}^{-1}$, and females had a growth coefficient of $0.13 \mathrm{yr}^{-1}$, demonstrating that males reach their asymptotic length more rapidly. During the late 1970's-early 1980's, overexploitation of Golden Tilefish in the NW Atlantic led to a dramatic population reduction, size and age truncation, and early maturation of males (Grimes et al. 1980, Grimes et al. 1988). For example, the strongest class of individuals reported in the Hudson Canyon ranged in size from $80-85 \mathrm{~cm}$ in length, while the strongest class reported in 1980 from the same area ranged in size between $55-60 \mathrm{~cm}$. This shows how severely the Tilefish size decreased at this time due to rapid overexploitation (Turner et al. 1983). The stock along Southern New England and the Mid-Atlantic Bight was previously assessed over the course of the population decline in the 1980's, and more recently in 2008 through data from commercial fisheries (Turner et al. 1983, Vidal 2009, McBride et al. 2013). Despite catch limits being put in place in the 1980's, as of 2008, the population was still experiencing effects from the previous population decline. While the population had returned to previous maturation ages, it was still experiencing size and age truncation, as the oldest fish in that study was age-25 (Vidal 2009, McBride et al. 2013).

It is important to note that changes in demographics of the Golden Tilefish population have been monitored solely through fish landings provided through the commercial fishing industry. It is well known that sampling gear and specified fishing locations can bias population demographic assessments as commercial fisheries are designed to target individuals of greatest market value (Pennino et al. 2016). Fishery-independent surveys, in comparison, are designed and standardized for assessing fish populations, thus 
removing some of the previous biases, though they are more limited in their time frame (Pennino et al. 2016). One example of how fishery-independent surveys capture a wider variety of the population is through using a wider size range of hooks. Deriving age and growth demographics from fish sampled during a fishery-independent survey is important for developing a more comprehensive understanding of population demographics, and accurately estimating age and growth patterns; all metrics important for calculating maximum sustainable yield, and informing management decisions, such as catch and size limits.

The objective of this chapter is to age Golden Tilefish sampled from the fisheryindependent long-line survey conducted in 2017 and compare our growth estimates to studies reporting age and growth parameters for this species in Southern New England and the Mid-Atlantic Bight (Turner et al. 1983, Vidal 2009, McBride et al. 2013). Specifically, in this chapter, I determine age through band counts, evaluate frequency distributions of length, weight and age, and estimate growth parameters for both male and female fish using the Von-Bertalanffy growth model. These results are then compared to similar estimates derived from commercial fishery landings. The estimates for individuals sampled from the fishery-independent survey will complement existing age and growth estimates and provide a more comprehensive evaluation of these demographic parameters, as the individuals sampled through this fishing method are more broadly representative of the population compared with those sampled through commercial fisheries. 


\subsection{Materials and Methods}

\subsubsection{Sample Collection}

Golden Tilefish were sampled during a fisheries-independent long-line survey conducted between July and August of 2017 across the continental shelf-edge of the northwest (NW) Atlantic Ocean from Georges Bank to Cape Hatteras (Figure 2.1; Frisk et al 2018). Detailed survey methods are reported in Frisk et al. (2018). Briefly, 196 sampling stations were randomly chosen from a stratified area consisting of nine north--south latitudinal and four depth (range $=75-310 \mathrm{~m})$ regions following the NOAA's NEFSC strata designations (Figure 2.1).

At each station bottom set long-lines were deployed. Each set consisted of a one-nautical mile steel cable mainline equipped with 150 evenly spaced gangions baited with squid. The average soak time for each long-line deployment was 40 minutes. For each sampling event, region (e.g., Georges Bank, Southern New England, Mid-Atlantic Bight) based on latitude and longitude, and depth (m) were recorded. Upon capture, Golden Tilefish were given an ID number, measured for fork length $(\mathrm{cm})$, weighed $(\mathrm{kg})$, sexed macroscopically via gonad examination upon dissection, and sagittal otoliths were obtained. Otoliths were rinsed with freshwater and stored in labeled envelopes for laboratory processing.

\subsubsection{Otolith Processing}

Otoliths were obtained from a total of 479 out of 486 individuals landed during the survey. Upon return to the laboratory, each otolith was first evaluated for damage. 
Specifically, in the case where a transverse section of the core would not be possible, including when the otoliths were broken lengthwise or there was damage to the core, the otolith was deemed unusable $(n=40)$ and removed from subsequent processing. One additional otolith was removed from subsequent processing and data analysis, as data for the fish's length and weight were inaccurate. Following this initial evaluation, the remaining otoliths $(n=438)$ were catalogued and measured from tip to end $(\mathrm{mm})$ and weighed (mg; see Table 2.2). Otoliths were then cleaned with diluted (10\%) bleach, rinsed three times with distilled water, and air-dried overnight in a laminar flow hood before being stored for sectioning.

Following initial cataloguing and cleaning, the core of each otolith $(n=438)$ was identified and marked with permanent marker as a visual aid when sectioning. The marked otoliths were then organized from smallest to largest based on fish fork length, embedded in silicone ice cube trays using Struers epoxy resin (Struers A/S, Ballerup, Denmark) following methods of Secor et al. (1991) and dried in the fume hood for 24 hrs. Each otolith was then cut into transverse sections using a Buehler ${ }^{\circledR}$ IsoMet low-speed saw (Buehler, Lake Bluff, Illinois) following methods of Lombardi-Carlson and Andrews (2015) and based on training at the NOAA Pensacola laboratory. Specifically, four IsoMet ${ }^{\mathrm{T}}$ diamond wafering blades [Buehler, Lake Bluff, Illinois; Arbor size: 0.5 (12.7 $\mathrm{mm})$ ] were spaced approximately $0.45 \mathrm{~mm}$ apart using three inserts cut from plastic folders $(\sim 0.15 \mathrm{~mm})$. The otolith was mounted into a chuck and secured so that the blades ran parallel through the dorsal and ventral sections of the otolith to create a transverse section. A micrometer was then used to bring the marked core into position between the 
middle blades. The IsoMet saw was started at a speed of 2-3 ( 60-90 RPM) and sped up to 8 ( 245 RPM) after a few seconds until the cut was complete (Lombardi-Carlson and Andrews 2015). This method produced three $0.45 \mathrm{~mm}$ sections including the core. The purpose of this approach was to ensure capture of the core. The three sections were then mounted to a prelabeled microscope slide using double-sided tape adhesive and stored in slide boxes for protection. No polishing was performed at this time.

Once mounted, each otolith section was photographed between 12.5 and 25.0 magnification using a digital camera (The Imaging Source`, DFK MKU226-10x22) under transmitted light with a stereomicroscope (Olympus ${ }^{\oplus}$, SZX9), resulting in three photographs per otolith. To enhance images for clarity, distilled water was pipetted onto the otolith section prior to photographing. Images of each section were stored digitally with a scale bar (mm). Magnifications were chosen for each otolith to allow for a comprehensive view of the otolith without extraneous space. The images were saved with reference to individual ID number, magnification, and section number, such as section one, two, or three. The images were edited using ImageJ software to maximize contrast when counting growth bands.

\subsubsection{Age Determination}

Age determination employed standardized otolith ageing protocols; counting pairs of opaque and translucent growth bands along the ventral side (Secor et al. 2014, LombardiCarlson and Andrews 2015). Visual enhancement and notation techniques of otolith images using ImageJ software, and calibration of the reader to a reference collection 
provided by Lombardi-Carlson and Andrews (2015) based on training at the NOAA Pensacola laboratory aided the primary reader. Two blind counts of annuli, where length and weight were not provided, were conducted for each otolith (Figure 2.2). These first blind counts were used to determine indices of precision for the primary reader (K. Dawson), including average percentage error (APE):

$$
A P E_{j}=100 \% * \frac{1}{R} \sum_{i=1}^{R} \frac{\left(X_{i j}-X_{j}\right)}{X_{j}}
$$

where $\mathrm{X}_{\mathrm{ij}}$ is the $i$ th age determination of the $j$ th fish, $\mathrm{X}_{\mathrm{j}}$ is the average age estimate of the jth fish, and $\mathrm{R}$ is the number of age readings (Campana 2001). Coefficient of variation (CV) was also calculated as:

$$
C V_{j}=100 \% * \frac{\sqrt{\sum_{i=1}^{R} \frac{\left(X_{i j}-X_{j}\right)^{2}}{R-1}}}{X_{j}}
$$

(Campana 2001). If the two counts differed, the otolith was read a third time, consulting the first two count estimates for a final age estimate. In addition, a random sample of otoliths ( $n=48$ total, 6 individuals aged by both) were sent to independent readers from NOAA Fisheries [N. Willett $(n=21)$ and K. Rogers $(n=34)$ ]. Average percentage error and percentage agreement \pm 1 and \pm 2 years were calculated for indices of precision between their readings with final age determination by the primary reader.

\subsubsection{Data Analysis}

Analyses were performed in R (version 4.0.5, R Development Core Team, 2021) within the RStudio interface (version 1.1.463, R Studio Team, 2021), SYSTAT (10, SYSTAT, 
Inc.), and Microsoft Excel (2018) and the level of statistical significance $\alpha$ was set at 0.05. Fork length and body weight data of the fishes and their otolith morphology were evaluated for normality using Shapiro-Wilks tests through the dplyr (Wickham et al. 2020) and ggpubr (Kassambara 2020) packages in RStudio, and for homogeneity of variance through visual inspection of residual plots.

Fork length, weight, age, and growth rate data of Golden Tilefish were not normal based on the Shapiro-Wilks tests (FL: $\mathrm{W}=0.77, \mathrm{p}<0.001$; Weight: $\mathrm{W}=0.42, \mathrm{p}<0.001$; Age: $\mathrm{W}=0.36, \mathrm{p}<.001$; Individual Growth Rate: $\mathrm{W}=0.9594, \mathrm{p}<0.001$ ), therefore differences in body size, and age and growth rates among sexes, were tested using the Kruskal-Wallis Test as a non-parametric alternative to an analysis of variance (ANOVA), followed by the Wilcoxon sum test for pairwise comparisons. The relationships between fork length and body weight were estimated using the power function for males, females and all fish combined.

Length at age for males, females and all individuals combined were calculated using the Von Bertalanffy growth function (VBL),

$$
L_{t}=L_{\infty}\left(1-\exp ^{\left\{-K\left(t-t_{0}\right)\right\}}\right)
$$

where $L_{t}$ represents length at age, $L_{\infty}$ represents asymptotic length $(\mathrm{cm}), K$ represents growth coefficient $\left(\mathrm{yr}^{-1}\right), t$ represents age $(\mathrm{yr})$, and $t_{0}$ represents age at size zero $(\mathrm{cm})$. Von-Bertalanffy values were calculated using the FSA (Ogle et al. 2019), FSAdata (Ogle 2019), and nlstools (Baty et al. 2015) packages in RStudio for the total population and 
males, and in SYSTAT (10, SYSTAT, Inc.) for females. Individual growth rates (cm/yr) were calculated using sex-specific VBL values; VBL values for the total population were used to calculate individual growth rates for individuals of unknown sex.

Age class growth rates were calculated using the length-weight relationship and the VBL values. Regression analysis was used to fit the relationships between fork length and weight for fish separated by sex. The regression statistics were used to create equations for VBL mass per age class using the following equation:

$$
M_{t}=\mathrm{a} *\left(L_{t}^{\mathrm{b}}\right)
$$

where $M_{t}$ represents mass at age, $L_{t}$ represents VBL length at age, and a and $\mathrm{b}$ are values specific for the best fit of the data. These were then used in combination with the VBL growth equations to estimate growth rates per age class and calculate the ages of unaged fish $(n=47)$.

Growth per year $(\mathrm{cm} / \mathrm{yr})$ for each age class was calculated with the equation:

$$
\frac{c m_{t}}{y r}=\frac{\left(L_{t+n}-L_{t}\right)}{n}
$$

Where $\frac{c m_{t}}{y r}$ represents the growth in $\mathrm{cm}$ per year for the age class, $L_{t}$ represents the VBL length at age, $L_{t+n}$ represents VBL length at the next age class, and $n$ represents the difference between the age class and the next (normally equals 1). Age class values are were calculated for each sex. 
In the case where the individual's otoliths were broken $(n=47)$, the age was calculated by reorganizing the VBL growth equation to create the equation:

$$
t=\left(\frac{1}{K}\right) * L N\left(1-\left(\frac{L_{t}}{L_{\infty}}\right)\right)+t_{0}
$$

These ages were subsequently used in the individual growth calculations, for a total of 485 individual growth rates estimated and analyzed.

Finally, individual growth rates $\left(\frac{c m_{i}}{y r}\right)$ were calculated through the division of individual fish length $\left(L_{i}\right)$ by the VBL length for the fish's age class and multiplying this by the age class growth rate $\left(\frac{c m_{t}}{y r}\right)$ :

$$
\frac{c m_{i}}{y r}=\left(\frac{L_{i}}{L_{t}}\right) *\left(\frac{c m_{t}}{y r}\right)
$$

\subsection{Results}

\subsubsection{Population Demographics}

Fork length and body mass summaries for all individuals are provided in Table 2.1 and Figures 2.3 and 2.4. Overall, there was a wide size range of individuals evaluated (FL; $26-110 \mathrm{~cm})$. There was a significant difference in FL between the sexes based on Kruskal-Wallis $\left(X^{2}=40.02, \mathrm{df}=2, \mathrm{p}<0.001\right)$. Male fish were significantly larger than females $(\mathrm{p}<0.001)$ and unknown sexed fish $(\mathrm{p}<0.001$; Table 2.1, Figure 2.5). Fish of unknown sex had the shortest FL and were significantly smaller than known male and female fish $(\mathrm{p}=0.035)$. 
Body mass was also significantly different between the sexes (Figure 2.6; KW: $X^{2}=$ 42.16, $\mathrm{df}=2, \mathrm{p}<0.001)$. Male fish, on average, were significantly heavier than both female and unknown sexed fish based on weight (Table 2.1). However, it was found that female body weight was not significantly different from fish of unknown sex $(\mathrm{p}=0.058)$.

The size metrics measured for aged otoliths followed similar trends observed for body size of fishes among sexes (Table 2.2). There was an overall significant difference in average otolith length between the sexes $\left(\mathrm{KW}: X^{2}=21.62 ; \mathrm{df}=2, \mathrm{p}<0.001\right)$. For example, otoliths measured from male fish were on average $1.0 \mathrm{~mm}$ longer than the otoliths taken from females $(\mathrm{p}<0.001)$ and $1.5 \mathrm{~mm}$ larger than the otoliths from fish of unknown sex $(\mathrm{p}<0.001$; Table 2.2). The difference in average length between the otoliths from female and fish of unknown sex, however, was not significant $(\mathrm{p}=0.200)$.

Otolith weight followed a similar pattern, with there being a significant difference in average weight between sexes (KW: $X^{2}=27.31, \mathrm{df}=2, \mathrm{p}<0.001$; Table 2.2). Otoliths from males were significantly heavier than otoliths from females $(\mathrm{p}<0.001)$ and fishes of unknown sex ( $p<0.001$; Table 2.2). Similar to previous results, the otolith weight from female fish and fish of unknown sex were not significantly different from each other $(\mathrm{p}=0.070 ;$ Table 2.2) 


\subsubsection{Age Determination}

Otoliths from 438 Golden Tilefish were aged, and included 175 females, 223 males, and 40 fish of unknown sex (Table 2.2). The indices of precision between my first and second readings was an APE of $1.2 \%$, and a $\mathrm{CV}$ of $1.7 \%$. The average APE between my final age determination and the external readers was 9.3\%. Reader agreement between my readings and K. Rogers was $30.6 \%$. Agreement increased to $72.2 \%$ and $88.9 \%$ within \pm 1 and \pm 2 years, respectively. Reader agreement between my readings and N. Willett was $28.6 \%$ with agreement increasing to $81.0 \%$ and $85.7 \%$ within \pm 1 and \pm 2 years, respectively. Age uncertainty was highest in fish older than age-15.

Golden Tilefish from this study ranged in age from 3-30 years old. Most individuals were age-15 or younger $(99.3 \%$; Figure 2.7$)$ with $47 \%$ of those younger individuals being age4 (Figure 2.7). Fishes between ages 10-12, 15-22, and 24-29 were largely absent from our sampled population (Figure 2.7). Age differed significantly between the sexes (KW $\left.X^{2}=16.79, \mathrm{df}=2, \mathrm{p}<0.001\right)$. Males were significantly older $(4.3 \pm 2.3 \mathrm{yr})$ than both females $(4.1 \pm 2.6 \mathrm{yr} ; \mathrm{p}=0.019)$ and fish of unknown sex $(3.5 \pm 0.6 \mathrm{yr} ; \mathrm{p}<0.001)$.

\subsubsection{Von-Bertalanffy Growth Curves}

Males and females showed different growth patterns (Table 2.3), which were more distinct in individuals $>$ age-5 (Figure 2.8). Male fish reached asymptotic length at larger sizes $\left(L_{\infty}=118.9 \mathrm{~cm}\right)$ than female fish $\left(L_{\infty}=96.9 \mathrm{~cm}\right.$; Table 2.3$)$. Male fish also showed a greater growth coefficient $\left(\mathrm{K}=0.10 \mathrm{yr}^{-1}\right)$ than females $\left(\mathrm{K}=0.09 \mathrm{yr}^{-1}\right.$; Table 2.3$)$, though 
the difference is small. Assessment of all captured individuals resulted in an asymptotic length of $L_{\infty}=105.2 \mathrm{~cm}$ and a growth coefficient of $\mathrm{K}=0.11 \mathrm{yr}^{-1}$ (Table 2.3; Figure 2.8).

\subsubsection{Individual Growth Patterns}

Model fits for the fork length-weight relationships were strong for males, females and all fish combined $\left(\mathrm{R}^{2}=0.85-0.88\right.$; Figure 2.9$)$. Average individual growth rate for the population $(n=485)$ was $6.0 \mathrm{~cm} / \mathrm{yr}$, with a range of $0.5-11.2 \mathrm{~cm} / \mathrm{yr}$ (Figure 2.10). There was a significant difference in the individual growth rates between the sexes $\left(\mathrm{KW} X^{2}=\right.$ 300.4; $\mathrm{p}<0.001)$. Females $(4.4 \mathrm{~cm} / \mathrm{yr})$ grew significantly slower than both males $(7.0$ $\mathrm{cm} / \mathrm{yr} ; \mathrm{p}<0.001)$ and fish of unknown sex $(6.7 \mathrm{~cm} / \mathrm{yr} ; \mathrm{p}<0.001$; Figure 2.11). Males also grew significantly faster than individuals of unknown sex $(\mathrm{p}=0.006)$.

Variability in growth rates was greatest in individuals $>$ age-5, with growth decreasing with age (Figure 2.10). The average individual growth rate for individuals < age-4 years was $6.2 \mathrm{~cm} / \mathrm{yr}$, decreasing to $4.8 \mathrm{~cm} / \mathrm{yr}$ for individuals > age-5 (Figure 2.10). When comparing by sex, females < age-5 showed average growth of $4.6 \mathrm{~cm} / \mathrm{yr}$ whereas females $>$ age- 5 showed average growth of $3.4 \mathrm{~cm} / \mathrm{yr}$. Males < age-5 grew $7.5 \mathrm{~cm} / \mathrm{yr}$ and growth decreased to $5.5 \mathrm{~cm} / \mathrm{yr}$ in males $>$ age- 5 .

\subsection{Discussion}

The age and growth parameter estimates reported here are consistent with previous studies for the northern stock of Golden Tilefish (Turner et al. 1983, Vidal 2009, McBride et al. 2013). However, those estimates, were based on fish collected from the 
commercial and recreational fishery, which target specific size classes of individuals in the population. For example, large Tilefish $(3.2-10.9 \mathrm{~kg})$ have the greatest market value, and are therefore the most heavily targeted size class in the fishery (NOAA 2018). The length and age ranges provided in this chapter are consistent with ranges derived from commercial fishing industry, while being skewed towards younger, immature, individuals due to the fishery-independent sampling design. This highlights the importance of fishery-independent surveys, as they contribute valuable information on a broader size range of individuals that are not as readily captured in commercial fisheries. Capture of younger, immature fish could also provide valuable information on reproductive strategy, as there have been varying determinations of whether the species is gonochoristic or hermaphroditic (Lombardi-Carlson 2012, McBride et al. 2013). This information provided from this survey, such as age structure, is valuable for monitoring the stock of Golden Tilefish, independent of commercial reports and will aid stock assessors in the management of this species.

\subsubsection{Population Demographics}

Golden Tilefish are reported to reach maximum lengths of approximately $110 \mathrm{~cm}$ FL (Turner et al. 1983) and mature between 40-50 cm FL (McBride et al. 2013) in the NW Atlantic. Our study included Golden Tilefish that ranged in size from 26-110 cm FL, indicating that our survey caught $\sim 75 \%$ of the life-span of this species. The fish sampled in this study ranged in age from 3-30 years old. The maximum age represented in the survey of 30 years old is similar to age estimates from a number of studies of Golden Tilefish for similarly sized fish sampled from the NW and SW Atlantic (35 yr, Turner et 
al. 1983; 33 yr, Harris and Grossman 1985, 1985; 34 yr. Harris et al. 2001; 40 yr, Palmer et al. 2004). The majority of individuals aged in this study were nearing maturity, and were between 4-5 years of age (57.3\%; 26-63 cm FL; McBride et al. 2013). Males were generally older than females on average, but they also were the largest on average, meaning that the age discrepancy could be due to the capture of different size ranges.

Age estimates were highly variable, especially for the older fish in this study. Golden Tilefish are known as a difficult species of fish to age through age estimation methods (Lombardi-Carlson and Andrews 2015). The difficulty in aging these otoliths is likely due to opaque band formation in the species. Temperatures are relatively stable yearround in the depth range where Golden Tilefish inhabit $\left(9-14^{\circ} \mathrm{C}\right.$; Grimes et al. 1986); they do not experience the same seasonal fluctuations in temperature that shallower water species experience. As a result, differences in growth between the seasons are not as pronounced, resulting in a weaker visible bands in the otolith cross-sections (Cailliet et al. 2001). However, precision estimates and percentage agreement between me and other readers are similar to other studies. The average APE between my final age determination and the external readers is only slightly higher (9.3\% vs. 5.5\%; Lombardi-Carlson et al. 2015), and the reader agreement was $30.6 \%$ and $28.6 \%$ between myself and the external readers, compared to 28\% for Lombardi-Carlson and Andrews (2015). The percentage agreement ( \pm 2 years) was near $90 \%$ between my final age determinations and both external age readers. Therefore, while age estimates were variable, the indices of reader precision and percentage agreement were similar between this study and other previously 
published Golden Tilefish studies providing confidence in final age estimates for the individuals reported here.

Differences in size demographics among studies can result from differential recruitment, total and fishing mortality rates, and the size selectivity of fisheries and sampling gear (Neumann and Allen 2007). The dominance of smaller individuals in our sampled population likely reflects the nature of the survey design being fishery-independent and the sampling gear used to catch fish. The majority of Golden Tilefish population data are derived from landings reported by commercial fisheries that target large fish to maximize market value for human consumption, whereas fishery-independent operations are designed to randomly sample a population for purposes of deriving an index of relative abundance. Moreover, commercial fisheries for Golden Tilefish in the NW Atlantic use medium-sized circle hooks to target specific size classes to maximize market value (12/013/0; Frisk et al. 2018). As the goal of the fishery-independent survey conducted in 2017 was to estimate the Golden Tilefish population outside of commercial fishing areas of non-targeted size classes, three different offset circle hook sizes, small (8/0), regular (12/0) and large (14/0), distributed at a ratio of 20-60-20 were deployed on each long-line set (Frisk et al. 2018). Catch-Per-Unit-Effort (CPUE) data from the survey showed that small hooks had higher CPUE of Golden Tilefish ranging in length from $30-50 \mathrm{~cm}$ compared to other hook sizes (Frisk et al. 2018). A similar finding was reported by Olin et al. (2021) for a survey conducted in 2020. The limited number of small fish common in commercial activities, likely results from difficulty taking the bait due to gape size or the ability of small individuals to consume bait without biting the hook. Alternatively, it has 
been suggested that small individuals may inhabit different areas than adults. For example, Freeman and Turner (1977) and Grimes et al. (1986) have speculated the potential for seasonal habitat use of Georges Bank in winter months by Golden Tilefish due to thermal preferences of the species, though this has not been further examined. Future research should focus on habitat use of different size classes of Golden Tilefish and determine whether or not size classes partition in the NW Atlantic.

\subsubsection{Von-Bertalanffy Growth Curves}

The Von-Bertalanffy model parameters estimated in this study are consistent with others developed for the NW Atlantic Golden Tilefish stock. To compare, estimates from a 1982 survey (Turner et al. 1983) showed an overall $\mathrm{L}_{\infty}=97.6 \mathrm{~cm}$ and estimates from a 2008 survey (Vidal 2009) showed an $L_{\infty}=123.8 \mathrm{~cm}$. Our estimates of $L_{\infty}=105 \mathrm{~cm}$ fall between the two years. The results, however, could be confounded by the higher proportion of young individuals caught in our survey, and the lower proportion of fish > age-9. In comparison, assessments made from the Golden Tilefish population from the Gulf of Mexico from 1997-2009 showed a lower $L_{\infty}$ of $83.0 \mathrm{~cm}$, although it was stated this was low given the largest observed fish (112.3 cm TL) (Longmore et al. 2010). These differences could result from differences in environment, stock demographics, or calculation methods.

Sexual dimorphism in growth, with females being smaller and growing more slowly than males, has been reported in previous studies of the NW Atlantic Golden Tilefish population (Turner et al. 1983), and of other Tilefish species, such as the Blueline 
Tilefish, Caulolatilus microps (Ross and Huntsman 1982). Results of our VonBertalanffy growth model are consistent with these reports whereby, males and females displayed sexually dimorphic asymptotic length and growth coefficients. Specifically, in our study males reached an asymptotic FL of $L_{\infty}=118.9 \mathrm{~cm}$, while females reached an asymptotic FL of $L_{\infty}=96.9 \mathrm{~cm}$. The same pattern is shown in previous studies of the NW Atlantic population, where in 1982, males showed an asymptotic length of $111.3 \mathrm{~cm}$, and females showed an asymptotic length of $90.2 \mathrm{~cm}$ (Turner et al. 1983). These values are only slightly smaller than our estimates, which could be due to the amount of time passed between the surveys. The trend has also been reported in Gulf of Mexico Golden Tilefish, where the asymptotic length for males was $76.7 \mathrm{~cm}$, and for females was $61.3 \mathrm{~cm}$ (Longmore et al. 2010). While the calculated values could vary by study due to environment, time period, or calculation methods, the pattern is consistent. The growth pattern divergence is more apparent as the individuals aged. This could be a consequence of the higher energetic costs for females after sexual maturation (Turner et al. 1983), but would require further analysis.

The growth coefficient $(\mathrm{K})$ represents the rate at which the asymptotic length is reached. This value has important implications with fisheries, as it helps determine when the animals will reach capture size. A greater growth coefficient means that the fish will reach the required capture size minimum faster, and would therefore be susceptible to pressure from the fishery. The estimated growth coefficient for all individuals captured in our survey was $0.11 \mathrm{yr}^{-1}$, with the sexes having slightly dimorphic values of $\mathrm{K}=0.10 \mathrm{yr}^{-1}$ for males and $\mathrm{K}=0.09 \mathrm{yr}^{-1}$ for males, although this difference is minimal. Previous 
studies of the population in the NW Atlantic showed similar overall $\mathrm{K}$ value of $0.10 \mathrm{yr}^{-1}$, with males showing a value of $\mathrm{K}=0.08 \mathrm{yr}^{-1}$, and females showing a value of $\mathrm{K}=0.10 \mathrm{yr}^{-}$

${ }^{1}$ (Vidal 2009). Interestingly, males in this previous data set had a lower growth coefficient than females, the inverse of our results. This could be due to males having greater asymptotic length, and it therefore taking longer for them to reach that length. Reports from the Golden Tilefish population in the Gulf of Mexico, however, showed an overall $\mathrm{K}$ value $0.13 \mathrm{yr}^{-1}$, with males having a growth coefficient of $0.15 \mathrm{yr}^{-1}$, and females having a growth coefficient of $0.13 \mathrm{yr}^{-1}$ (Lombardi et al. 2010). While these values are slightly greater, these results show a similar pattern to our study, where the male $\mathrm{K}$ value was greater than the female.

\subsubsection{Individual Growth Patterns}

Average individual growth for all fish aged-4 and younger was $6.2 \mathrm{~cm} / \mathrm{yr}$, decreasing to $4.8 \mathrm{~cm} / \mathrm{yr}$ for individuals aged-5 and older. Previous studies of Golden Tilefish, however, showed higher growth rates of $\sim 10 \mathrm{~cm}$ FL/yr for the first four years of life (Turner et al. 1983). This difference, however, may be due to aged-one and aged-two individuals not being directly sampled in our data set, and the difference in calculation, as Turner et al. (1983) calculated growth rates through otolith mean incremental analysis and then back calculated age. The estimated FL for an age- 4 fish is $46 \mathrm{~cm}$ based on the VBL calculations of the total population, which leads to an average of $11.5 \mathrm{~cm}$ for the first four years of life; slightly greater than the estimations from Turner et al. (1983). The individual growth estimations as expected, also displayed sexual dimorphism, where 
males had an average individual growth rate of $7.0 \mathrm{~cm} / \mathrm{yr}$, while females had an average individual growth rate of $4.4 \mathrm{~cm} / \mathrm{yr}$.

As Golden Tilefish are long lived, many age groups of the 2008 survey (Vidal 2009) should also be represented in our 2017 survey. For example, the 4- and 5-year-old age class from 2008 should be 13 and 14-year-olds in this survey. In our analysis, there are only a few individuals in this age group. This could be due to large, presumably older fish being more heavily targeted by commercial fisheries. Due to the greater fecundity of large Golden Tilefish, however, they have a greater spawning potential than smaller individuals, and therefore have the opportunity to contribute more heavily to future generations if left in the population(Grimes et al. 1988, McBride et al. 2013). Therefore, it is important to assess the impact of fisheries on this older age group. Other causes of mortality include predation and recreational fisheries. Recreational fisheries contributed 700,000 lbs of harvest in 2019, and are therefore an important factor in Golden Tilefish mortality that is necessary to evaluate (NOAA 2021). Future research should focus on tracking age cohorts over multiple years using fishery-independent surveys. This will help to improve the understanding of mortality in this species and contribute estimates toward recruitment of juvenile fishes into the adult population.

\subsubsection{Conclusions}

Current fishing practices of the NW Atlantic Golden Tilefish stock are well managed, and the stock is not considered overfished (SAW 2014, NOAA 2018, NOAA 2020). The first fishery-independent survey of the population compliments landing data provided by the 
commercial fisheries and provides a more detailed understanding of the population in its entirety, unbiased by the targeting of market sized individuals. The findings from this survey also show varying age structure and year classes expected to be recruited into the fishery in subsequent years, including the high number of small individuals nearing maturity, highlighting the importance of fishery-independent surveys. Continued independent evaluation of the NW Atlantic Golden Tilefish population outside of commercial landings is important for evaluating the sustainability of the fishery and population changes.

Determining sustainability in fish stocks relies on estimates of growth, age at maturity, longevity, natural mortality, and recruitment variability; all of which rely on an accurate estimate of age. By providing a large sample size of age data and other demographic data, such as length, weight, and growth rates, this study adds further insights into previous Golden Tilefish studies and contributes key data for life history research and population monitoring. This data can also now be used to access any future changes in age and size structure, or growth rates of the species, which is necessary due to their sensitivity to environmental changes.

Given their highly specialized environmental, sediment and thermal preferences, Golden Tilefish may be highly vulnerable to environmental changes caused by climate change. For example, in 1882, there was a mass mortality of Golden Tilefish along Southern New England due to an intrusion of cold water from the Labrador Current (Fisher et al. 2014). This displays how sensitive the species is to temperature changes outside of their 
traditional $9-14^{\circ} \mathrm{C}$ range (Grimes et al. 1986). While warming temperatures may initially increase fish growth, we cannot conclude that environmental variability from climate change will be advantageous to the species (Fisher et al. 2014). Having the detailed demographic information presented from our survey, such as length and age frequency distribution, will help monitor the population in their response to future human pressures and global warming. 


\subsection{Tables}

Table 2.1. Fork length $(\mathrm{cm})$ and weight $(\mathrm{kg})$ by sex of Golden Tilefish sampled from NW Atlantic. Data are mean $\pm 1 \mathrm{SD}$ and range and represent all sampled individuals, except individual excluded from analysis for inaccurate weight and length

\begin{tabular}{cccc}
\hline Sex & $n$ & Fork Length $(\mathrm{cm})$ & Weight $(\mathrm{kg})$ \\
\hline \multirow{2}{*}{ Female } & \multirow{2}{*}{195} & $43.8 \pm 7.7$ & $1.2 \pm 1.2$ \\
& & $(29.0-101.0)$ & $(0.3-13.0)$ \\
Male & 241 & $48.0 \pm 11.4$ & $1.7 \pm 2.1$ \\
& & $(26.0-110.0)$ & $(0.1-22.1)$ \\
Unknown & 49 & $41.3 \pm 4.6$ & $0.9 \pm 0.3$ \\
& & $(29.0-49.0)$ & $(0.3-1.8)$ \\
\hline
\end{tabular}


Table 2.2. Summary of otolith morphometrics, including number collected, age (yr), length (post-rostrum to rostrum; mm) and weight (mg) measured by sex from NW Atlantic Golden Tilefish that were used in age analyses. Data are mean \pm 1 SD and range, and only represent otoliths from aged individuals (i.e., excluding back-calculate individuals).

\begin{tabular}{lcccc}
\hline Sex & $n$ & Age $(\mathrm{yrs})$ & Length $(\mathrm{mm})$ & Weight $(\mathrm{mg})$ \\
\hline \multirow{2}{*}{ Female } & 175 & $\begin{array}{c}4.09 \pm 2.6 \\
(3-30)\end{array}$ & $\begin{array}{c}13.5 \pm 2.4 \\
(7.0-29.0)\end{array}$ & $\begin{array}{c}262.6 \pm 223.1 \\
(74.2-2518.4)\end{array}$ \\
\multirow{2}{*}{ Male } & 223 & $\begin{array}{c}4.31 \pm 2.3 \\
(3-30)\end{array}$ & $\begin{array}{c}14.5 \pm 2.7 \\
(7.0-28.0)\end{array}$ & $\begin{array}{c}320.3 \pm 226.8 \\
\end{array}$ \\
& & & & \\
& & & & \\
Unknown & 40 & $3.48 \pm .6$ & $13.0 \pm 1.5$ & $2150.7)$ \\
& & $(3-5)$ & $(9.0-16.0)$ & $(106.9-330.1)$ \\
\hline
\end{tabular}


Table 2.3. Von Bertalanffy growth curve model results $\left[\mathrm{L}_{\infty}\right.$ represents the asymptotic length at which growth equals zero $(\mathrm{cm}), \mathrm{K}$ represents the growth coefficient $\left(\mathrm{yr}^{-1}\right)$, and $\mathrm{t}_{0}$ represents age at size zero] summarized by female, male and the total population (including all aged individuals, even of unknown sex) of Golden Tilefish sampled from the NW Atlantic. Values are based on growth zone counts.

\begin{tabular}{lclcc}
\hline & $n$ & $\boldsymbol{L}_{\infty}$ & $\mathrm{K}$ & $\mathrm{t}_{0}$ \\
\hline Female & 175 & 96.9 & 0.09 & -3.03 \\
Male & 223 & 118.9 & 0.10 & -0.80 \\
All & 438 & 105.2 & 0.11 & -1.08 \\
\hline
\end{tabular}




\subsection{Figures}

Figure 2.1. 2017 map of the sampling area. Red dots represent longline station locations. These were divided into 9 North-South regions (01-09) based on the NESFC bottom trawl survey latitudinal strata boundaries, and 4 depth strata $(75-303.6 \mathrm{~m})$, represented in the figure as a gradient from light blue-dark blue.

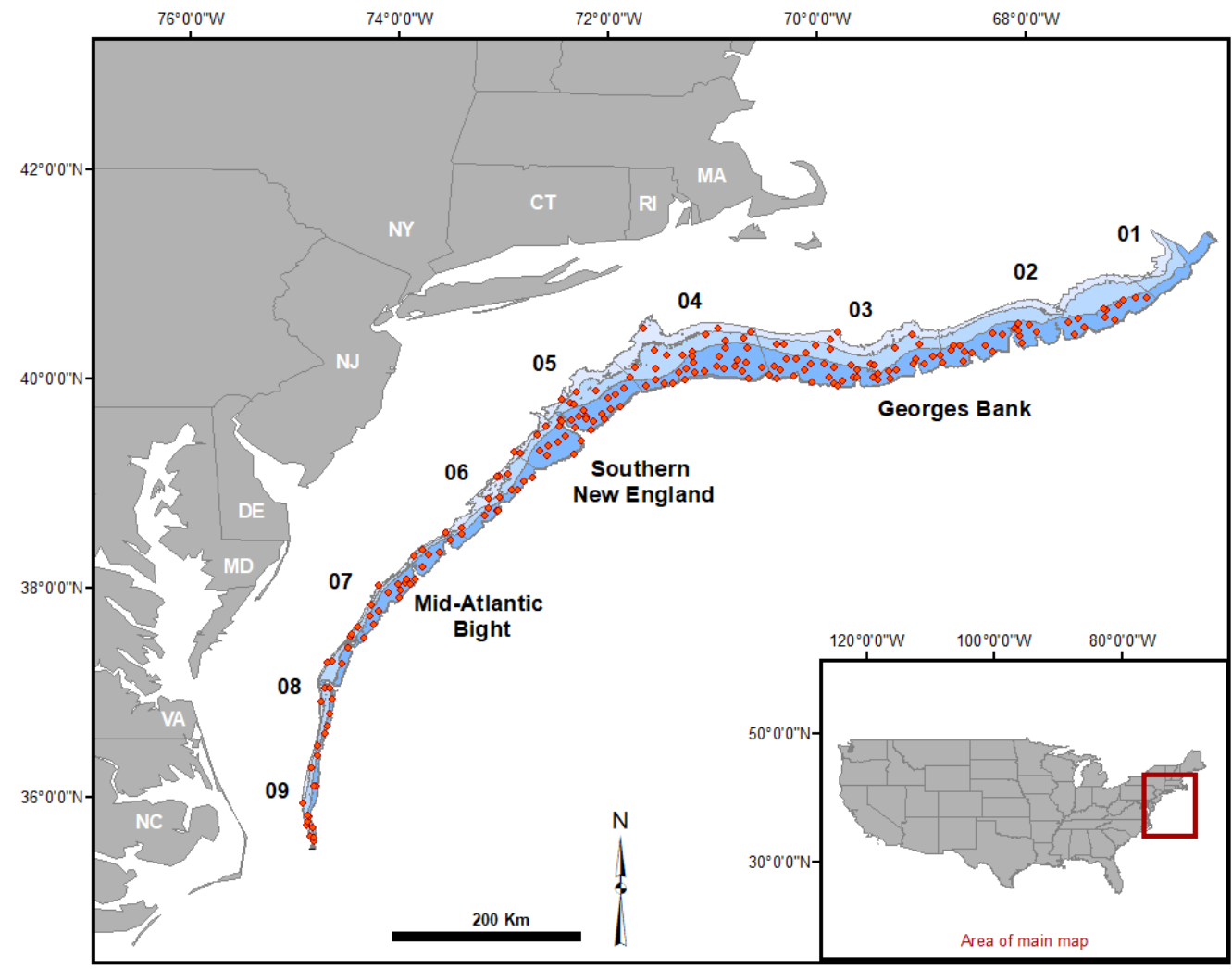


Figure 2.2. Annotated example of a thin sectioned Golden Tilefish sagittal otolith (male, fork length $=53 \mathrm{~cm}$, est. age-5) viewed using a stereomicroscope with transmitted light (20x) with a $1 \mathrm{~mm}$ scale bar. Age estimates were determined by interpreting opaque zones along the ventral growth axis (represented as white dots).

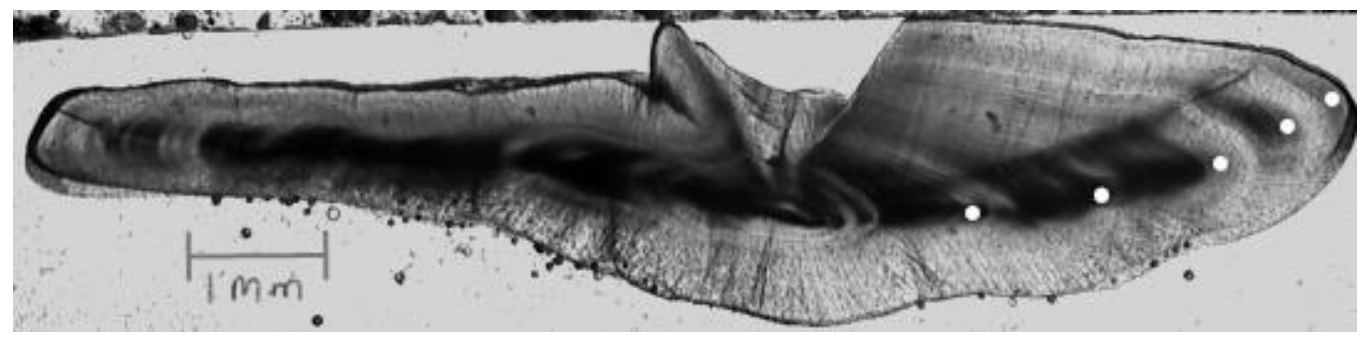


Figure 2.3. Frequency distribution of fork length $(\mathrm{cm})$ of female (left panel), male (middle panel) and Golden Tilefish of unknown sex (right panel) collected from the NW Atlantic in 2017. Frequency is displayed as proportion relative to the total population.

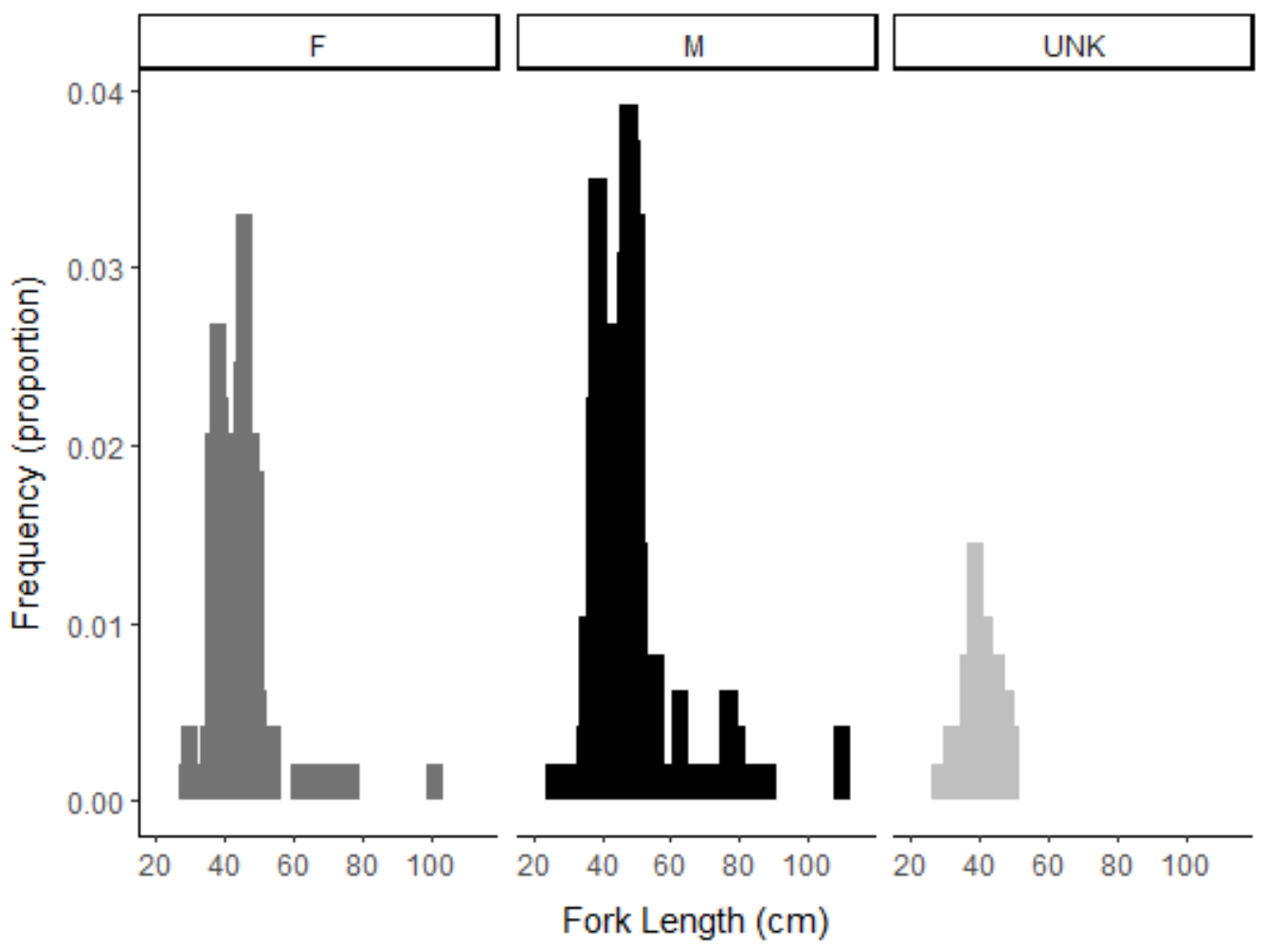


Figure 2.4. Boxplots comparing fork length $(\mathrm{cm})$ of female (left), male (middle) and Golden Tilefish of unknown sex (right) collected from the NW Atlantic in 2017. The notch represents the median, the top and bottom indicate the interquartile range (the $25^{\text {th }}$ and $75^{\text {th }}$ percentiles), and the whiskers represent the maximum and minimum ranges. Black points represent outliers.

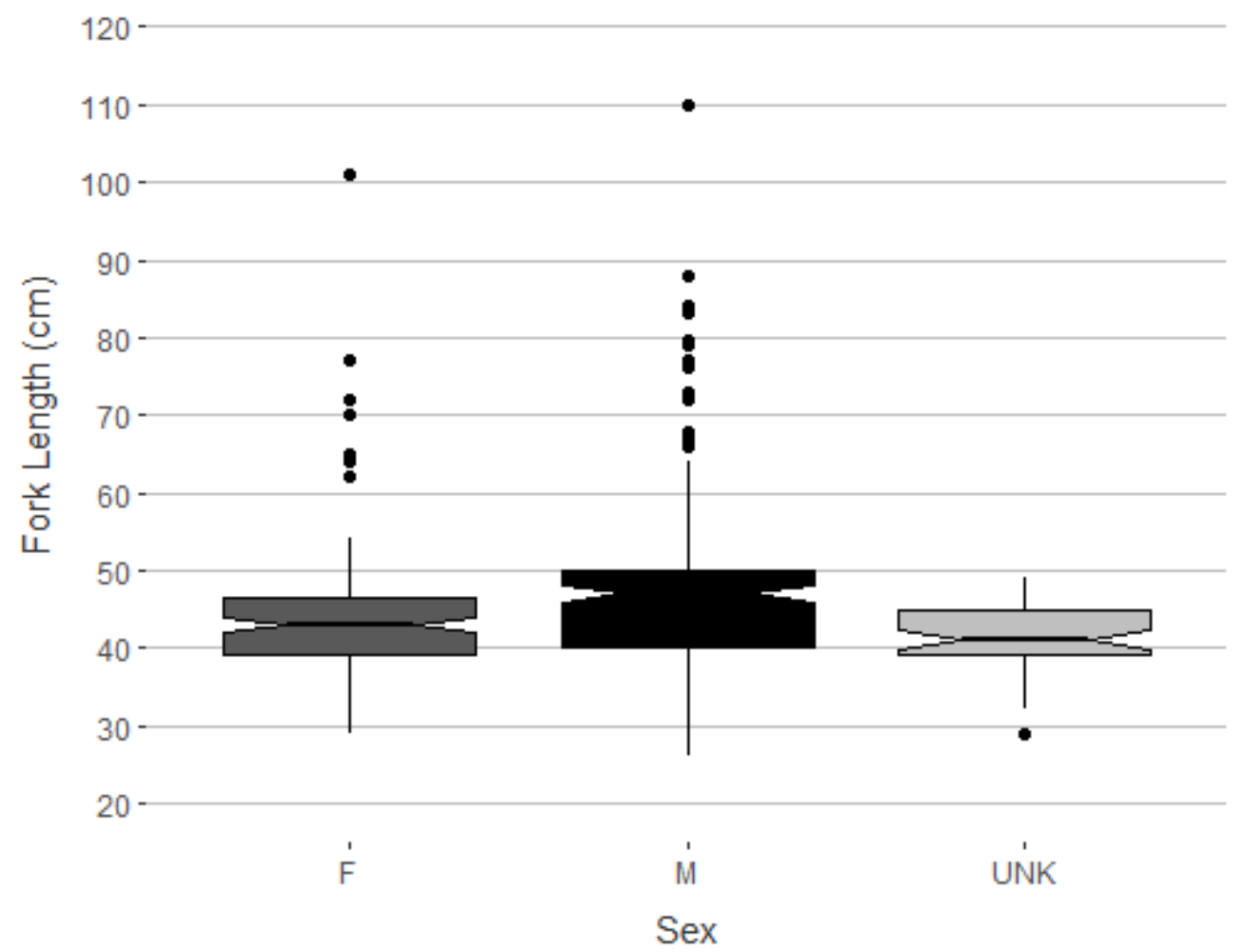


Figure 2.5. Frequency distribution of weight $(\mathrm{kg})$ of female (left panel), male (middle panel) and Golden Tilefish of unknown sex (right panel) collected from the NW Atlantic in 2017. Frequency is displayed as proportion relative to the total population.

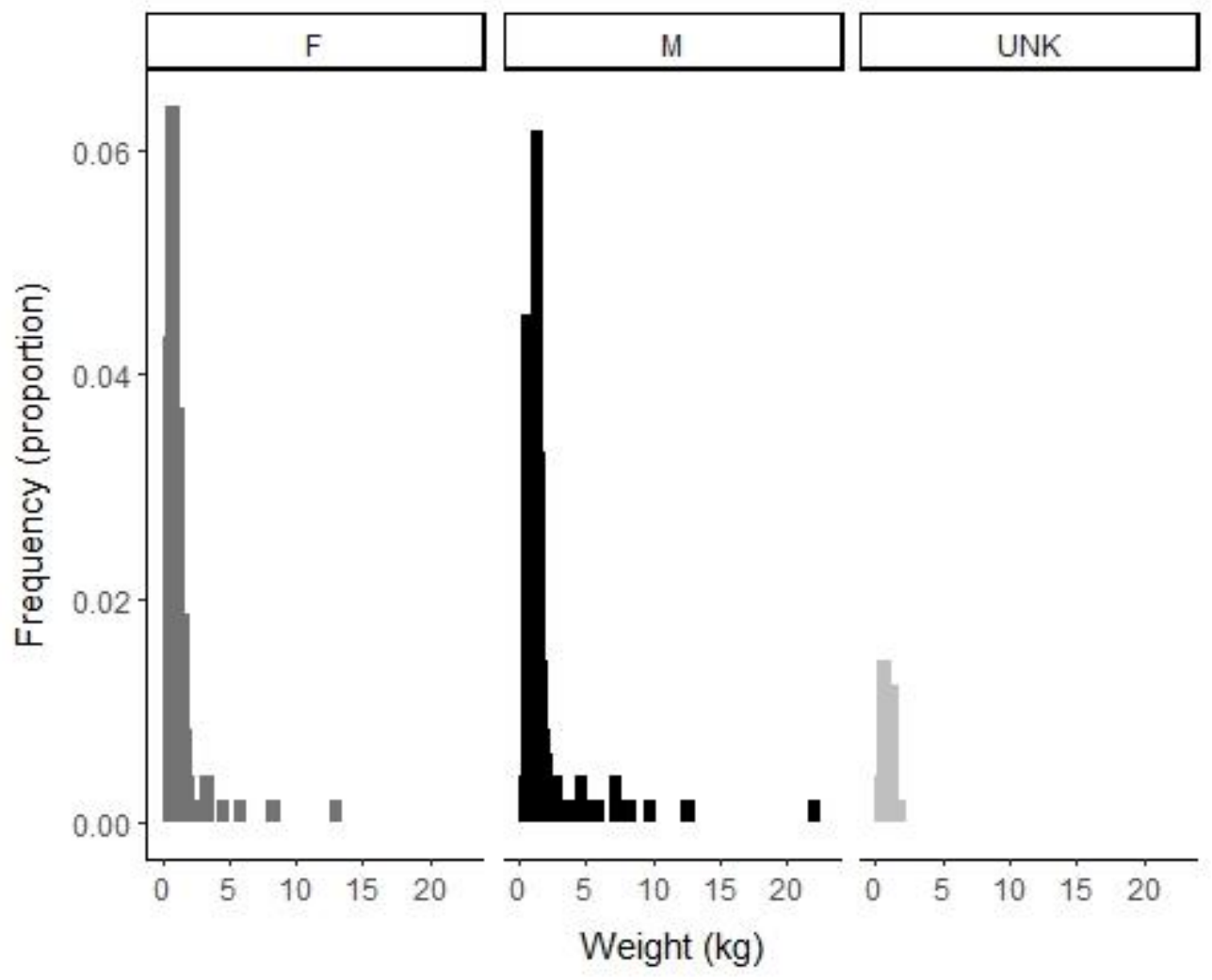


Figure 2.6. Boxplots comparing body weight (kg) of female (left), male (middle) and Golden Tilefish of unknown sex (right) collected from the NW Atlantic in 2017. The notch represents the median, the top and bottom indicate the interquartile range (the $25^{\text {th }}$ and $75^{\text {th }}$ percentiles), and the whiskers represent the maximum and minimum ranges. Black points represent outliers.

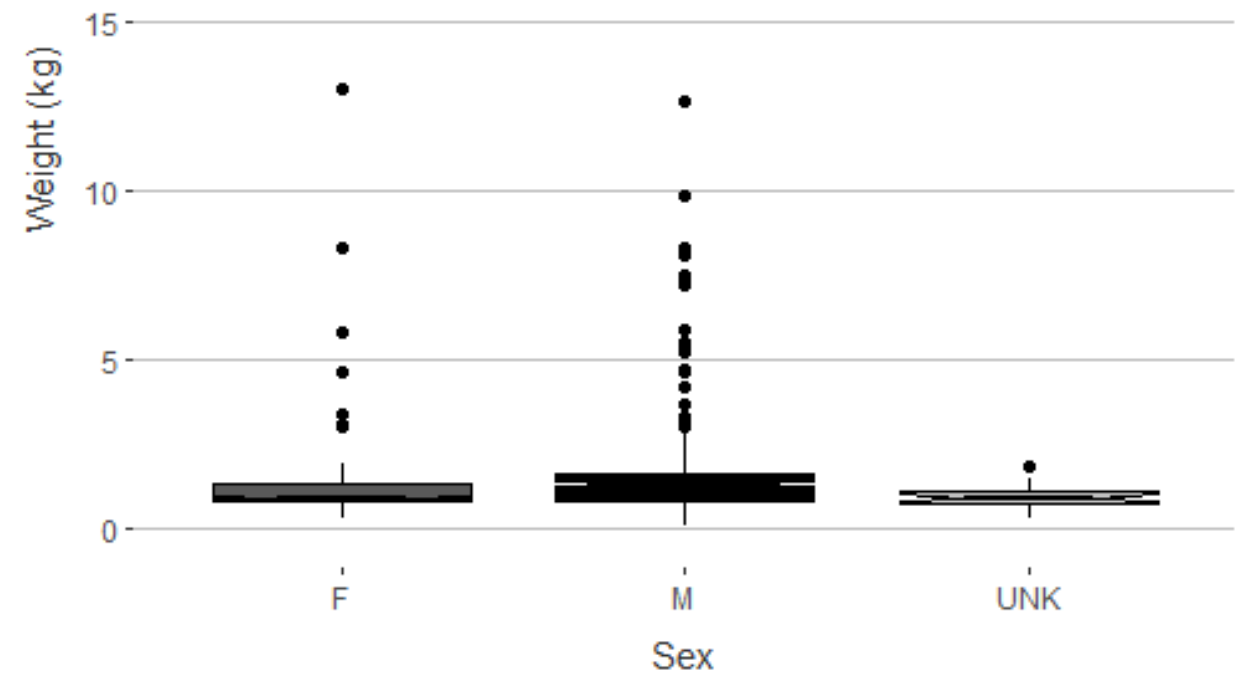


Figure 2.7. Frequency distribution of age (years) of female (left panel), male (rmiddle panel), and individuals of unknown sex (right panel) collected from the NW Atlantic in 2017. Frequency is displayed as proportion relative to the total population.

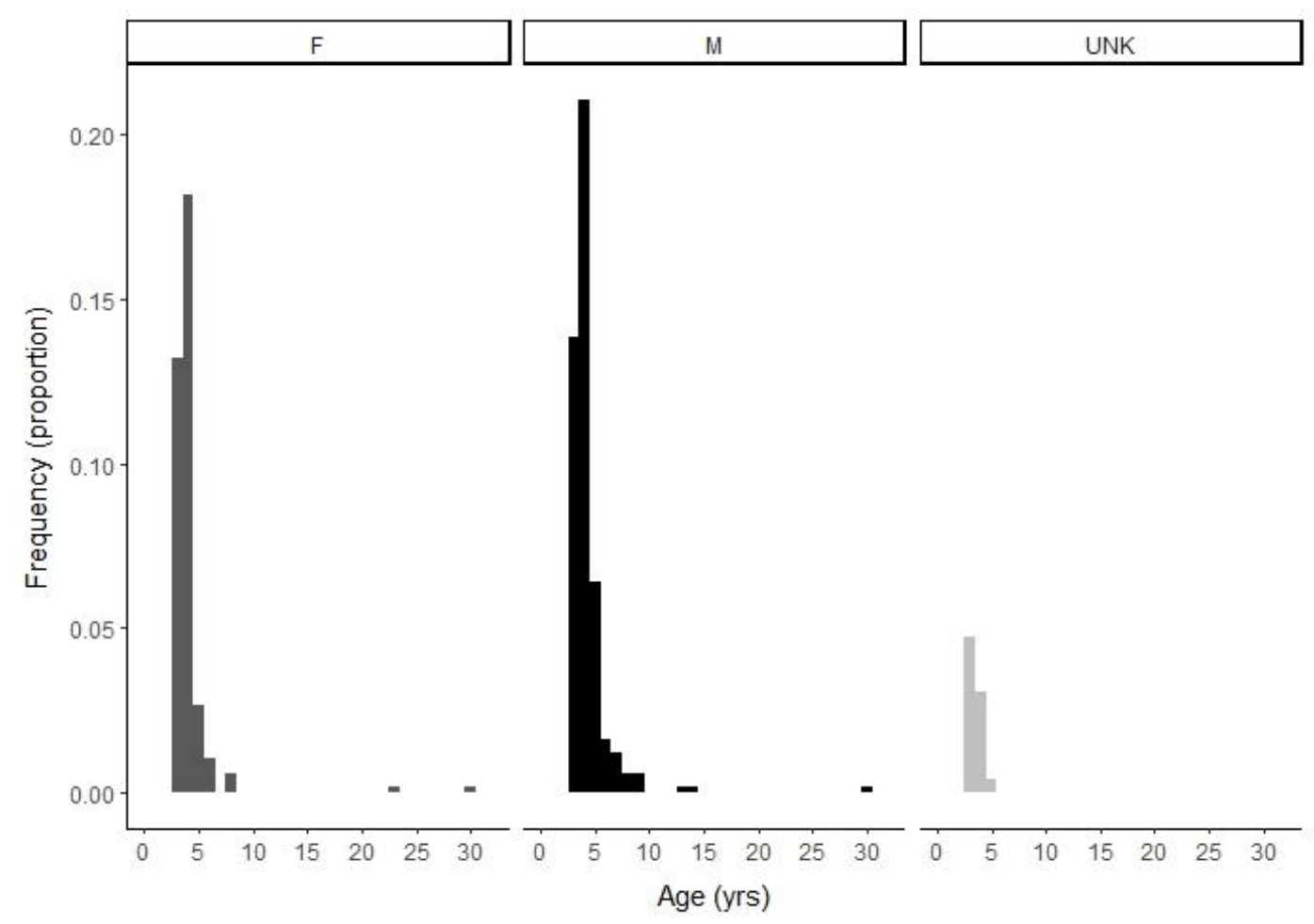


Figure 2.8. Von Bertalanffy growth curves estimated for female (dark grey points, solid line), male (black points, short-dashed line) and all (unknown sex are light gray points, long-dashed line) Tilefish sampled from the NW Atlantic in 2017. For specific growth model estimates see Table 2.3.

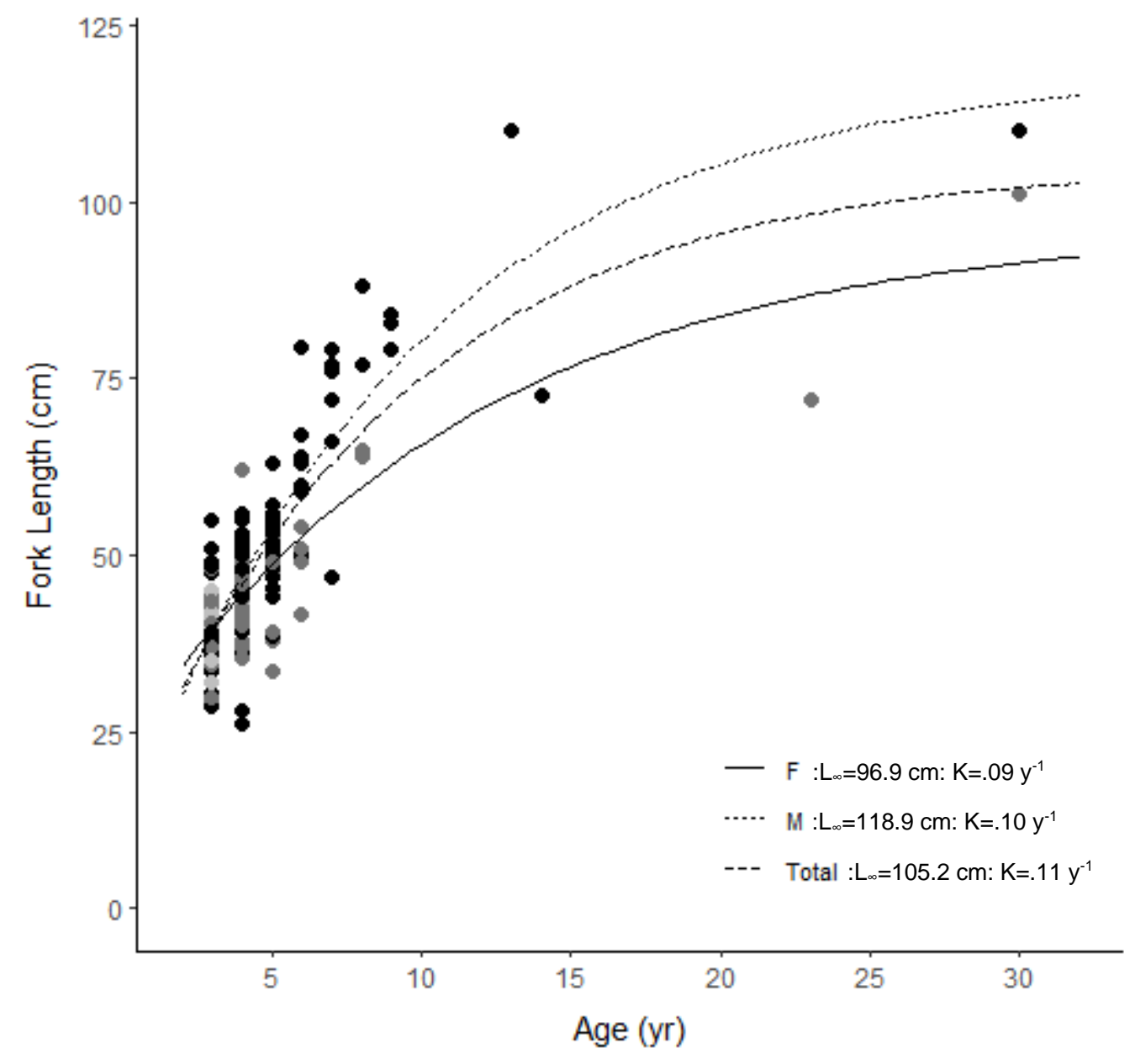


Figure 2.9. Fork length-weight relationships for female (dark grey points, solid line), male (black points, short-dashed line) and all (unknown sex are light gray points, longdashed line) Golden Tilefish sampled from the NW Atlantic in 2017. The power function trendline equations are shown on the top left of the graph

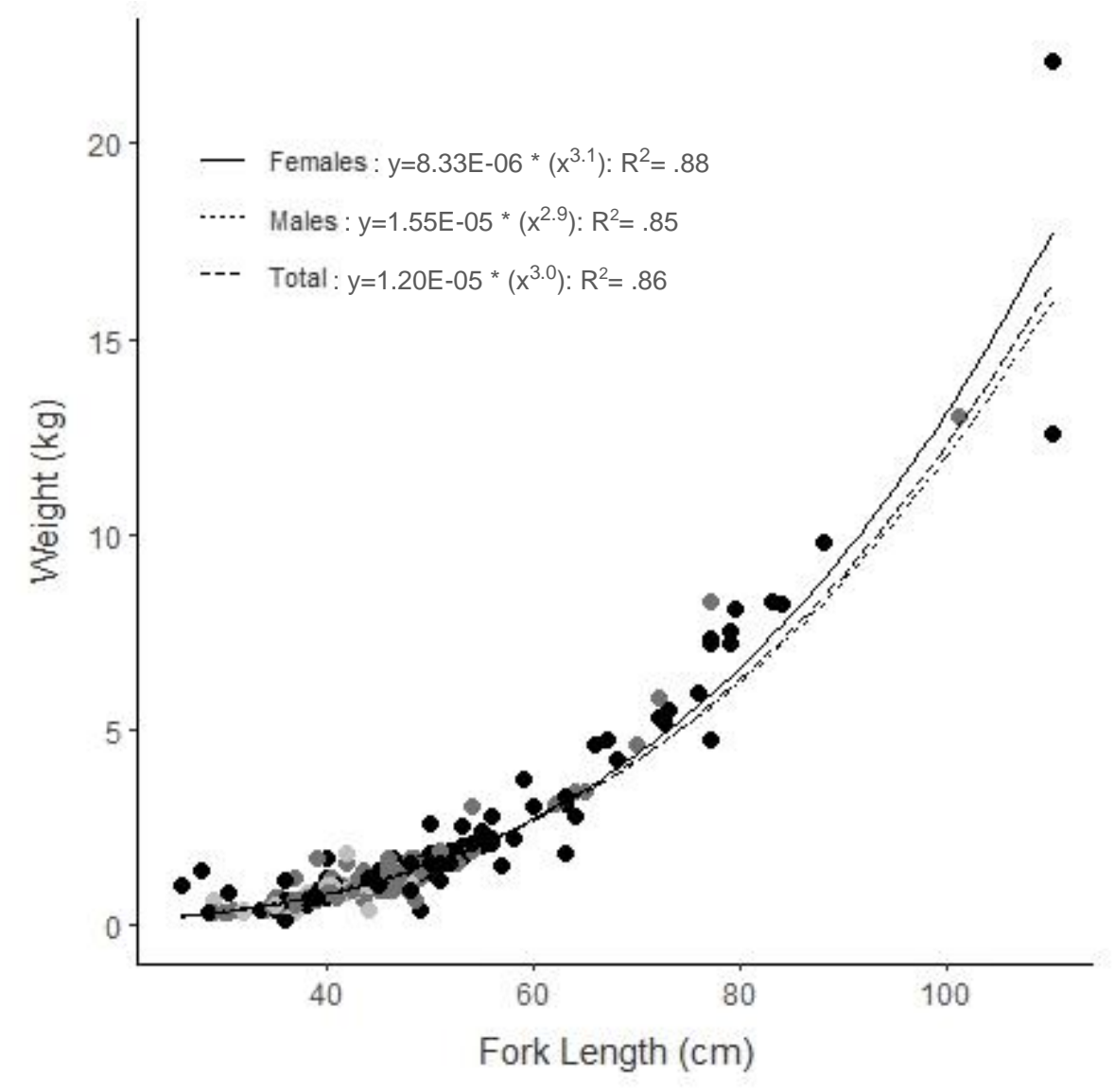


Figure 2.10. Individual growth rates $(\mathrm{cm} / \mathrm{yr})$ for all Golden Tilefish sampled from the NW Atlantic in 2017. This includes female (dark grey points), male (black points) and unknown sex (light gray points). Frequency is displayed as proportion relative to the total population.

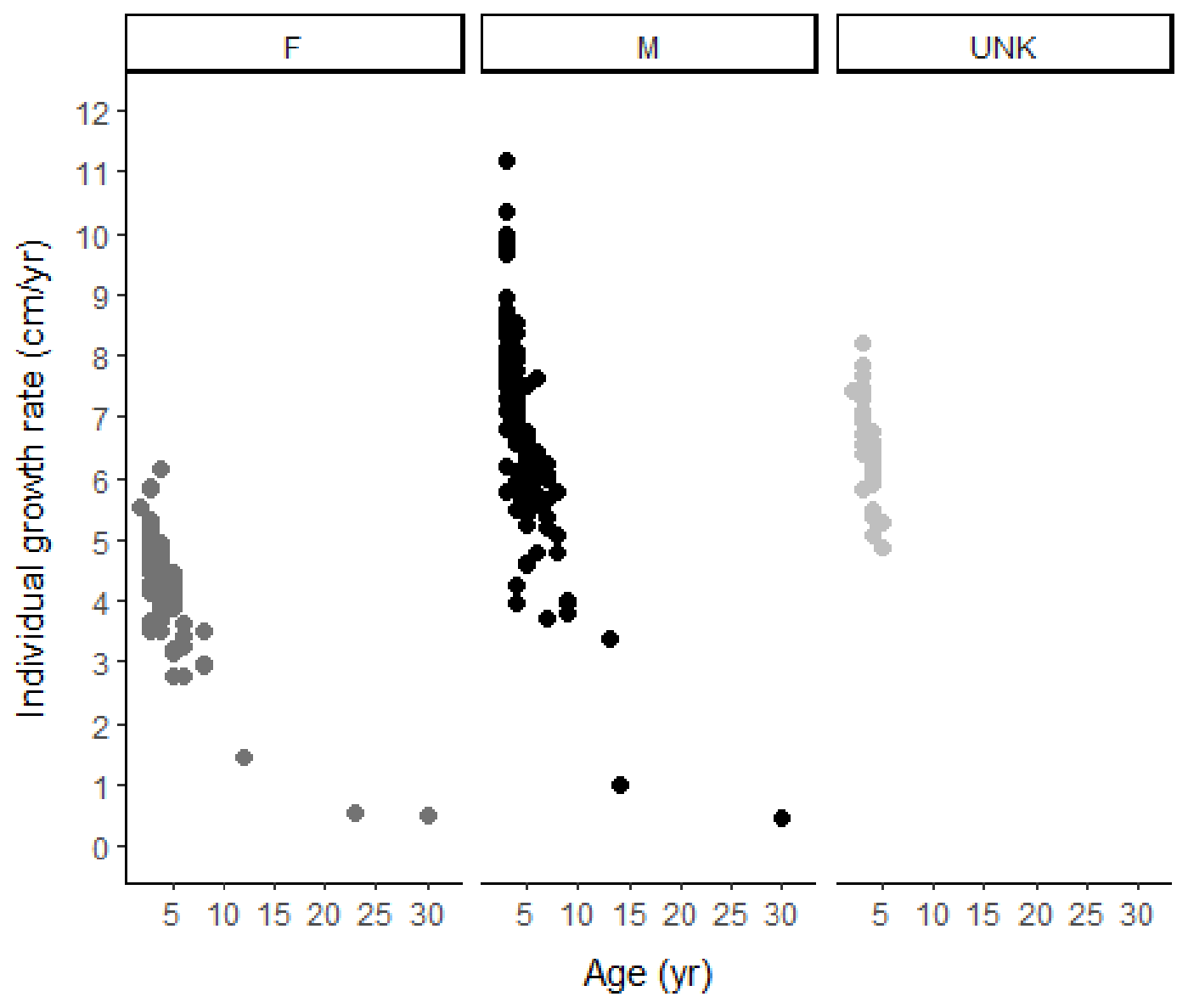


Figure 2.11. Boxplot comparing growth (cm/yr) of female (left panel), male (middle panel) and Golden Tilefish of unknown sex (right panel) collected from the NW Atlantic in 2017. The notch represents the median, the top and bottom indicate the interquartile range (the $25^{\text {th }}$ and $75^{\text {th }}$ percentiles), and the whiskers represent the maximum and minimum ranges. Black points represent outliers.

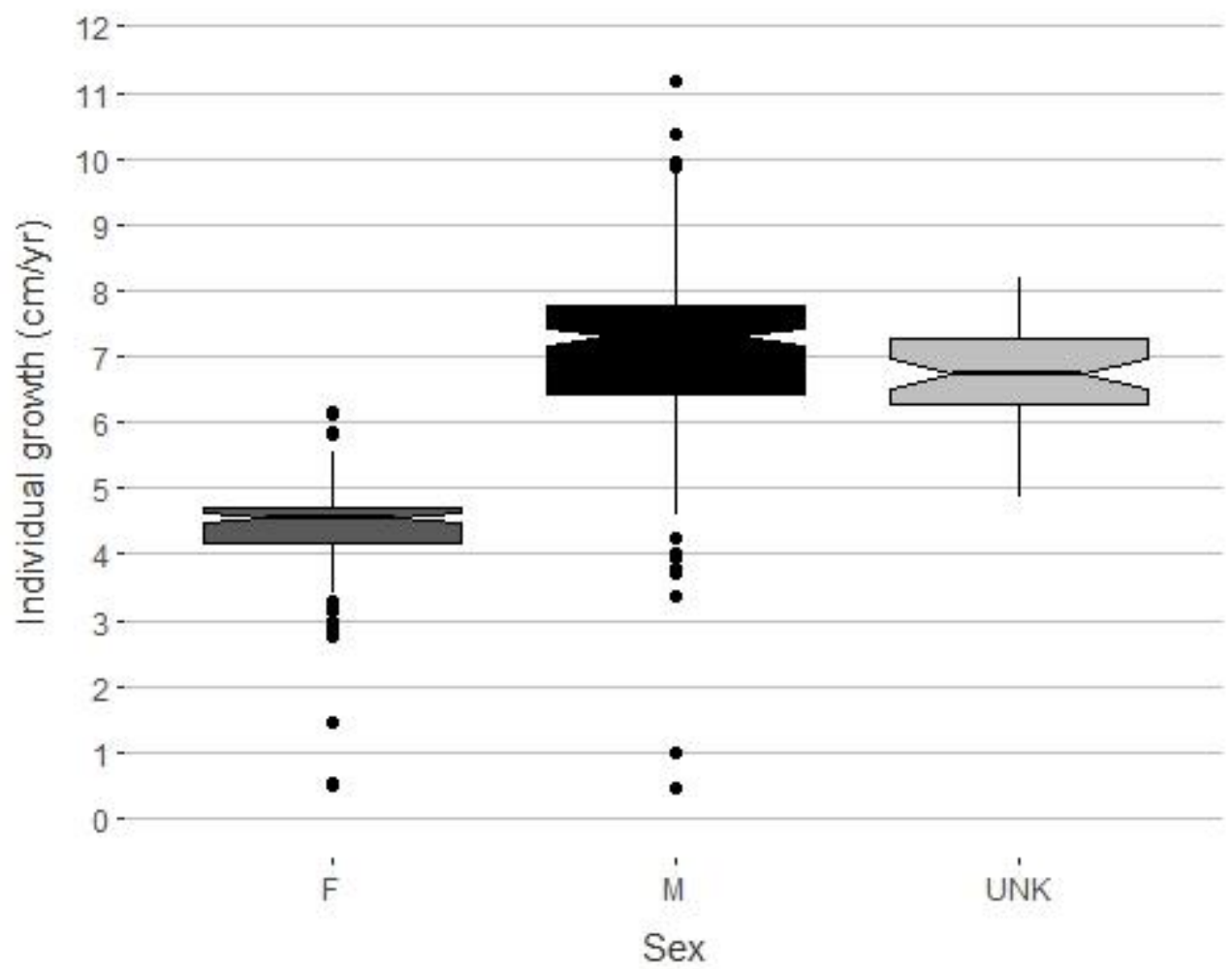




\section{SPATIAL AND TEMPORAL PATTERNS IN OTOLITH \\ CHEMICAL SIGNATURES OF JUVENILE GOLDEN \\ TILEFISH (LOPHOLATILUS CHAMAELEONTICEPS) IN THE NW ATLANTIC}

\subsection{Introduction}

Patterns of connectivity or the exchange of individuals among subpopulations of a species, are important considerations in fisheries management, yet population connectivity remains unknown for many marine species (Clarke et al. 2009). The prevailing assumption for most marine fish species is that large-scale dispersal leads to highly connected, homogenous populations (Swearer et al. 2002). This, however, has been disputed in recent years. For example, Green and Wroblewski (2000) showed distinct spawning site fidelity, and migration patterns in Atlantic Cod (Gadus morhua) throughout Gilbert Bay, Labrador. This demonstrates the occurrence of subpopulations, even in close proximity, are possible in marine fish species, and can function as a metapopulation (Smedbol and Wroblewski 2002)

Estimating connectivity is ecologically relevant across the range of a species' distribution, as habitats or regions may contribute disproportionately to adult populations and influence the structure of these populations (Gillanders 2005, Vasconcelos et al. 2008). Such information is decisive for managing commercially and recreationally 
important fish populations, as well as identifying ecologically important habitats and resources that contribute to fisheries (Beck et al. 2001). Failure to recognize population complexity, namely the individual origin and composition, may lead to depletion of portions of the population with distinct ecological importance (Stephenson 1999), which can critically affect the long-term stability and sustainability of stocks (Fritsch et al. 2007).

Population connectivity is commonly delineated through tagging and tracking techniques (Gillanders et al. 2003, Pittman and McAlpine 2003) that determine movement patterns of a species. Conventional tagging methods, however, are difficult to execute for many marine fish species for a variety of reasons, including the large numbers of larvae with high mortality rates, the small size of juveniles, and tagging trauma (Thorrold et al. 2001, Gillanders 2002). Specifically, deep-water species may experience barotrauma during handling which results in swim bladder overexpansion, due to rapid changes in depth during tagging. This and other forms of stress from handling can lead to high rates of fish mortality post-tagging (Rummer and Bennett 2005, Nichol and Chilton 2006, Campbell et al. 2009, Williams et al. 2015).

More recently, Laser Ablation Inductively Coupled Plasma Mass Spectrometry (LAICPMS) has been used to study the connectivity of marine species through the characterization of the elemental composition of otoliths. This technique has been successful in distinguishing three primary stocks of Australian Snapper (Chrysophrys auratus) along the coast of Southern Australia (Fowler et al. 2017). Otoliths serve as 
natural tags, as calcium carbonate material is accreted continuously into the otolith during fish growth(Campana 1999). As otoliths form, trace elements are incorporated based on the ambient water conditions and fish physiology (Campana 1999, Thomas et al. 2017). This results in the creation of distinct elemental bands or signatures that are permanently recorded into the otolith, which can then be used as chronological tracers across life history, including migration patterns and habitat use (Thorrold et al. 1998, Campana et al. 2000) Otolith microchemistry has be applied to distinguish among spawning populations of Atlantic Cod (Gadus morhua) in the Kattegat and Öresund despite genetic homogeneity, most likely due to the greater sensitivity of otoliths to minor environmental influences (Svedäng et al. 2010).

A wide variety of elements in the otolith have been shown to correlate with the environmental and physiological characteristics a fish experiences across life history. Strontium ( $\mathrm{Sr}$ ) and Barium $(\mathrm{Ba})$, for example, correlate with salinity and temperature, with Strontium increasing and Barium decreasing in higher salinity waters, and Manganese (Mn) has been shown to increase in concentration in anoxic conditions (Bath et al. 2000, Limburg et al. 2015, Limburg and Casini 2018). Because otolith elemental concentrations reflect a fish's environment and physiology, differences in temperature, salinity, or other environmental characteristics can provide spatial and temporal information about a fish's habitat use. Differences in elemental signatures have been identified among fish from different estuaries and riverine systems (Gillanders 2002, Vasconcelos et al. 2008). For example, Secor et al. (2001) showed that the $\mathrm{Sr} / \mathrm{Ca}$ ratio is high in Striped Bass (Morone saxatilis) that occupy the higher salinity mesohaline 
estuary habitats of the Hudson River, whereas $\mathrm{Ba} / \mathrm{Ca}$ ratio are high in individuals that were resident in the low salinity areas.

Discrimination between distinct habitats such as estuary and riverine environments can be done at extremely fine scales, due to their isolation from each other and influence from freshwater sources allowing for variability in environmental qualities such as salinity and temperature. For example, (Ley and Rolls 2018) demonstrated the ability to distinguish Common Snook (Centropomus undecimalis) between river tributary nursery sites at scales of $1.0-4.5 \mathrm{~km}$ based on variability in $\mathrm{Sr} / \mathrm{Ca}, \mathrm{Ba} / \mathrm{Ca}$ and $\mathrm{Mn} / \mathrm{Ca}$ ratios. Marine environments, such as the NW Atlantic Ocean, however, are large bodies of water with minimal physical isolation, and therefore have more homogenous environmental characteristics, such as salinity, that is less likely to vary between locations and years. Most microchemical analyses of marine fish that don't have an estuary-dependent lifehistory stage are, therefore, conducted at large spatial scales, even different ocean basins (Rooker et al. 2001, Ashford et al. 2005). Clarke et al. (2009) however, observed elemental differences in otoliths of the Atlantic Silverside (Menidia menidia), at finer spatial scales, 5-10 km, using $\mathrm{Sr} / \mathrm{Ca}, \mathrm{Ba} / \mathrm{Ca}$, and $\mathrm{Mn} / \mathrm{Ca}$ ratios, and demonstrated temporal variation in these ratios between years, highlighting the potential of this approach for understanding spatial and temporal habitat use of marine fish species.

Understanding population connectivity, particularly for species in hard to reach environments, such as the deep-sea, is important for effective fisheries and ecosystembased management. Juvenile and adult life-history stages of the Golden Tilefish 
(Lopholatilus chamaeleonticeps) in the NW Atlantic display a patchy distribution along the continental shelf and slope break (Frisk et al. 2018, Olin et al. 2020), with a propensity for high site fidelity that may be linked to thermal and sediment preferences for burrow construction (Able et al. 1982, Grimes et al. 1986). Golden Tilefish are fractional or batch spawners, releasing between two and eight million eggs (Grimes et al. 1988) with spawning occurring from March-November with a peak in May-September in the NW Atlantic (Dooley 1978, Erickson et al. 1985). Larval duration, dispersal, and settlement data, however, is limited, impeding determination of population connectivity, as recruitment to local populations is dependent on larval settlement as well as juvenile and adult site fidelity.

Assessment of population connectivity and subpopulation structure through otolith microchemistry requires environmental differences to be present between the study locations, such as salinity and temperature regimes. In the NW Atlantic, temperature and salinity can vary in the NW Atlantic, due to the influence of the Gulf Stream and the Hudson River respectively (Zhang and Gawarkiewicz 2015, Chen et al. 2018), resulting in possible differences in otolith $\mathrm{Sr} / \mathrm{Ca}$ and $\mathrm{Ba} / \mathrm{Ca}$ ratios at locations along regions influenced by these varying warm and freshwater masses. Moreover, the influence of the Hudson River to the NW Atlantic is not limited to freshwater input, as historically high levels of contamination due to human pollution, including metals such as Iron $(\mathrm{Fe})$, Copper (Cu), Zinc ( $\mathrm{Zn})$, and Lead $(\mathrm{Pb})$ (Benoit et al. 1999) have been noted. Assimilation of these heavy metals in the otoliths from the environment could possibly be used to distinguish individuals inhabiting the Hudson Canyon from other canyons along the 
continental shelf. As otolith elemental incorporation is reflective of localized

environments, such as Hudson Canyon, evaluation of these elemental concentrations may be valuable for identifying subpopulations.

The objectives of this chapter are to use Laser Ablation Inductively Coupled Plasma Mass Spectrometry (LA-ICPMS) to characterize the elemental signatures of Golden Tilefish otoliths collected from juvenile fish sampled from two different regions in the NW Atlantic and across two years to investigate the ability of otolith microchemistry to act as a natural tag to discriminate Golden Tilefish subpopulations. I hypothesize that the elemental signatures will differ regionally, reflecting regional environmental characteristics, but not temporally due to the resident behavior of the species. As this species has a patchy distribution, with high site fidelity, this study contributes valuable data for understanding subpopulation structure and other life history characteristics of Golden Tilefish in the NW Atlantic Ocean, aiding in management of the stock.

\subsection{Materials and Methods}

\subsubsection{Sample Collection and Otolith Preparation}

Complete sample collections and sagittal otolith processing methods, including embedding, sectioning, and age analysis, are presented in Chapter 1. Briefly, Golden Tilefish were captured during a fishery-independent survey along the NW Atlantic in the summer of 2017 (see Figure 2.1 for complete sampling area; Frisk et al. 2018). After body size metrics [fork length $(\mathrm{cm})$ and weight $(\mathrm{kg})$ ] were obtained, sagittal otoliths were 
removed, and stored in dry envelopes before being embedded and transversely sectioned for age analysis.

To specifically address hypotheses related to spatial and temporal variability, otoliths ( $n$ $=22$ ) were selected for microchemistry analysis based on two criteria: sampling location and individual age. To evaluate the first hypothesis of regional differences, otoliths were selected from individuals sampled from two regions in the NW Atlantic Ocean-the Southern New England (near Hudson Canyon; SNE), and the Southern New England Middle Grounds (near Atlantis/Veatch Canyon; SNE-MG) regions (Figure 3.1). These regions are separated by approximately $200 \mathrm{~km}$ and are potentially influenced by contrasting levels of environmental conditions such as freshwater and anthropogenic inputs from the Hudson River and the Gulf Stream (Figure 3.1). To evaluate the second hypothesis of resident behavior, otoliths were selected from similarly aged juvenile fish, specifically aged-3/aged-4 fish (Chapter 1) that have experienced the same environmental regime.

Sections containing the otolith core were mounted to a petrographic slide (Lakeside ${ }^{\circledR}$ Brand, \#452, Monee, IL) using crystal bond ${ }^{\mathrm{TM}} 509$ adhesive. The mounted sections were then polished using a sequence of 40,15 , and $9 \mu \mathrm{m} 3 \mathrm{M}$ micro-finishing film wetted with distilled water until the core was visualized under reflected light (Figure 3.2). 


\subsubsection{Laser Ablation}

Laser ablation using a Teledyne Analyte Excite Excimer Laser Ablation System equipped with an ARIS (Aerosol Rapid Introduction System) coupled with a Thermo iCAP-TQ inductively coupled plasma mass spectrometer was performed at the State University of New York School of Environmental Science and Forestry (SUNY-ESF), Syracuse, NY, in collaboration with K. Limburg and D. Driscoll. Instrument power was set between 20$25 \%, 10 \mathrm{~Hz}$, with a $110 \mu \mathrm{m}$ spot size, at speeds between $5-10 \mu \mathrm{m} / \mathrm{sec}$. A 30 second warm up was done before ablation. Data was acquired over 3 channels with a 0.1 second dwell time. Otoliths were ablated from the ventral to dorsal edges through the core (Figure 3.3). The elements analyzed were Calcium $\left({ }^{43} \mathrm{Ca}\right.$, with ${ }^{44} \mathrm{Ca}$ being used as a check), Strontium $\left({ }^{88} \mathrm{Sr}\right)$, Barium $\left({ }^{138} \mathrm{Ba}\right)$, Copper $\left({ }^{63} \mathrm{Cu}\right)$, Zinc $\left({ }^{66} \mathrm{Zn}\right)$, Manganese $\left({ }^{55} \mathrm{Mn}\right)$, Lead $\left({ }^{207} \mathrm{~Pb}\right)$, Magnesium $\left({ }^{24} \mathrm{Mg}\right)$, Phosphorus $\left({ }^{31} \mathrm{P}\right)$, Lithium $\left({ }^{7} \mathrm{Li}\right)$, Boron $\left({ }^{11} \mathrm{~B}\right)$, and Iodine $\left({ }^{127} \mathrm{I}\right)$. These elements were selected due to the frequency of use in previous microchemical analyses for stock discrimination and correlation with environmental factors (Clarke et al. 2009, Limburg et al. 2015, Fowler et al. 2017, Limburg et al. 2018). The MAPS-4 USGS phosphate standard or the MACS-3 USGS carbonate standard were used to calibrate the samples. Standard precision was mostly below 10\% RSD. Standards and samples are background subtracted and drift corrected, and some spikes were removed by interpolation. Data reduction was performed in Microsoft Excel to produce concentration data (ppm). Granneman et al. (2017) determined that many of these elements, including $\mathrm{Pb}$, were consistently recorded above detection limits in Golden Tilefish otoliths from the Gulf of Mexico, giving confidence in the application of the technique for the species. 


\subsubsection{Microchemistry Data Analysis}

Elemental concentrations were expressed as ratios to $\mathrm{Ca}$ to account for variations in the amount of ablated otolith material (Limburg and Casini 2018). Data analysis was performed in Microsoft Excel (2018) and in R (version 4.0.5, R Development Core Team, 2021) within the RStudio interface (version 1.1.463, R Studio Team, 2021).

Elemental data was graphically represented by distance from the core (um). To correlate elemental data with the transect, an image of its corresponding polished otolith was edited to display the transect path as linearly as possible, and overlaid with element/Ca plots. Elemental data was categorized by year along the ventral side through the alignment of growth zones with $\mathrm{Mg} / \mathrm{Ca}$, where the chemical minima generally corresponded with translucent annuli (Figure 3.4). For age-3 fish, the total transect area of first opaque growth zone on the ventral side past the core to the first translucent annulus was categorized as the year 2015, the second growth zone to the second translucent annulus was categorized as 2016, and the last growth zone to the otolith edge was categorized as 2017. For age-4 fish, the first growth zone past the core was categorized as 2014, and the following growth zones were categorized accordingly. The dorsal side of the otolith was not used for analysis due to limited ability to distinguish growth zones, and therefore categorize by year.

Elemental data was transformed using Box-Cox transformations to improve normality through the geoR (Ribeiro Jr et al. 2020), MASS (Venables and Ripley 2002), readxl 
(Wickham and Bryan 2019), knitr (Xie 2021), tidyverse (Wickham et al. 2012), and dplyr (Wickham et al. 2020) packages in R. Ratios below detection were removed before transformation. $\mathrm{Cu} / \mathrm{Ca}, \mathrm{Zn} / \mathrm{Ca}$, and $\mathrm{I} / \mathrm{Ca}$ were removed from analysis due to frequency of values below detection. Li/Ca was left untransformed based on the qqplot showing normality. Box-Cox transformation lambda values for the elemental ratios were: 0.264 (B/Ca), $0.353(\mathrm{Ba} / \mathrm{Ca}),-1.033(\mathrm{Mg} / \mathrm{Ca}), 0.121(\mathrm{Mn} / \mathrm{Ca}), 0.258(\mathrm{P} / \mathrm{Ca}),-0.068(\mathrm{~Pb} / \mathrm{Ca})$, and $-0.670(\mathrm{Sr} / \mathrm{Ca})$.

To test for regional and temporal differences in overall microchemical signatures between regions and years, a multivariate analysis of variance (MANOVA) was performed using Box-Cox transformed elemental ratios, averaged individually by year, with region and year set as factors. Interaction between these two factors was also tested. Pillai's trace statistic was used for this MANOVA test due to its robustness when handling small sample sizes and deviations from MANOVA assumptions (Scheiner and Gurevitch 2001). Significance was set at an $\alpha$ value of 0.05 . To examine regional and temporal differences of individual elements, univariate output of the MANOVA (ANOVA) was subsequently examined, with region and year set as factors. Interaction between these two factors was also tested.

To examine the ability of otolith microchemistry to distinguish between regions and years, quadratic discriminant function analysis (QDFA) with leave-one out cross validation was used to determine classification success through the MASS (Venables and Ripley 2002) package in R. This was run using both Box-Cox transformed values of the 
otolith transect (regional fingerprint) and for each annulus (temporal fingerprint). Element/Ca ratios below detection (i.e., NAs) were excluded. Non-metric Multidimensional Scaling (NMDS) plots were created using the vegan (Oksanen et al. 2020) package in $\mathrm{R}$ with $95 \%$ confidence ellipses to visualize regional and temporal differences in multi-elemental signatures.

\subsection{Results}

A summary of capture location, age, total length and weight of fish used for microchemistry analysis, is shown in Table 3.1. Data derived from the annulus representing 2017 was not included in subsequent analyses due to incomplete growth of that age band and ablated transects ending prematurely in some individuals.

\subsubsection{Regional Differences in Otolith Signatures}

Golden Tilefish otoliths from juvenile individuals did not show significant geographic differences in elemental signatures between SNE and SNE-MG regions in the NW Atlantic Ocean based on MANOVA analysis ( $\mathrm{p}=0.071$, Table 3.2). The $\mathrm{Pb} / \mathrm{Ca}$ ratios, however, showed significant regional differences based on subsequent univariate output of the MANOVA (i.e., ANOVA) with higher ratios in individuals from the SNE-MG compared to those from SNE (Table 3.3, Figure 3.5). The Mn/Ca ratios, in general, tended to be greater in the SNE region, and $\mathrm{Mg} / \mathrm{Ca}$ ratios tended to be greater in the SNEMG (Figure 3.5), though not significant for either comparison. 
Regional fingerprint separations identified by the QDFA are visualized in a Non-Metric Multi-Dimensional Scaling plot with 95\% confidence ellipses indicating substantial overlap among elemental signatures across regions (Figure 3.6). The Southern Hudson Canyon appeared to show some separation from other regions when looking at canyon specific signatures, specifically from the Northern Hudson Canyon region, although confidence ellipses were not examined (Figure 3.6). The SNE Tilefish had wider confidence ellipses, indicating greater variability in the elemental composition in this region in comparison to the SNE-MG (Figures 3.6, 3.7).

\subsubsection{Temporal Differences in Otolith Signatures}

Multivariate otolith elemental signatures of Golden Tilefish showed significant temporal differences between 2015 and 2016 ( $p=0.017$, Table 3.2). In general, temporal trends varied by element, with neither year being consistently lower or greater in their element/Ca ratios (Figure 3.5). The univariate output of the MANOVA showed that significant year effects were present for two of the eight elements, $\mathrm{Ba} / \mathrm{Ca}$ and $\mathrm{Mn} / \mathrm{Ca}$ (Table 3.3). For these elements, $\mathrm{Ba} / \mathrm{Ca}$ was greater in 2016, while $\mathrm{Mn} / \mathrm{Ca}$ was greater in 2015 (Figure 3.5). Mg/Ca decreased between years with lower ratios being recorded in 2016, and Sr/Ca increased between the years with higher ratios recorded in 2016, especially for the SNE-MG (Figure 3.5), though these trends were not significant. No significant region $\times$ year interaction $(\mathrm{p}=0.973$, Table 3.2$)$ was observed.

A Non-Metric Multi-Dimensional Scaling plot fitted with 95\% confidence ellipses showed overlap among regions in each year (Figure 3.7). In general, annual ellipses were 
larger for fish sampled from the SNE compared to SNE-MG (Figure 3.7). A similar trend was observed between locations; specifically, widening confidence ellipses were observed between years (Figure 3.7). There appeared to be a greater distinction between the two locations in 2015 than in 2016, given the more concise nature of the ellipse.

\subsubsection{Classification to Region of Capture}

Results of the QDFA with leave-one-out cross validation showed classification at both regional and temporal scales of the juvenile Golden Tilefish otolith signatures, however the classification success was relatively low. Classification accuracy using individual chemical signatures (i.e., transect of two annuli) showed an overall classification success of $31.8 \%$ (Table 3.4). Using year-specific signatures, the percentage of positively classified Golden Tilefish was 50\% for 2015 but decreased to 10\% for the 2016 signatures (Table 3.4). Classification was highest (54.5\%) for fish sampled from SNEMG in 2015.

\subsection{Discussion}

Few studies to date have used otolith elemental signatures to examine patterns of connectivity in marine fish species, especially those with unique habitat preferences and resident burrowing behavior, and are largely limited to studies of species that use distinct habitats across life-history such as estuaries and rivers (Clarke et al. 2009). The elemental signatures of juvenile Golden Tilefish otoliths collected from the NW Atlantic Ocean analyzed in this study showed subtle spatial and temporal patterns in concentrations 
suggesting the potential for this technique to provide insight into the habitat use and connectivity of Golden Tilefish in this region. Results suggest, therefore, that there is elemental variability at relatively small spatial scales $(200 \mathrm{~km})$ in the continental shelf and slope environment, to use otolith microchemistry to track habitat connectivity of Golden Tilefish, however refinement in the approach is needed for the use of this technique as natural tags in this species.

\subsubsection{Regional Differences}

Statistically significant spatial differences in overall otolith elemental signatures were not observed, rather the differences in elemental signatures observed between regions were subtle and, in some cases, contrary to our predictions. We expected that the possible differential influence of the Hudson River and the Gulf Stream would distinguish the two regions based on different associations with these water masses. Otoliths of individuals captured from the SNE-MG exhibited significantly higher $\mathrm{Pb} / \mathrm{Ca}$ ratios compared to individuals from SNE; this is despite the Hudson River delivering anthropogenic contaminants, such as Lead, onto the continental shelf, and should have been reflected as greater concentrations in the otoliths of individuals from the SNE region (Benoit et al. 1999, Balcom et al. 2008, Roose et al. 2021). Moreover the similarity between regions in $\mathrm{Ba} / \mathrm{Ca}$ and $\mathrm{Sr} / \mathrm{Ca}$ ratios (Zhang and Gawarkiewicz 2015, Chen et al. 2018) suggest that salinity and temperature were consistent and that cool, freshwater from the Hudson River did not differentiate elemental composition among regions. The lack of statistical significance between regions likely reflects the narrow habitat characteristics in terms of temperature, salinity and sediment preference for burrow construction preferred by the 
species. For example, Golden Tilefish CPUE is highest in areas where temperature and salinity ranged between $10.0-12.4^{\circ} \mathrm{C}$ and $34.2-35.3 \mathrm{psu}$, respectively, and bottom type was characterized as medium sand (0.25-0.5 mm grain size) (Frisk et al. 2018); areas where samples for this study were derived. This could suggest that the microchemistry reflects the broad habitat preferences of the species and propensity to reside in stable environmental regimes across the study area. Alternatively, the limited spatial discrimination could suggest movement of individuals between the regions. Directed evaluation of movement in these species across their life history is largely absent from the literature. Current knowledge regarding site fidelity is based on observation (Able et al. 1982) and a single mark-recapture study of adults conducted in the Hudson Canyon implying minimal movement from established burrows (Grimes et al. 1986). A greater understanding of movement patterns across life-history stages, including larval and young-of-year individuals, should therefore be a future priority for resource managers particularly over smaller spatial scales given this species' patchy distribution.

Higher $\mathrm{Mg} / \mathrm{Ca}$ concentrations were observed in Golden Tilefish from the SNE-MG compared to those from SNE. This may be a consequence of the dominant age group analyzed from each region, as age-3 fish were in greater proportion to age-4 fish in SNEMG, with the opposite proportions for fish from the SNE. Magnesium concentrations in otoliths have been linked to the physiological condition and growth of fishes. For example, Limburg et al. (2018) showed that the incorporation of Mg correlates with metabolic activity, whereby higher $\mathrm{Mg} / \mathrm{Ca}$ levels were noted in early life-history of fishes, followed by a transition to lower levels as the fish age. Thus, the higher proportion 
of age-3 fish could explain the differences between regions as fish from the SNE-MG have a greater growth rate compared to fish from SNE (Dawson Chapter 2). Observed ontogenetic differences in $\mathrm{Mg} / \mathrm{Ca}$ in otoliths and the magnitude of those differences could be related to differences in larval/juvenile and adult habitats, trophic levels, behaviors, among other (Limburg et al. 2018), though we cannot distinguish those influences in this study. A longer time series in Golden Tilefish otoliths could help to inform on these mechanisms. Magnesium could also serve as a proxy for growth in Golden Tilefish, but would need to be further evaluated with traditional age estimates and growth models. Given the sample size of fish used in this analysis and the limited age range, this correlation was not possible to confirm. Future work, however, should consider this line of inquiry. Development of a proxy to traditional age and growth techniques would be valuable for aging species, such as Blueline Tilefish (Caulolatilus microps), a sympatric deep-water species, that does not exhibit clear opaque and translucent growth bands needed for traditional aging techniques (SEDAR 2017).

Otolith elemental signatures were classified with some success to the different regions (31.8\%; Table 3.4). Though this classification rate is much lower than observed for the Atlantic Silverside (Clarke et al. 2009), it does suggest variability in elemental signatures among regions. To standardize our comparisons, we focused our analysis on similarly aged juvenile fish. To accommodate this, juvenile fishes were selected from regions of different size. The SNE region encompassed an area of $2,508 \mathrm{~km}^{2}$ and included sites east and west of the Hudson Canyon, whereas the SNE-MG encompassed an area of 1,711 $\mathrm{km}^{2}$ and included sites from two canyons, Veatch and Atlantis. Considering a sample size 
of eleven individuals from each location the differences observed merits continued investigation, though refining the approach may be needed. For example, analyzing fish from specific longlines may produce more spatially explicit signatures and should be considered in the future. Similarly, analyzing fish from other locations such as Baltimore Canyon in the southern extent of the species NW Atlantic Ocean range could produce a broader perspective on subpopulation structure in addition to the use of otolith elemental signatures for delineate regional canyon habitats. Spatial scales of this extent are more in line with finding of other marine deep-sea species such as the Patagonian Toothfish, Dissostichus eloninoides, whose otolith microchemistry demonstrated significant separation between fish captured in South America and Antarctica basins (Ashford et al. 2005). Regardless, and despite overlap, the elemental signatures of fish from SNE-MG were narrower than the elemental signatures of fish from SNE, based on smaller confidence ellipses and suggest that there are some differences between the two regions. Furthermore, analysis at smaller scales may show more elemental differences, as displayed by individuals from Northern and Southern Hudson Canyon demonstrating some separation when examining more specific locations. Whether these differences reflect environmental or physiological differences among regions, requires further investigating. At a minimum, the application of this approach to discriminate subpopulation structure holds promise and highlights the point that additional work to understand the otolith microchemistry in these species is warranted.

\subsubsection{Temporal Differences}


The elemental signatures of Golden Tilefish captured along the NW Atlantic shelf-edge demonstrated significant temporal variability. This was an unexpected finding, given the noted habitat specificity of the species, and the expectation that this specificity would result in temporally stable elemental signatures. However, what this does suggest is that environmental characteristics or water quality differed among years. The differences observed among year was driven by two elements, $\mathrm{Ba}$ and $\mathrm{Mn}$ that exhibited opposite trends; $\mathrm{Ba} / \mathrm{Ca}$ ratios increased over time while $\mathrm{Mn} / \mathrm{Ca}$ ratios decreased over time. The $\mathrm{Ba} / \mathrm{Ca}$ ratios in the otolith have been shown to negatively correlate with salinity, indicating freshwater input (Bath et al. 2000, Secor et al. 2001). Manganese has been positively associated with hypoxia, with potential for growth effects (Limburg et al. 2015, Limburg and Casini 2018). Collectively these elements suggest that in 2015, Golden Tilefish experienced a less salty and less oxygenated environment relative to 2016. Interestingly, in contradiction of the possibility of greater freshwater intrusions in 2016, though not significant, the $\mathrm{Sr} / \mathrm{Ca}$ ratios also increased from 2015, though this could be a result of increasing temperature or physiological effects. These results are not limited to Golden Tilefish in one region, therefore making inference regarding drivers of these water quality differences challenging. However, it important to note, that $\mathrm{Mg} / \mathrm{Ca}$, a proxy for growth and metabolism (Limburg et al. 2018) showed a decreasing trend between 2015 and 2016 as the fish age. Whether this trend was limited to one year is unclear but highlights the importance for evaluating temporal trends in otolith chemistry, particularly if there is evidence for effects on growth rates in juvenile age classes. 
In the NDMS graphs, it appeared that the SNE-MG displayed temporal variation in their microchemical signatures, while the SNE area appeared to have more temporally stable signatures, indicated by their confidence ellipses. Temporal differences suggest that environmental variability over time might be more important in SNE-MG, and that while there are less factors influencing the otolith composition in the region, these influences are more variable. NMDS plots also indicate that variability in elemental signature increased over time. This could indicate increasing environmental variability, or physiological changes in the fish due to aging.

Temporal differences in otolith elemental signatures of sequential year classes suggest that the natural tags are year-class specific. These differences were consistent across regions with increased variance in otolith signatures between years as evidenced by the MDS plots that showed. Classification accuracies of Golden Tilefish mimicked these trends with higher accuracies in $2015(\sim 50 \%)$ relative to $2016(\sim 10 \%)$. Other studies investigating temporal trends in otolith signatures of marine fish have reported similar annual differences (Gillanders 2002, Warner et al. 2005, Clarke et al. 2009) in classification accuracy, suggesting that spatial differences can vary by year in many species. This highlights that the cause of interannual variability in Golden Tilefish elemental signatures needs more thorough evaluation. Regardless of the underlying causes of the observed temporal differences, our results suggest knowledge of temporal variation in otolith elemental concentrations is required at a range of scales to determine how they can be used for studies of connectivity between the juvenile and adult life history stages. Overall, the otolith signatures were relatively consistent over time, 
however additional data in a times series is needed to resolve residence behavior of the species.

Change in elemental signatures over time could be due to environmental change or physiological differences. For example, Clarke et al. (2009) demonstrated temporal variability in elemental signatures of the Atlantic Silverside, concluding the need for year-specific signatures (Clarke et al. 2009) to understand habitat connectivity. This study examined the first few years of Golden Tilefish life, a period of high growth (Dawson Chapter 2). The earliest year examined, 2015, consists of age-1 and age-2 fishes. The elemental signature of age-1 may reflect a portion of the individual's pelagic larval stage before settlement. This may have also led to the greater distinction between regions in 2015, with SNG-MG being dominated by younger individuals in this study, as the pelagic environments could have been more environmentally distinct than the fish experience post-settlement. Similarly, growth rates among male and female Golden Tilefish differ (Dawson Chapter 2), with males growing faster than females. Though we were not able to compare males and females in this study due to sample size, the interannual differences observed could reflect the different growth rates among sexes. Future work should address sex, particularly during juvenile life stages when growth varies.

\subsubsection{Implications}

I expected to observe distinct spatial differences in microchemical signatures given the ecology of the species (specific habitat preferences) and the differentially influenced 
areas in the NW Atlantic; one that is possibly more greatly influenced by freshwater from the Hudson River and one that is more influenced by the Gulf Stream. Regardless, we did see subtle variability among locations and among years to suggest that the utility of this approach for further research. While otolith microchemistry has previously been used to access Golden Tilefish heavy metal exposure and lesion formation after the Deepwater Horizon oil spill (Granneman et al. 2017), this is the first study to access spatial and temporal variability and discrimination for the species using otolith elemental signatures and is the first step in providing information regarding metapopulation dynamics.

Here we demonstrated that the elemental signatures of juvenile Golden Tilefish otoliths showed subtle regional differences along the continental shelf and slope environment, though this was not significant overall based on the MANOVA. One element (Lead), however, demonstrated significant regional variability. This led to low accuracy success when attempting to classify the individuals back to their capture location. Therefore, this research indicated that microchemistry analysis was insufficient to currently distinguish localized populations, and that subpopulation structure is not present across the study area. This could indicate that the signature represents the distinct environmental characteristics, such as temperature, required to sustain Golden Tilefish populations. Nuance is, therefore, required when assessing microchemistry. Our study, however, was limited by a small sample size, and variable individual age. Therefore, more research is needed to determine if there is subpopulation structure and metapopulation dynamics and determine the feasibility in using microchemistry as a natural tag. Future research should 
assess whether these results are consistent when using larger sample sizes, age consistency, and varying spatial scales. 


\subsection{Tables}

Table 3.1. Demographics of Golden Tilefish used for otolith microchemistry analysis.

\begin{tabular}{l|l|l|l|l|l}
\hline Individual & Location & $\begin{array}{l}\text { Age } \\
(\mathrm{yrs})\end{array}$ & $\begin{array}{l}\text { Fork Length } \\
(\mathrm{cm})\end{array}$ & $\begin{array}{l}\text { Weight } \\
(\mathrm{kg})\end{array}$ & Sex \\
\hline GTL-0002 & Southern New England & 3 & 38.0 & 0.6 & $\mathrm{M}$ \\
GTL-0007 & Southern New England & 3 & 40.0 & 0.7 & UNK \\
GTL-0008 & Southern New England & 4 & 38.0 & 0.6 & $\mathrm{~F}$ \\
GTL-0097 & Southern New England & 3 & 38.0 & 0.7 & $\mathrm{~F}$ \\
GTL-0126 & Southern New England & 4 & 44.0 & 1.2 & $\mathrm{~F}$ \\
GTL-0154 & Southern New England & 4 & 43.5 & 0.9 & $\mathrm{~F}$ \\
GTL-0159 & Southern New England & 4 & 37.0 & 0.3 & $\mathrm{UNK}$ \\
GTL-0160 & Southern New England & 4 & 43.5 & 0.6 & $\mathrm{~F}$ \\
GTL-0168 & Southern New England & 4 & 37.0 & 0.6 & $\mathrm{~F}$ \\
GTL_0172 & Southern New England & 4 & 45.0 & 1.1 & $\mathrm{M}$ \\
GTL-0174 & Southern New England & 4 & 37.0 & 1.2 & $\mathrm{~F}$ \\
\hline GTL-0312 & SNE Middle Grounds & 3 & 40.0 & 0.7 & $\mathrm{M}$ \\
GTL-0316 & SNE Middle Grounds & 3 & 42.0 & 0.9 & $\mathrm{~F}$ \\
GTL-0317 & SNE Middle Grounds & 3 & 42.0 & 1.0 & $\mathrm{UNK}$ \\
GTL-0328 & SNE Middle Grounds & 3 & 39.0 & 0.9 & $\mathrm{M}$ \\
GTL-0369 & SNE Middle Grounds & 3 & 42.0 & 0.9 & $\mathrm{~F}$ \\
GTL-0373 & SNE Middle Grounds & 4 & 51.0 & 1.5 & $\mathrm{M}$ \\
GTL-0376 & SNE Middle Grounds & 4 & 41.0 & 0.8 & $\mathrm{~F}$ \\
GTL-0439 & SNE Middle Grounds & 3 & 42.0 & 0.8 & F \\
GTL-0455 & SNE Middle Grounds & 4 & 47.5 & 1.4 & M \\
GTL-0462 & SNE Middle Grounds & 4 & 44.0 & 1.0 & $\mathrm{UNK}$ \\
GTL-0463 & SNE Middle Grounds & 3 & 42.0 & 0.9 & $\mathrm{UNK}$ \\
\hline
\end{tabular}


Table 3.2. Results of MANOVA examining regional and temporal differences in the otolith chemistry of Golden Tilefish. Significant results at $\alpha=0.05$ are bolded.

\begin{tabular}{lcccc}
\hline & df & Pillai Test & $F$ & $\mathrm{p}$ \\
\hline Region & 1 & 0.356 & 2.076 & 0.071 \\
Year & 1 & 0.434 & 2.873 & $\mathbf{0 . 0 1 7}$ \\
Region $\times$ Year & 1 & 0.139 & 0.608 & 0.764 \\
Residuals & 37 & & & \\
\hline
\end{tabular}


Table 3.3. Univariate results of MANOVA examining regional and temporal differences in otolith chemistry of Golden Tilefish. Significant results at $\alpha=0.05$ are bolded.

\begin{tabular}{lcccc}
\hline & df & MS & $F$ & $\mathrm{p}$ \\
\hline B/Ca & & & & \\
Region & 1 & 0.07 & 2.48 & 0.124 \\
Year & 1 & 0.00 & 0.11 & 0.741 \\
Region x year & 1 & 0.00 & 0.11 & 0.743 \\
Residuals & 37 & 0.03 & &
\end{tabular}

\section{$\mathrm{Ba} / \mathrm{Ca}$}

$\begin{array}{lcccc}\text { Region } & 1 & 0.00 & 0.40 & 0.533 \\ \text { Year } & 1 & 0.03 & 4.71 & \mathbf{0 . 0 3 6} \\ \text { Region x year } & 1 & 0.00 & 0.03 & 0.857 \\ \text { Residuals } & 37 & 0.01 & & \end{array}$

\section{$\mathbf{L i} / \mathbf{C a}$}

$\begin{array}{lcccc}\text { Region } & 1 & 0.00 & 0.16 & 0.696 \\ \text { Year } & 1 & 0.00 & 1.79 & 0.190 \\ \text { Region x year } & 1 & 0.00 & 0.06 & 0.805 \\ \text { Residuals } & 37 & 0.00 & & \end{array}$

\section{$\mathrm{Mg} / \mathrm{Ca}$}

$\begin{array}{lcccc}\text { Region } & 1 & 0.29 & 3.08 & 0.088 \\ \text { Year } & 1 & 0.00 & 0.03 & 0.856 \\ \text { Region x year } & 1 & 0.07 & 0.81 & 0.374 \\ \text { Residuals } & 37 & 0.09 & & \end{array}$

\section{$\mathrm{Mn} / \mathrm{Ca}$}

$\begin{array}{lcccc}\text { Region } & 1 & 0.05 & 0.69 & 0.410 \\ \text { Year } & 1 & 0.36 & 4.83 & \mathbf{0 . 0 3 4} \\ \text { Region x year } & 1 & 0.14 & 1.92 & 0.174 \\ \text { Residuals } & 37 & 0.08 & & \end{array}$

\section{$\mathbf{P} / \mathbf{C a}$}

$\begin{array}{lcccc}\text { Region } & 1 & 0.51 & 0.90 & 0.348 \\ \text { Year } & 1 & 0.04 & 0.07 & 0.789 \\ \text { Region x year } & 1 & 0.00 & 0.00 & 0.977 \\ \text { Residuals } & 37 & 0.56 & & \end{array}$

\section{$\mathrm{Pb} / \mathrm{Ca}$}

\begin{tabular}{|c|c|c|}
\hline Region & 146.82 & 8.32 \\
\hline Year & 1.16 & 0.21 \\
\hline
\end{tabular}




\begin{tabular}{lcccc} 
Region x year & 1 & 1.89 & 0.34 & 0.566 \\
Residuals & 37 & 5.62 & & \\
& & & & \\
Sr/Ca & & & & \\
Region & 1 & 0.00 & 0.35 & 0.558 \\
Year & 1 & 0.00 & 1.30 & 0.262 \\
Region x year & 1 & 0.00 & 0.50 & 0.483 \\
Residuals & 37 & 0.00 & & \\
\hline
\end{tabular}


Table 3.4. QDFA classification success using leave-one out cross-validation of Box-Cox transformed ratios. The predicted region columns represent the number of individuals assigned to a region based on elemental signature, while the rows represent the actual capture region. Bold numbers represent the number of individuals correctly assigned to their capture region, and \% correct represents this number divided by the actual number of individuals captured from the region. The first matrix represents the total classification success using Box-Cox transformed elemental ratios averaged over both years, while the following matrixes represent the year specific classification. SNE = Southern New England, SNE-MG = SNE-Middle Grounds.

\begin{tabular}{lccc}
\hline \multicolumn{3}{c}{ Predicted Region } & $\%$ Correct \\
\hline Region & SNE & SNE-MG & \\
SNE & $\mathbf{4}$ & 7 & $36.4 \%$ \\
SNE- MG & 8 & $\mathbf{3}$ & $27.3 \%$ \\
Mean & & & $31.8 \%$ \\
& & & \\
Region $\times$ Year & & & \\
2015 & & & \\
SNE & $\mathbf{5}$ & 6 & $45.5 \%$ \\
SNE-MG & 5 & $\mathbf{6}$ & $54.5 \%$ \\
Mean & & & $50.0 \%$ \\
& & & \\
2016 & & & \\
SNE & $\mathbf{2}$ & 8 & $20.0 \%$ \\
SNE-MG & 9 & $\mathbf{0}$ & $0.0 \%$ \\
Mean & & & $10.0 \%$ \\
\hline
\end{tabular}




\subsection{Figures}

Figure 3.1. Distribution of the Golden Tilefish chosen for microchemical analysis sampled from the NW Atlantic Ocean. Red points indicate capture stations within the two regions of the study; Southern New England near Hudson Canyon and Southern New England Middle Grounds near Veatch and Atlantis Canyons.

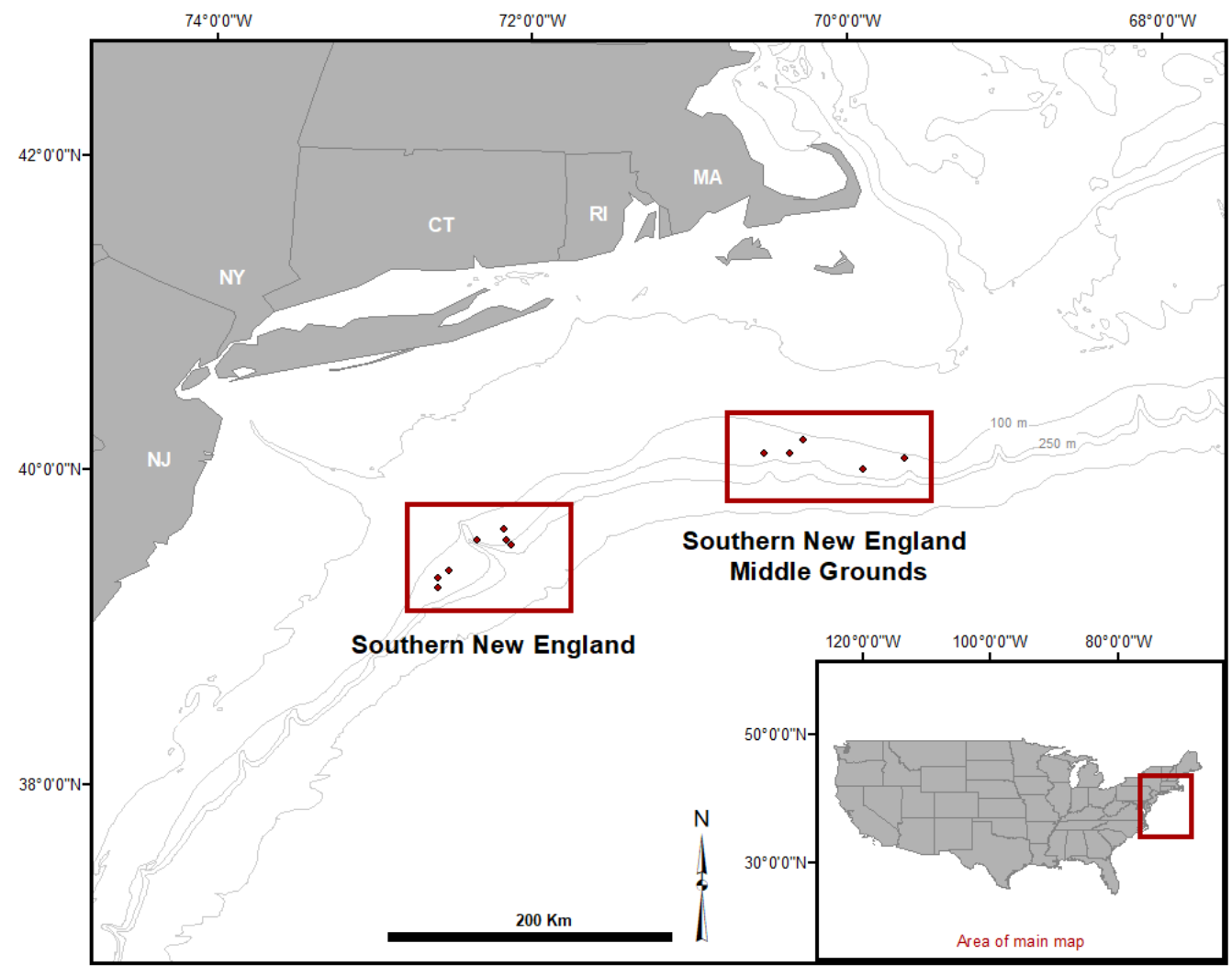


Figure 3.2. Polished otolith of an aged-3 Golden Tilefish imaged under reflected light (magnification 25x). The core is visible, having an appearance similar to an eye, and is designated by an arrow

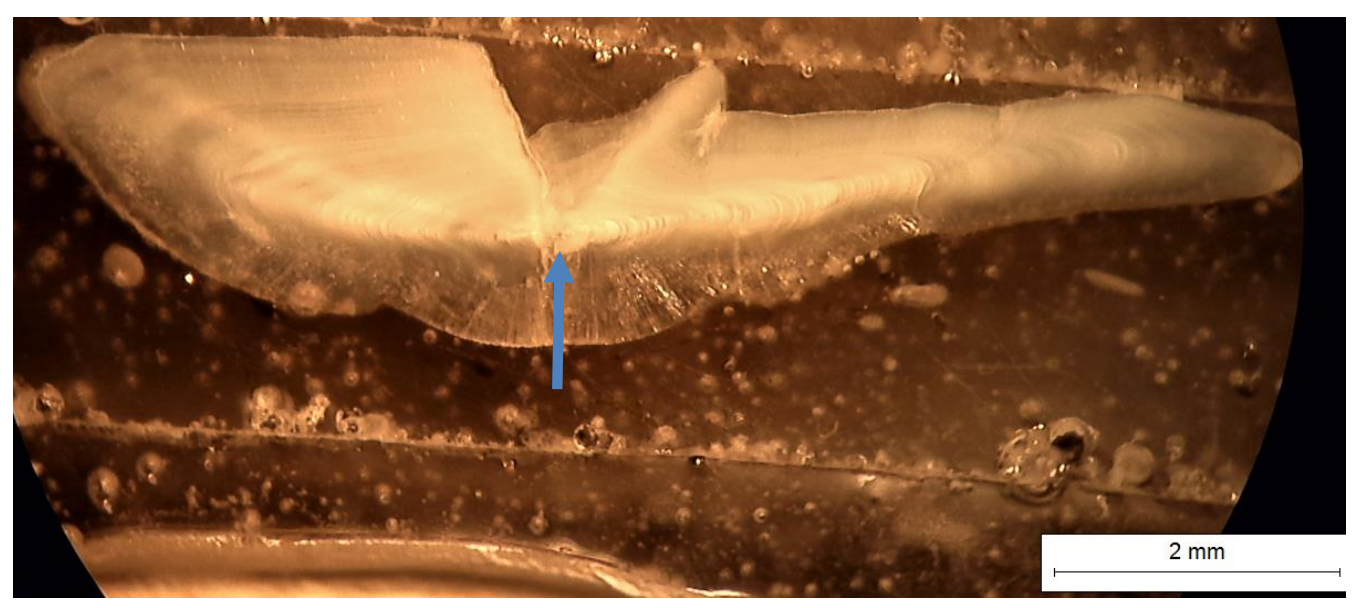


Figure 3.3. Sectioned otolith post-ablation. The transect path of the laser can be seen left to right from the dorsal to ventral side, covering the entire span of the otolith.

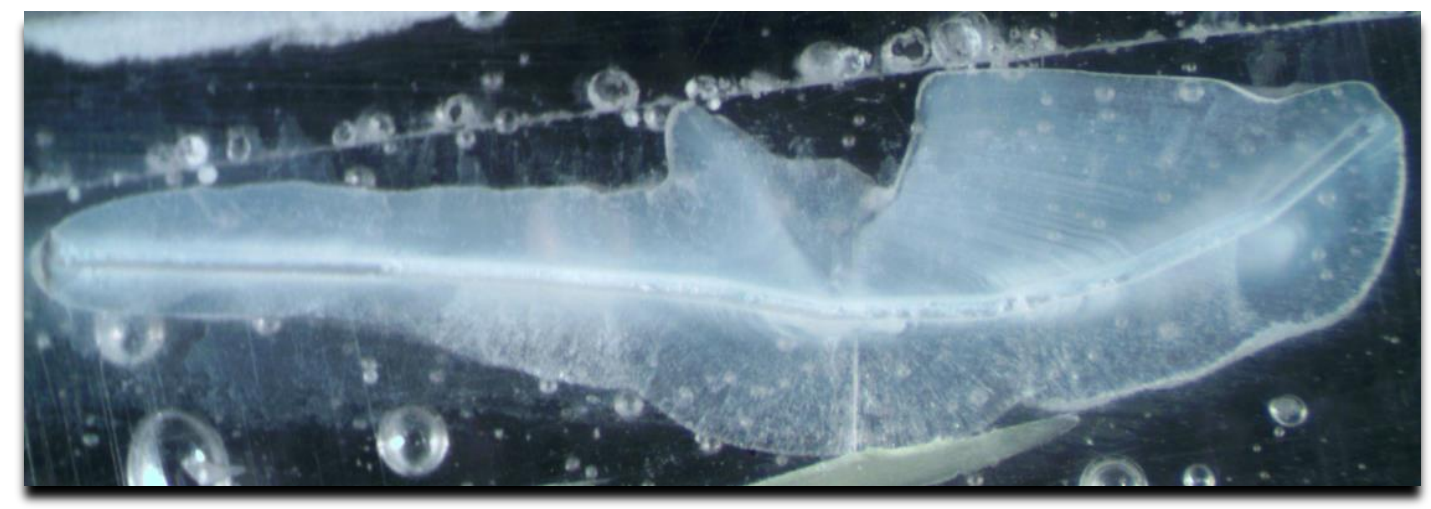


Figure 3.4. Annual classification of an aged-3 fish. The image has been edited to display the transect path linearly. The $\mathrm{Mg} / \mathrm{Ca}$ ratio transect was overlaid on an image of the otolith to aid in the annuli designation, following Limburg et al. (2018). The transect section corresponding to the first growth band or annuli represents 2015 (yellow); the transect section corresponding to the second annuli represents 2016 (green); the transect section corresponding to the third annuli represents 2017 (red bar) or the year of capture.

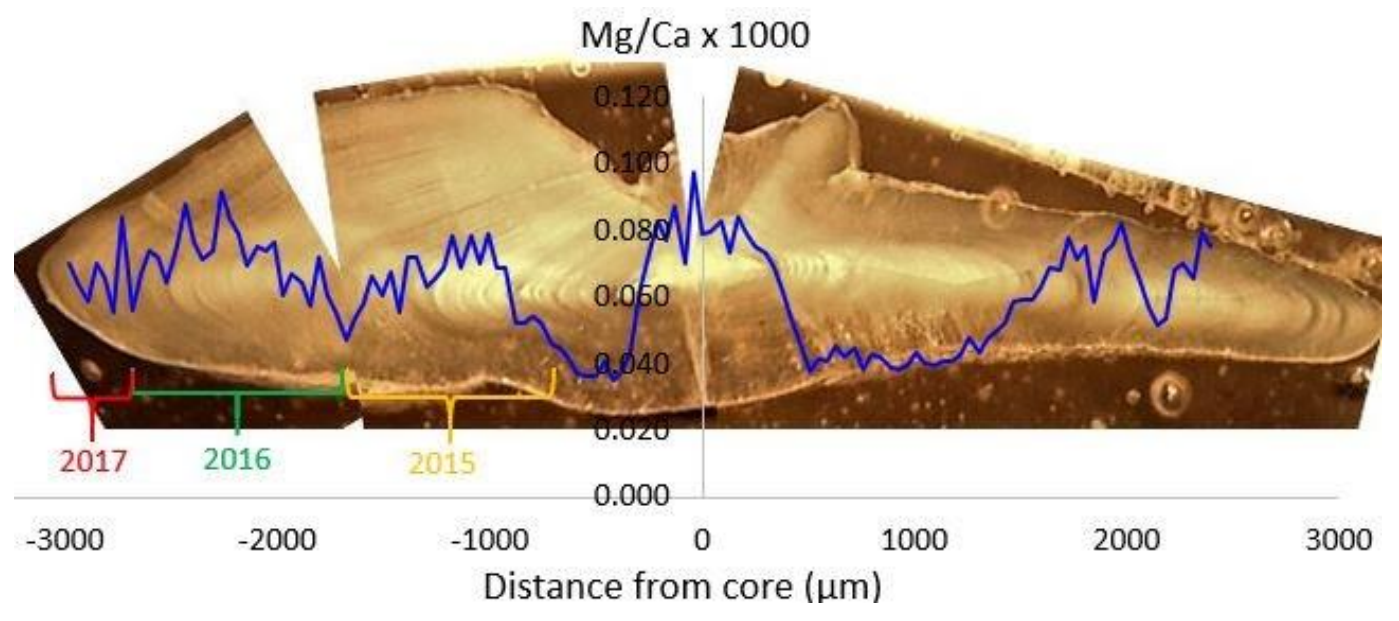


Figure 3.5. Box plots depicting raw otolith Element/Ca ratios by region and year. The notch represents the median, the top and bottom indicate the interquartile range (the $25^{\text {th }}$ and $75^{\text {th }}$ percentiles), and the whiskers represent the maximum and minimum ranges.

Black points represent outliers.
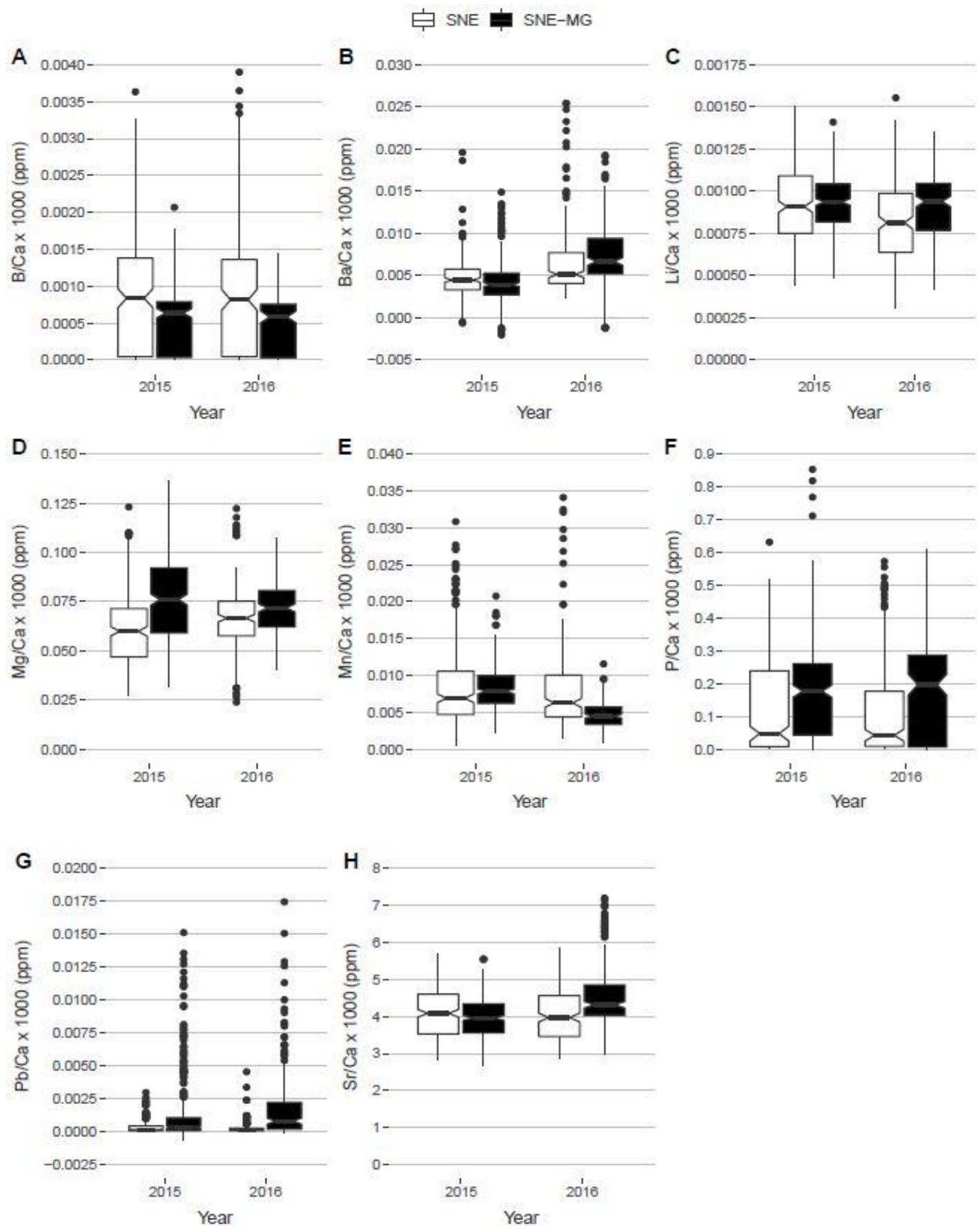
Figure 3.6. Multidimensional Scaling (MDS) plot of regional Golden Tilefish otolith elemental signatures fitted with $95 \%$ confidence ellipses. Each point represents Box-Cox transformed Element/Ca ratios, including eight element/calcium ratios of the respective otolith. Black points represent individuals from Southern New England (SNE) and light grey points represent individuals from the SNE-Middle Grounds (SNE-MG). Squares represent the Northern Hudson Canyon (NHC), circles represent the Southern Hudson Canyon (SHC), triangles represent the Atlantis Canyon (AC), and diamonds represent the Veatch Canyon (VC)

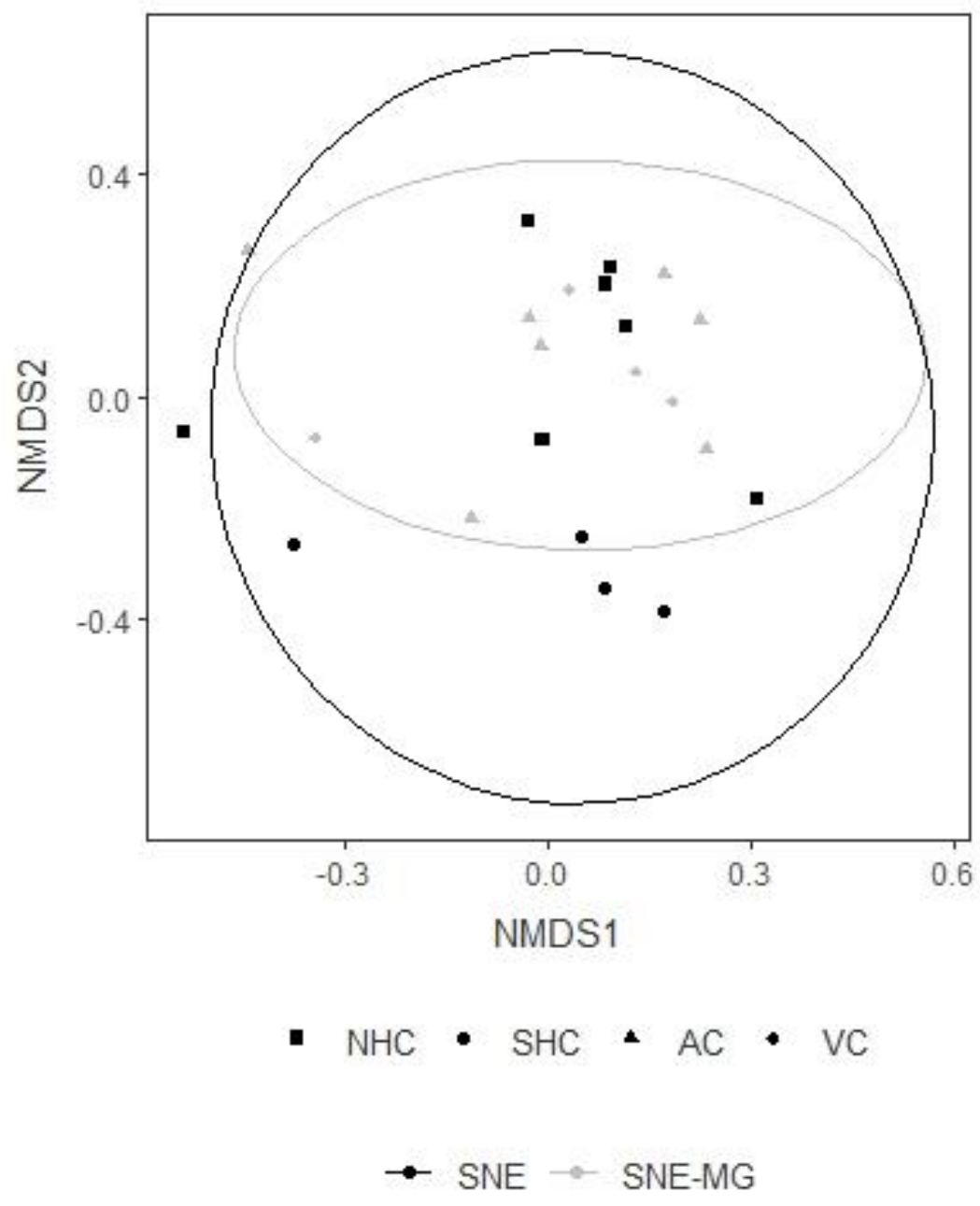


Figure 3.7. Multidimensional Scaling (MDS) plot of temporal Golden Tilefish otolith elemental signatures fitted with $95 \%$ confidence ellipses. Each point represents Box-Cox transformed Element/Ca ratios, including eight element/calcium ratios of the respective otolith. Black points represent individuals from Southern New England (SNE) and light grey points represent individuals from the SNE-Middle Grounds (SNE-MG). Circles represent individuals that were 1 year old during the year in question, triangles represent individuals that were 2 years old during the year in question, and squares were individuals that were 3 years old during the year in question

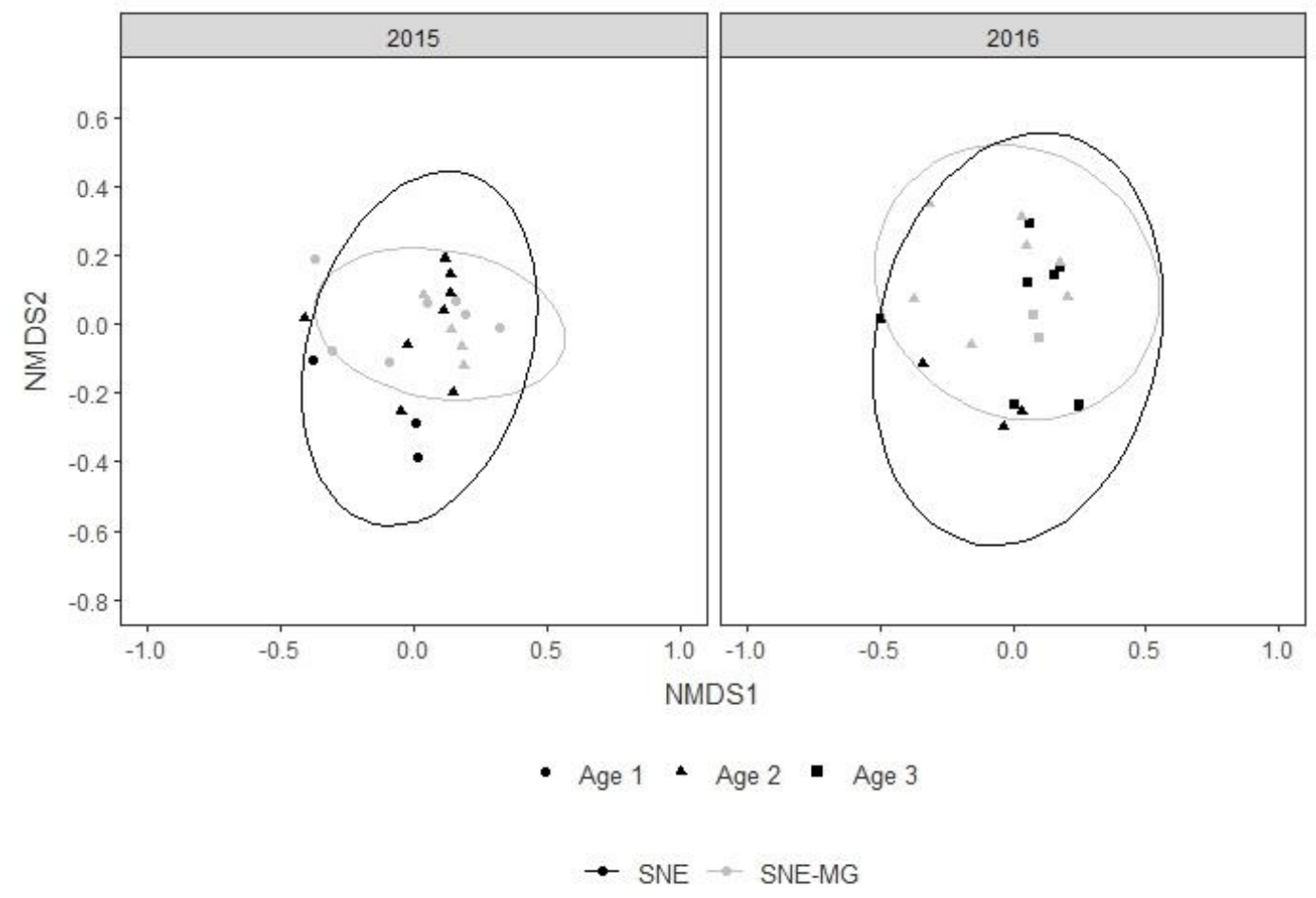




\section{GENERAL DISCUSSION}

Increasing demand has caused fisheries to expand their reach to further depths (Haedrich et al. 2001). Deep-sea fish, however are understudied, with limited knowledge on their life history characteristics such as growth, age, and population structure (Dransfeld et al. 2013). This includes Golden Tilefish, a patchily distributed, long-lived, demersal fish that creates and occupies burrows along the NW Atlantic Ocean continental shelf-edge (Turner et al. 1983). The majority of information towards deep-sea fish demographics is derived from the fishing industry, specifically from reported commercial and recreational catches. Fishery-dependent data, however, is limited, most notably by size-selectivity due to fishery regulations such as minimum size limit, gear restriction (e.g., hook size, bait type), area closures, and depth restrictions. Fishery-independent surveys provide an opportunity to collect data without the influences of the dynamics of a fishery as listed above. My research used fish collected as part of fishery-independent survey to advance our understanding of Golden Tilefish in the NW Atlantic through the estimation of age and growth parameters, and the application of otolith microchemistry to distinguish patterns of habitat connectivity among individuals inhabiting relatively small spatial scales $(200 \mathrm{~km})$.

Age and growth estimates are essential for informing stock assessment and management decisions. Information on the age and growth of fish is commonly used to construct age/length relationships used in population assessment models, estimate growth parameters, and perform comparative studies of growth performance among different 
stocks and species experiencing different environmental factors (Begg 2005). In Chapter 2, I estimated age and modeled growth parameters of Golden Tilefish caught off the continental shelf of the NW Atlantic during a fishery-independent survey of the species population and distribution. Though studies have reported age and growth estimates for the northern stock of Golden Tilefish (Turner et al. 1983, Vidal 2009, McBride et al. 2013) those studies focused on fish collected from the commercial and recreational fishery, which are targeted towards a specific size class of individuals in the population. I demonstrated that the age estimates and growth parameters were consistent with previous studies derived from the commercial fishing industry, complementing existing estimates, but also providing a more detailed understanding of the population in its entirety, unbiased by the targeting of market sized individuals. The findings from my assessment also show varying age structure and year classes expected to be recruited into the fishery in subsequent years. These data are valuable for monitoring the stock of Golden Tilefish, independent of commercial reports and will aid stock assessors in the management of this species. They also highlight the importance of independent assessment of the NW Atlantic Golden Tilefish population outside of commercial landings for evaluating the sustainability of the fishery and population changes by demonstrating a higher proportion of small, immature individuals that would not be as readily captured in commercial fisheries.

Golden Tilefish are managed as three stocks in U.S. waters: The Southern New England/Mid-Atlantic stock, The Southern Atlantic stock, and the Gulf of Mexico stock (NOAA 2021). Due to the habitat preferences and resident behavior of the species, 
however, there is a possibility of localized, subpopulations. Evidence of subpopulations and connectivity among individuals within a stock is potentially important when considering such things as the resilience of a population to fishing pressure and when designing marine protected areas (Clarke et al. 2009). In Chapter 3, I evaluated spatial and temporal patterns in otolith microchemical signatures, used as natural environmental and physiological tags, to understand subpopulation structure of Golden Tilefish in the NW Atlantic. I demonstrated subtle regional and temporal differences in the microchemical signatures of juvenile Golden Tilefish, such as smaller confidence ellipses in the SNE-MG though the microchemical signatures did overlap among regions. These results could be due to the environmental selectivity of the species due to their strict habitat requirements for burrowing leading to a more homogenous environmental experience, and small spatial scale. The spatial signatures therefore could signify the environmental characteristics that are capable of supporting Tilefish populations. The elemental signatures did vary by year, possibly due to environmental or physiological variability over time, suggesting that any further analysis of elemental signatures would need to be year specific.

This research is the first step in analyzing the metapopulation dynamics of Golden Tilefish using otolith microchemistry. While my results did not confirm subpopulations, more research is required to evaluate subpopulation structure in the area. Future studies should focus on collecting and analyzing larval and newly settled individuals to estimate settlement time, and natal origins using otolith microchemistry. For example, larval lifehistory stages would contribute to our understanding of connectivity among populated 
areas, in addition to defining larval duration prior to settlement; two components of the Golden Tilefish's ecology that remain unknown. Moreover, analysis of older fish, such as age- 6 to age- 7 , would contribute to our understanding of movement behaviors. These individuals are slower growing and have been settled for longer periods of time, meaning that they are more physiologically stable, therefore limiting variability in otolith elemental signature to environmental changes or movement. My results do show that there is subtle spatial variability among two different regions, suggesting that evaluation of a broader spatial scale may be a promising avenue of future research. Evaluating Golden Tilefish across their range in the NW Atlantic, in areas of high abundance including the Baltimore Canyon may be more informative.

Overall, the information and data generated in this thesis provides a baseline for further research of the Golden Tilefish population in the NW Atlantic. The thesis contributes valuable demographic details for the species from an unbiased fishery-independent survey, such as growth rate and age structure that can be used as a baseline for monitoring any changes in the species stock health. The research also took the first step in examining metapopulation structure, population connectivity, and habitat use in the population using otolith microchemistry. These insights are key for the effective management of the species, including stock designation, and capture and size limits, which are of vital importance in the face of increasing human demand and climate change. 


\section{REFERENCES}

Able KW, Grimes CB, Cooper RA, Uzmann JR. 1982. Burrow Construction and Behavior of Tilefish, Lopholatilus Chamaeleonticeps, in Hudson Submarine-Canyon. Environmental Biology of Fishes. 7(3): 199-205.

Able KW, Grimes CB, Jones RS, Twichell DC. 1993. Temporal and Spatial Variation in Habitat Characteristics of Tilefish (Lopholatilus Chamaeleonticeps) Off the East-Coast of Florida. Bulletin of Marine Science. 53(3): 1013-1026.

Able KW, Twichell DC, Grimes CB, Jones RS. 1987. Tilefishes of the Genus Caulolatilus Construct Burrows in the Sea-Floor. Bulletin of Marine Science. 40(1): 1-10.

Allendorf FW, England PR, Luikart G, Ritchie PA, Ryman N. 2008. Genetic Effects of Harvest on Wild Animal Populations. Trends in Ecology and Evolution. 23(6): 327-337.

Ashford JR, Jones CM, Hofmann E, Everson I, Moreno C, Duhamel G, Williams R. 2005. Can Otolith Elemental Signatures Record the Capture Site of Patagonian Toothfish (Dissostichus Eleginoides), a Fully Marine Fish in the Southern Ocean? Canadian Journal of Fisheries and Aquatic Sciences. 62(12): 2832-2840.

Balcom PH, Hammerschmidt CR, Fitzgerald WF, Lamborg CH, O'Connor JS. 2008. Seasonal Distributions and Cycling of Mercury and Methylmercury in the Waters of New York/New Jersey Harbor Estuary. Marine Chemistry. 109(1-2): 1-17.

Bath GE, Thorrold SR, Jones CM, Campana SE, Mclaren SE, Lam JWH. 2000. Strontium and Barium Uptake in Aragonitic Otoliths of Marine Fish. Geochimica et Cosmochimica Acta. 64(10): 1705-1714.

Baty F, Ritz C, Charles S, Brutsche M, Flandrois J-P, Delignette-Muller M-L. 2015. A Toolbox for Nonlinear Regression in R: The Package Nlstools. Journal of Statistical Software, 66(5), 1-21. http://www.jstatsoft.org/v66/i05/.

Beck MW, Heck KL, Childers DL, Eggleston DB, Gillanders BM, Halpern B, Hays CG, Hoshino K, Minello TJ, Orth RJ, Sheridan PF, Weinstein MR. 2001. The Identification, Conservation, and Management of Estuarine and Marine Nurseries for Fish and Invertebrates. Bioscience. 51: 633-641.

Begg GA. 2005. Life History Parameters. Stock Identification Methods. 119-150.

Benoit G, Wang EX, Neider WC, Levandowsky M, Breslin VT. 1999. Sources and Deposition in History of Heavy Metal Contamination and Sediment Tivoli South Bay, Hudson River, New York. Estuaries and Coasts. 22(2A): 167-178.

Brown RJ, Severin KP. 2009. Otolith Chemistry Analyses Indicate That Water Sr:Ca Is the Primary Factor Influencing Otolith Sr:Ca for Freshwater and Diadromous Fish but 
Not for Marine Fish. Canadian Journal of Fisheries and Aquatic Sciences. 66(10): 17901808.

Cailliet GM, Andrews AH, Burton EJ, Watters DL, Kline DE, Ferry-Graham LA. 2001. Age Determination and Validation Studies of Marine Fishes: Do Deep-Dwellers Live Longer. Experimental Gerontology. 36: 739-764.

Campana S. 2001. Accuracy, Precision and Quality Control in Age Determination, Including a Review of the Use and Abuse of Age Validation Methods. Journal of Fish Biology. 59(2): 197-242.

Campana SE. 1999. Chemistry and Composition of Fish Otoliths: Pathways, Mechanisms and Applications. Marine Ecological Progress Series. 188: 263-297.

Campana SE, Chouinard GA, Hanson JM, Frechet A, Brattey J. 2000. Otolith Elemental Fingerprints as Biological Tracers of Fish Stocks. Fisheries Research. 46: 343-357.

Campana SE, Thorrold SR, Jones CM, Günther D, Tubrett M, Longerich H, Jackson S, Halden NM, Kalish JM, Piccoli P, de Pontual H, Troadec H, Panfili J, Secor DH, Severin KP, Sie SH, Thresher R, Teesdale WJ, Campbell JL. 1997. Comparison of Accuracy, Precision, and Sensitivity in Elemental Assays of Fish Otoliths Using the Electron Microprobe, Proton-Induced X-Ray Emission, and Laser Ablation Inductively Coupled Plasma Mass Spectrometry. Canadian Journal of Fisheries and Aquatic Sciences. 54(9): 2068-2079.

Campbell MD, Patino R, Tolan J, Strauss R, Diamond SL. 2009. Sublethal Effects of Catch-and-Release Fishing: Measuring Capture Stress, Fish Impairment, and Predation Risk Using a Condition Index. ICES Journal of Marine Science. 513-521.

Carlström D. 1963. A Crystallographic Study of Vertebrate Otoliths. Biological Bulletin. 125(3): 441-463.

Chen Z, Curchitser E, Chant R, Kang D. 2018. Seasonal Variability of the Cold Pool over the Mid-Atlantic Bight Continental Shelf. Journal of Geophysical Research: Oceans. 123(11): 8203-8226.

Clarke LM, Munch SB, Thorrold SR, Conover DO. 2010. High Connectivity among Locally Adapted Populations of a Marine Fish (Menidia Menidia). Ecology. 91(12): 3526-3537.

Clarke LM, Walther BD, Munch SB, Thorrold SR, Conover DO. 2009. Chemical Signatures in the Otoliths of a Coastal Marine Fish, Menidia Menidia, from the Northeastern United States: Spatial and Temporal Differences. Marine Ecology Progress Series. 384: 261-271. 
Cook GS. 2011. Changes in Otolith Microchemistry over a Protracted Spawning Season Influence Assignment of Natal Origin. Marine Ecology Progress Series. 423: 197-209.

Devine JA, Baker KD, Haedrich RL. 2006. Fisheries: Deep-Sea Fishes Qualify as Endangered. Nature. 439(7072): 29.

Dooley JK. 1978. Systematics and Biology of the Tilefishes (Perciformes, Branchiostegidae and Malacanthidae) with Description of Two New Species, Department of Commerce, National Oceanic and Atmospheric Administration Admission, National Marine Fisheries Service.

Dransfeld L, Gerritsen HD, Hareide NR, Lorance P. 2013. Assessing the Risk of Vulnerable Species Exposure to Deepwater Trawl Fisheries: The Case of Orange Roughy Hoplostethus Atlanticusto the West of Ireland and Britain. Aquatic Living Resources. 26(4): 307-318.

Edeline E, Carlson SM, Stige LC, Winfield IJ, Fletcher JM, James JB, Haugen TO, Vellestad LAs, Stenseth NC. 2007. Trait Changes in a Harvested Population Are Driven by a Dynamic Tug-of-War between Natural and Harvest Selection. Proceedings of the National Academy of Sciences. 104(40): 15799-15804.

Elsdon TS, Wells BK, Campana SE, Gillanders BM, Jones CM, Limburg KE, Secor DH, Thorrold SR, Walther BD. 2008. Otolith Chemistry to Describe Movements and LifeHistory Parameters of Fishes: Hypotheses, Assumptions, Limitations and Inferences. Oceanography and Marine Biology: An Annual Review. 46(1): 297-330.

Erickson DL, Harris MJ, Grossman GD. 1985. Ovarian Cycling of Tilefish, Lopholatilus Chamaeleonticeps Goode and Bean, from the South Atlantic Bight, U.S.A. Journal of Fish Biology. 27: 131-146.

Fablet R, Pecquerie L, de Pontual H, Hoie H, Millner R, Mosegaard H, Kooijman SA. 2011. Shedding Light on Fish Otolith Biomineralization Using a Bioenergetic Approach. Public Library of Science One. 6(11): e27055.

Fisher JAD, Frank KT, Petrie B, Leggett WC. 2014. Life on the Edge: Environmental Determinants of Tilefish (Lopholatilus Chamaeleonticeps) Abundance since Its Virtual Extinction in 1882. ICES Journal of Marine Science. 71(9): 2371-2378.

Fowler AJ, Hamer PA, Kemp J. 2017. Age-Related Otolith Chemistry Profiles Help Resolve Demographics and Meta-Population Structure of a Widely-Dispersed, Coastal Fishery Species. Fisheries Research. 189: 77-94.

Freeman BL, Turner SC. 1977. Biological and Fisheries Data on Tilefish, Lopholatilus Chamaeleonticeps Goode and Bean, Sandy Hook Laboratory, Northeast Fisheries Center, National Marine Fisheries Service. 
Frisk MG, Jordaan A, Miller TJ. 2014. Moving Beyond the Current Paradigm in Marine Population Connectivity: Are Adults the Missing Link? Fish and Fisheries. 15(2): 242254.

Frisk MG, Olin JA, Cerrato RM, Nitschke P, Nolan L. 2018. Fisheries-Independent Pilot Survey for Golden (Lopholatilus Chamaelonticeps) \& Blueline (Caulolatilus Microps) Tilefish Throughout the Range from Georges Bank to Cape Hatteras. Mid-Atlantic Fishery Management Council Report. Dover, DE. 37

Fritsch M, Morizur Y, Lambert E, Bonhomme F, Guinand B. 2007. Assessment of Sea Bass (Dicentrarchus Labrax, L.) Stock Delimitation in the Bay of Biscay and the English Channel Based on Mark-Recapture and Genetic Data. Fisheries Research. 83(2-3): 123132.

Garcia SM, Kolding J, Rice J, Rochet MJ, Zhou S, Arimoto T, Beyer JE, Borges L, Bundy A, Dunn D, Fulton EA, Hall M, Heino M, Law R, Makino M, Rijnsdorp AD, Simard E, Smith ADM. 2012. Reconsidering the Consequences of Selective Fisheries. Science. 335: 1045-1047.

Gillanders BM. 2002. Connectivity between Juvenile and Adult Fish Populations: Do Adults Remain near Their Recruitment Estuaries? Marine Ecology Progress Series. 240: 215-223.

Gillanders BM. 2002. Temporal and Spatial Variability in Elemental Composition of Otoliths: Implications for Determining Stock Identity and Connectivity of Populations. Canadian Journal of Fisheries and Aquatic Sciences. 59(4): 669-679.

Gillanders BM. 2005. Using Elemental Chemistry of Fish Otoliths to Determine Connectivity between Estuarine and Coastal Habitats. Estuarine, Coastal and Shelf Science. 64(1): 47-57.

Gillanders BM, Able KW, Brown JA, Eggleston DB, Sheridan PF. 2003. Evidence of Connectivity between Juvenile and Adult Habitats for Mobile Marine Fauna: An Important Component of Nurseries. Marine Ecology Progress Series. 247: 281-295.

Goode GB, Bean TH. 1879. Description of a New Genus and Species of Fish, Lopholatilus Chamaeleonticeps, from the South Coast of New England. Proceedings of the United States National Museum. 205-209.

Granneman JE, Jones DL, Peebles EB. 2017. Associations between Metal Exposure and Lesion Formation in Offshore Gulf of Mexico Fishes Collected after the Deepwater Horizon Oil Spill. Marine Pollution Bulletin. 117(1-2): 462-477.

Green JM, Wroblewski JS. 2000. Movement Patterns of Atlantic Cod in Gilbert Bay Labrador Evidence for Bay Residency and Spawning Site Fidelity. Journal of the Marine Biological Association of the United Kingdom 80: 1077-1085. 
Grimes CB, Able KW, Jones RS. 1986. Tilefish, Lopholatilus Chamaeleonticeps, Habitat, Behavior and Community Structure in Mid-Atlantic and Southern New-England Waters. Environmental Biology of Fishes. 15(4): 273-292.

Grimes CB, Able KW, Turner SC. 1980. A Preliminary-Analysis of the Tilefish, Lopholatilus Chamaeleonticeps, Fishery in the Mid-Atlantic Bight. Marine Fisheries Review. 42(11): 13-18.

Grimes CB, Idelberger CF, Able KW, Turner SC. 1988. The Reproductive-Biology of Tilefish, Lopholatilus Chamaeleonticeps Goode and Bean, from the United-States MidAtlantic Bight, and the Effects of Fishing on the Breeding System. Fishery Bulletin. 86(4): 745-762.

Group SDW. 2014. Stock Assesment of Tilefish in the Mid-Atlantic/Southern New England Region for 2014. 58th SAW Assessment Report Woods Hole MA. 351-528

Haedrich RL, Hamilton LC. 2000. The Fall and Future of Newfoundland's Cod Fishery. Society \& Natural Resources. 13(4): 359-372.

Haedrich RL, Merrett NR, O'Dea NR. 2001. Can Ecological Knowledge Catch up with Deep-Water Fishing? A North Atlantic Perspective. Fisheries Research. 51: 113-122.

Hammerschlag N, Sulikowski J. 2011. Killing for Conservation: The Need for Alternatives to Lethal Sampling of Apex Predatory Sharks. Endangered Species Research. 14(2): 135-140.

Hanski I. 1998. Metapopulation Dynamics. Nature. 396: 41-49.

Harris MJ, Grossman GD. 1985. Growth, Mortality, and Age Composition of a Lightly Exploited Tilefish Substock Off Georgia. American Fisheries Society 114(6): 837-846.

Harris PJ, Padgett SM, Powers PT. 2001. Exploitation-Related Changes in the Growth and Reproduction of Tilefish and the Implications for the Management of Deepwater Fisheries. American Fisheries Society Symposium. American Fisheries Society: 199-210

Heimbrand Y, Limburg KE, Hussy K, Casini M, Sjoberg R, Palmen Bratt AM, Levinsky SE, Karpushevskaia A, Radtke K, Ohlund J. 2020. Seeking the True Time: Exploring Otolith Chemistry as an Age-Determination Tool. Journal of Fish Biology. 97(2): 552565.

Heupel MR, Simpfendorfer CA. 2010. Science or Slaughter: Need for Lethal Sampling of Sharks. Conservation Biology. 24(5): 1212-1218.

Hixon MA, Johnson DW, Sogard SM. 2014. Boffffs: On the Importance of Conserving Old-Growth Age Structure in Fishery Populations. ICES Journal of Marine Science. 71(8): 2171-2185. 
Hsieh CH, Reiss CS, Hunter JR, Beddington JR, May RM, Sugihara G. 2006. Fishing Elevates Variability in the Abundance of Exploited Species. Nature. 443(7113): 859-862.

Hüssy K, Limburg KE, de Pontual H, Thomas ORB, Cook PK, Heimbrand Y, Blass M, Sturrock AM. 2020. Trace Element Patterns in Otoliths: The Role of Biomineralization. Reviews in Fisheries Science \& Aquaculture. 1-33.

Hüssy K, Radtke K, Plikshs M, Oeberst R, Baranova T, Krumme U, Sjöberg R, Walther Y, Mosegaard H. 2016. Challenging Ices Age Estimation Protocols: Lessons Learned from the Eastern Baltic Cod Stock. ICES Journal of Marine Science. 73(9): 2138-2149.

Hutchings JA. 2000. Collapse and Recovery of Marine Fishes. Nature. 406: 882-885.

Jackson JR. 2007. Earliest References to Age Determination of Fishes and Their Early Application to the Study of Fisheries. Fisheries 32(7): 321-328.

Jennings S, Greenstreet SPR, Reynolds JD. 1999. Structural Change in an Exploited Fish Community: A Consequence of Differential Fishing Effects on Species with Contrasting Life Histories. Journal of Animal Ecology. 68: 617-627.

Jennings S, Kaiser MJ. 1998. The Effects of Fishing on Marine Ecosystems. Advances in Marine Biology. 34: 201-352.

Jorgensen C, Enberg K, Dunlop ES, Arlinghaus R, Boukal DS, Brander K, Ernande B, Gardmark A, Johnston F, Matsumurs S, Pardoe H, Raab K, Silva A, Vainikka A, Dieckmann U, Heino M, Rijnsdorp AD. 2007. Managing Evolving Fish Stocks. Science. 318(5854): 1247-1248.

Kassambara A. 2020. Ggpubr: 'Ggplot2' Based Publication Ready Plots. R package version 0.4.0. https://CRAN.R-project.org/package=ggpubr.

Katz SJ, Grimes CB, Able KW. 1983. Delineation of Tilefish, Lopholatilus Chamaeleonticeps, Stocks Along the United-States East Coast and in the Gulf of Mexico. Fishery Bulletin. 81(1): 41-50.

Kerr LA, Hintzen NT, Cadrin SX, Clausen LW, Dickey-Collas M, Goethel DR, Hatfield EMC, Kritzer JP, Nash RDM, Hidalgo M. 2017. Lessons Learned from Practical

Approaches to Reconcile Mismatches between Biological Population Structure and Stock Units of Marine Fish. ICES Journal of Marine Science. 74(6): 1708-1722.

Khan S, Khan MA, Miyan K, Lone FA. 2015. Precision of Age Esimates from Different Ageing Structures in Selecterd Freshwater Teleosts. Journal of Environmental Biology. 36: 507-512. 
Kumbar SM, Lad SB. 2016. Estimation of Age and Longevisty of Freshwater Fish Salmophasia Balookee from Otolith, Scales and Vertebrae. Journal of Environmental Biology. 37: 943-947.

Kurlansky M. 2011. Cod: A Biography of the Fish That Changed the World, Vintage Canada.

Law R. 2000. Fishing, Selection, and Phenotypic Evolution. ICES Journal of Marine Science. 57(3): 659-668.

Ley JA, Rolls HJ. 2018. Using Otolith Microchemistry to Assess Nursery Habitat Contribution and Function at a Fine Spatial Scale. Marine Ecology Progress Series. 606: 151-173.

Limburg KE. 1995. Otolith Strontium Traces Environmental History of Subyearling American Shad Alosa Sapidissima. Marine Ecological Progress Series. 119: 25-35.

Limburg KE, Casini M. 2018. Effect of Marine Hypoxia on Baltic Sea Cod Gadus Morhua: Evidence from Otolith Chemical Proxies. Frontiers in Marine Science. 5.

Limburg KE, Elfman M. 2017. Insights from Two-Dimensional Mapping of Otolith Chemistry. Journal of Fish Biology. 90(2): 480-491.

Limburg KE, Walther BD, Lu Z, Jackman G, Mohan J, Walther Y, Nissling A, Weber PK, Schmitt AK. 2015. In Search of the Dead Zone: Use of Otoliths for Tracking Fish Exposure to Hypoxia. Journal of Marine Systems. 141: 167-178.

Limburg KE, Wuenschel MJ, Hüssy K, Heimbrand Y, Samson M. 2018. Making the Otolith Magnesium Chemical Calendar-Clock Tick: Plausible Mechanism and Empirical Evidence. Reviews in Fisheries Science \& Aquaculture. 26(4): 479-493.

Lombardi-Carlson LA 2012. Life History, Population Dynamics, and Fishery Management of the Golden Tilefish, Lopholatilus Chamaeleonticeps, from the Southeast Atlantic and Gulf of Mexico. Doctor of Philosophy, University of Florida.

Lombardi-Carlson LA, Andrews AH. 2015. Age Estimation and Lead-Radium Dating of Golden Tilefish, Lopholatilus Chamaeleonticeps. Environmental Biology of Fishes. 98(7): 1787-1801.

Lombardi LA, Fitzhugh G, Lyon H. 2010. Golden Tilefish (Lopholatilus Chamaeleonticeps) Age, Growth, and Reproduction from the Northeastern Gulf of Mexico: 1985, 1997-2009. National Marine Fisheries Service. Panama City FL.

Longmore C, Fogarty K, Neat F, Brophy D, Trueman C, Milton A, Mariani S. 2010. A Comparison of Otolith Microchemistry and Otolith Shape Analysis for the Study of 
Spatial Variation in a Deep-Sea Teleost, Coryphaenoides Rupestris. Environmental Biology of Fishes. 89(3-4): 591-605.

McBride RS, Vidal TE, Cadrin SX. 2013. Changes in Size and Age at Maturity of the Northern Stock of Tilefish (Lopholatilus Chamaeleonticeps) after a Period of Overfishing. Fishery Bulletin. 111(2): 161-174.

McCain JSP, Cull DJ, Schneider DC, Lotze HK. 2016. Long-Term Shift in Coastal Fish Communities before and after the Collapse of Atlantic Cod (Gadus Morhua). ICES Journal of Marine Science. 73(5): 1415-1426.

McQuinn IH. 2009. Pelagic Fish Outburst or Suprabenthic Habitat Occupation: Legacy of the Atlantic Cod (Gadus Morhua) Collapse in Eastern Canada. Canadian Journal of Fisheries and Aquatic Sciences. 66: 2256-2262.

Muir AM, Ebener MP, He JX, Johnson JE. 2008. A Comparison of the Scale and Otolith Methods of Age Estimation for Lake Whitefish in Lake Huron. North American Journal of Fisheries Management. 28(3): 625-635.

Myers RA, Worm B. 2003. Rapid Worldwide Depletion of Predatory Fish Communities. Nature. 423: 280-284.

Neumann R, Allen M. 2007. Analysis and Interpretation of Freshwater Fisheries Data. Size Structure. Bethesda, Maryland, American Fisheries Society: 375-421.

Nichol DG, Chilton EA. 2006. Recuperation and Behaviour of Pacific Cod after Barotrauma. ICES Journal of Marine Science. 63(1): 83-94.

Nitschke P, Miller A. 2016. Summary of Mid-Atlantic Commercial Blueline Tilefish Data Sedar50-Dw10. Charleston, SC. 13

NOAA. 2018. Golden Tilefish- Advisory Panel Information Document. MAFMC: 1-23

NOAA. 2018. Golden Tilefish Fishery Performance Report. 2018 Tilefish Advisory Panel $(A P)$. David Arbeitman, Skip Feller, Jeffry Gutman and John Nolan

NOAA. 2020. Fisheries of the Northeastern United States; Golden Tilefish Fishery; 2021 and Projected 2022 Specifications and Emergency Action. 85: 72616-72619

NOAA. 2021. Tilefish Lopholatilus Chamaeleonticeps. Fisheries management. https://www.fishwatch.gov/profiles/tilefish?_ga=2.2857139.2095765405.1618317686945958795.1599589401.

Norse EA, Brooke S, Cheung WWL, Clark MR, Ekeland I, Froese R, Gjerde KM, Haedrich RL, Heppell SS, Morato T, Morgan LE, Pauly D, Sumaila R, Watson R. 2012. Sustainability of Deep-Sea Fisheries. Marine Policy. 36(2): 307-320. 
Ogle DH. 2019. Fsadata: Fisheries Stock Analysis, Datasets. R package version 0.3.8.

Ogle DH, Wheeler P, Dinno A. 2019. Fsa: Fisheries Stock Analysis. R package version 0.8.25. https://github.com/droglenc/FSA.

Oksanen J, Blanchet G, Friendly M, Kindt R, Legendre P, McGlinn D, Minchin PR, O'Hara RB, Simpson GL, Solymos P, Stevens HH, Szoecs E, Wagner H. 2020. Vegan: Community Ecology Package. R package version 2.5-7. https://CRAN.Rproject.org/package $=$ vegan.

Olin JA, Nitschke P, Nolan L. 2021. Fishery-Independent 2020 Bottom Longline Survey for the Mid-Atlantic Golden Tilefish (Lopholatilus Chamaeleonticeps) Stock (Award \#: 1910035). Mid-Atlantic FIsheries Management Council Report

Olin JA, Shipley ON, Cerrato RM, Nitschke P, Magen C, Frisk MG. 2020. Separation of Realized Ecological Niche Axes among Sympatric Tilefishes Provides Insight into Potential Drivers of Co-Occurrence in the Nw Atlantic. Ecology and Evolution. 10(19): 10886-10898.

Ortega-Ortiz JG, Ainsworth CH, Gracia A. 2020. Comparing Ecosystem Model Outcomes between Ixtoc 1 and Deepwater Horizon Oil Spills. Deep Oil Spills: Facts, Fate, and Effects. Steven A. Murawski, Cameron H. Ainsworth, Sherryl Gilbert et al. Cham, Springer International Publishing: 551-568.

Palmer SM, Harris PJ, Powers PT. 2004. Age, Growth and Reproduction of Tilefish, Lopholatilus Chamaeleonticeps, Along the Southeast Atlantic Coast of the United States, 1980-87 and 1996-98. SEDAR4-DW-18. South Carolina Department of Natural Reseources. Charleston SC.

Panella G. 1971. Fish Otoliths: Daily Growth Layers and Periodical Patterns. Science. 173(4002): 1124-1127.

Pennino MG, Conesa D, López-Quílez A, Muñoz F, Fernández A, Bellido JM. 2016. Fishery-Dependent and -Independent Data Lead to Consistent Estimations of Essential Habitats. ICES Journal of Marine Science. 73(9): 2302-2310.

Pikitch EK, Santora C, Babcock EA, Bakun A, Bonfil R, Conover DO, Dayton P, Doukakis P, Fluharty D, Heneman B. 2004. Ecosystem-Based Fishery Management. Science. 305: 304-305.

Pittman SJ, McAlpine CA. 2003. Movements of Marine Fish and Decapod Crustaceans: Process, Theory and Application. Advances in Marine Biology. 44: 205-294.

Ribeiro Jr PJ, Diggle PJ, Schlather M, Bivand R, Ripley B. 2020. Geor: Analysis of Geostatistical Data. R package version 1.8-1. https://CRAN.R-project.org/package=geoR. 
Rooker JR, Secor DH, Zdanowicz VS, Itoh T. 2001. Discrimination of Northern Bluefin Tuna from Nursery Areas in the Pacific Ocean Using Otolith Chemistry. Marine Ecology Progress Series. 218(275-282): 275.

Roose H, Paterson G, Frisk MG, Cerrato RM, Nitschke P, Olin JA. 2021. Regional Variation in Mercury Bioaccumulation among Nw Atlantic Golden (Lopholatilus Chamaeleonticeps) and Blueline (Caulolatilus Microps) Tilefish. Environmental Pollution. 284: 117177.

Ross JL, Huntsman GR. 1982. Age, Growth, and Mortality of Blueline Tilefish from North Carolina and South Carolina Transactions of the American Fisheries Society. 111: 585-592.

Rummer JL, Bennett WA. 2005. Physiological Effects of Swim Bladder Overexpansion and Catastrophic Decompression on Red Snapper. Transactions of the American Fisheries Society. 134(6): 1457-1470.

Scheiner SM, Gurevitch J. 2001. Design and Analysis of Ecological Experiments, Oxford University Press.

Schnetz L, Pfaff C, Libowitzky E, Johanson Z, Stepanek R, Kriwet J. 2019. Morphology and Evolutionary Significance of Phosphatic Otoliths within the Inner Ears of Cartilaginous Fishes (Chondrichthyes). BMC Evolutionary Biology. 19(1): 238.

Secor DH. 2010. Is Otolith Science Transformative? New Views on Fish Migration. Environmental Biology of Fishes. 89(3): 209-220.

Secor DH, Allman R, Busawon Dheeraj, Gahagan B, Golet W, Koob E, Luque PL, Siskey M. 2014. Standardization of Otoltih-Based Ageing Protocols for Atlantic Bluefin Tuna. Collective Volume of Scientifics Papers. 70: 368-371.

Secor DH, Dean JM, Laban EH. 1991. Manual for Otolith Removal and Preparation for Microstructural Examination. University of South Carolina, Columbia South Carolina, Baruch Institute for Marine Biology and Coastal Research.

Secor DH, Rooker JR, Zlokovitz E, Zdanowicz VS. 2001. Identification of Riverine, Estuarine, and Coastal Contingents of Hudson River Striped Bass Based Upon Otolith Elemental Fingerprints. Marine Ecological Progress Series. 211(245-253): 245.

Secor DH, Trice TM, Hornick HT. 1995. Validation of Otolith-Based Ageing and a Comparison of Otolith and Scale Based Ageing in Markrecaptured Chesapeake Bay Striped Bass, Marone Saxatilis. Fishery Bullletin. 98: 186-190.

SEDAR. 2017. Sedar50- Atlantic Blueline Tilefish Assesment Report. North Charleston SC. 542 
Smedbol RK, Wroblewski JS. 2002. Metapopulation Theory and Northern Cod Population Structure: Interdependence of Subpopulations in Recovery of a Groundfish Population. Fisheries Research. 55: 161-174.

Spies I, Spencer PD, Punt AE, Krkošek M. 2015. Where Do We Draw the Line? A Simulation Approach for Evaluating Management of Marine Fish Stocks with Isolationby-Distance Stock Structure. Canadian Journal of Fisheries and Aquatic Sciences. 72(7): 968-982.

Stephenson RL. 1999. Stock Complexity in Fisheries Management: A Perspective of Emerging Issues Related to Population Sub-Units. Fisheries Research. 43: 247-249.

Stolarski JT, Hartman KJ. 2008. An Evaluation of the Precision of Fin Ray, Otolith, and Scale Age Determinations for Brook Trout. North American Journal of Fisheries Management. 28(6): 1790-1795.

Svedäng H, André C, Jonsson P, Elfman M, Limburg KE. 2010. Migratory Behaviour and Otolith Chemistry Suggest Fine-Scale Sub-Population Structure within a Genetically Homogenous Atlantic Cod Population. Environmental Biology of Fishes. 89(3-4): 383397.

Swain DP, Sinclair AF, Mark Hanson J. 2007. Evolutionary Response to Size-Selective Mortality in an Exploited Fish Population. Proceedings of the Royal Society B:

Biological Sciences. 274(1613): 1015-1022.

Swearer SE, Shima JS, Hellberg ME, Thorrold SR, Jones GP, Robertson DR, Morgan SG, Selkoe KA, Ruiz GM, Warner RR. 2002. Evidence of Self-Recruitment in Demersal Marine Populations. Bulletin of Marine Science. 70(1): 251-271.

Team RDC. 2021. R: A Language and Environment for Statistical Computing. R Foundation for Statistical Computing. version 4.0.5. https://www.R-project.org/.

Team RS. 2021. Rstudio Interface. 1.1463.

Thomas OR, Ganio K, Roberts BR, Swearer SE. 2017. Trace Element-Protein Interactions in Endolymph from the Inner Ear of Fish: Implications for Environmental Reconstructions Using Fish Otolith Chemistry. Metallomics. 9(3): 239-249.

Thorrold SR, Jones CM, Swart PK, Targett TE. 1998. Accurate Classification of Juvenile Weakfish Cynoscion Regalis to Estuarine Nursery Areas Based on Chemical Signatures in Otoliths. Marine Ecological Progress Series. 173: 253-265.

Thorrold SR, Latkoczy C, Swart PK, Jones CM. 2001. Natal Homing in a Marine Fish Metapopulation. Science. 291: 5502. 
Thorrold SR, Shuttleworth S. 2000. In Situ Analysis of Trace Elements and Isotope Ratios in Fish Otoliths Using Laser Ablation Sector Field Inductively Coupled Plasma Mass Spectrometry. Canadian Journal of Fisheries and Aquatic Sciences. 57: 12321242.

Thresher RE. 1999. Elemental Composition of Otoliths as a Stock Delineator in Fishes. Fisheries Research. 43: 165-204.

Trippel EA. 1995. Age at Maturity as a Stress Indicator in Fisheries. Bioscience. 45(11): $759-771$.

Tuckey T, Yochum N, Hoenig J, Lucy J, Cimino. 2007. Evaluating Localized Vs. LargeScale Management: The Example of Tautog in Virginia. Fisheries. 32(1): 21-28.

Turner SC, Grimes CB, Able KW. 1983. Growth, Mortality, and Age Size Structure of the Fisheries for Tilefish, Lopholatilus Chamaelonticeps, in the Middle Atlantic-Southern New-England Region. Fishery Bulletin. 81(4): 751-763.

Vasconcelos RP, Reis-Santos P, Tanner S, Maia A, Latkoczy C, Günther D, Costa MJ, Cabral H. 2008. Evidence of Estuarine Nursery Origin of Five Coastal Fish Species Along the Portuguese Coast through Otolith Elemental Fingerprints. Estuarine, Coastal and Shelf Science. 79(2): 317-327.

Venables WN, Ripley BD. 2002. Modern Applied Statistics with S.

Vidal TE. 2009. Evaluating Shifts in Size and Age at Maturity of Golden Tilefish from the Mid-Atlantic Bight. 48th SAW Assessment Report. A 2 NOAA/UMass Cooperative Marine Education \& Research Program: 150- 170

Warner RR, Swearer SE, Casselle JE, Sheehy M, Paradis G. 2005. Natal Trace-Elemental Signatures in the Otoliths of an Open-Coast Fish. Limnology Oceanography. 50(5): 15291542.

Wickham H, Averick M, Bryan J, Chang W, McGowan LDA, François R, Grolemund G, Hayes A, Henry L, Hester J, Kuhn M, Pederson TL, Miller E, Bache SM, Muller K, Ooms J, Robinson D, Seidel DP, Spinu V, Takahashi K, Vaughan D, Wilke C, Woo K, Yutani H. 2012. Welcome to the Tidyverse. Journal of Open Source Software, 4(43), 1686. https://doi.org/10.21105/joss.01686.

Wickham H, Bryan J. 2019. Readxl: Read Excel Files. R package version 1.3.1. https://CRAN.R-project.org/package=readxl.

Wickham H, François R, Henry L, Müller K. 2020. Dplyr: A Grammar of Data Manipulation. R package version 0.8.5. https://CRAN.R-project.org/package=dplyr. 
Williams LJ, Herbig JL, Szedlmayer ST. 2015. A Cage Release Method to Improve Fish Tagging Studies. Fisheries Research. 172: 125-129.

Worm B, Hilborn R, Baum JK, Branch TA, Collie JS, Costello C, Fogarty MJ, Fulton EA, Hutchings JA, Jennings S, Jensen OP, Lotze HK, Mace PM, McClanahan TR, Minto C, Palumbi SR, Parma AM, Ricard D, Rosenberg AA, Watson R, Zeller D. 2009. Rebuilding Global Fisheries. Science. 325(5940): 578-585.

Xie Y. 2021. Knitr: A General-Purpose Package for Dynamic Report Generation in R. R package version 1.32 .

Ying Y, Chen Y, Lin L, Gao T, Quinn T. 2011. Risks of Ignoring Fish Population Spatial Structure in Fisheries Management. Canadian Journal of Fisheries and Aquatic Sciences. 68(12): 2101-2120.

Zhang WG, Gawarkiewicz GG. 2015. Dynamics of the Direct Intrusion of Gulf Stream Ring Water onto the Mid-Atlantic Bight Shelf. Geophysical Research Letters. 42(18): 7687-7695. 